NBS

A\\\02 6 31360

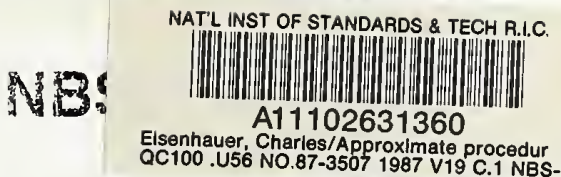

Approximate Procedures for Calculating Protection From Initial Auclear Radiation From Weapons

C. Mi. Eisentiauer and L. V. Spencer

U.S. DEPAETMENT OF COMMERCE

Netional Gursay of Standards

Center for Radiation Researsh

Gaithersturg, MD 20899

February 1987

$-Q C$

100

ifor:

.456

I Emergency Management Agency

87-3507 Igton, DC 20472

1987

c. 2 



\section{APPROXIMATE PROCEDURES FOR CALCULATING PROTECTION FROM INITIAL NUCLEAR RADIATION FROM WEAPONS}

C. M. Eisenhauer and L. V. Spencer

U.S. DEPARTMENT OF COMMERCE National Bureau of Standards Center for Radiation Research

Gaithersburg, MD 20899

February 1987

Prepared for:

Federal Emergency Management Agency

Washington, DC 20472

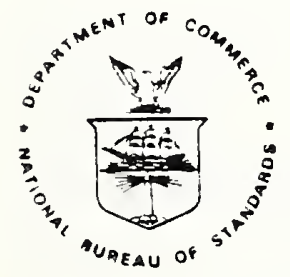

U.S. DEPARTMENT OF COMMERCE, Malcolm Baldrige, Secretary NATIONAL BUREAU OF STANDARDS, Ernest Ambler, Director 


\section{CONTENTS}

Page

I. Introduction . . . . . . . . . . . . . . . . 1

II. Source Distribution . . . . . . . . . . . . 2

III. Approach to Shielding Calculations . . . . . . . . . . 3

A. General Approach . . . . . . . . . . . . . 3

B. irutual Shielding Factor . . . . . . . . . . . . 5

C. Barrier Factor . . . . . . . . . . . . . . . 6

D. Geometry Factor . . . . . . . . . . . . . . 8

E. Attenuation Factor . . . . . . . . . . . . . 13

F. Overall Proctection Factors . . . . . . . . . . . 14

IV. Discussion of INR Computer Codes . . . . . . . . . 15

A. Limitations of Codes . . . . . . . . . . . . 15

B. Description of Subroutines . . . . . . . . . . . 1 ?

C. Listings of Computer Codes . . . . . . . . . . . ? 7

V. Comparison with Monte Carlo Calculations . . . . . . . . 28

A. Monte Carlo Calculations on Benchmark Structures . . . . 28

B. Combined Components . . . . . . . . . . . . 29

C. AS and FP Secondary Gamma Rays . . . . . . . . . . . 29

D. Neutrons and Secondary Gamma Rays . . . . . . . . . 32

VI. Conclusions . . . . . . . . . . . . . 35

References . . . . . . . . . . . . . . . . . 36

Tables . . . . . . . . . . . . . . . . . . . . 37

List of figures . . . . . . . . . . . . . . . . . . . 55

Appendix A. Sources of Data for INR Computer Codes . . . . . . . . 79

B. Treatment of Mutual Shielding for Neutrons . . . . . . 80

C. FORTRAN Listing of Computer Codes . . . . . . . . 82

D. Sample Input Data . . . . . . . . . . . . 118

E. Sample Output Data . . . . . . . . . . . 121 

In this report we discuss procedures for routine evaluation of the protection of complex structures against the initial radiations from nuclear detonations. We describe procedures for evaluating and combining dose reduction factors for four radiation components: early fission product gamma rays, air secondary gamma rays generated by neutron interactions in the air, neutrons, and wall capture gamma rays generated by neutrons through interactions with nuclei in structural materials. We describe computer codes developed to evaluate reduction factors for each of these components. The radiation field in the vicinity of the structure was generated for a $30^{\circ}$ elevation angle for the detonation, as well as a "ring source" averaging over the points of the compass. Comparisons are made with Monte Carlo calculations for a series of five benchmark structures. 



\section{INTRODUCTION}

The purpose of developing approximate shielding procedures is to allow calculation of shielding in many structures with a simple method that can be proyrammed for fast operation on a personal or mainframe computer. In this paper, we report on approximate procedures developed at NBS to calculate protection afforded by structures against initial gamma and neutron radiation.1 These procedures are modeled on earlier procedures $[1,2]^{2}$ for estimating protection from fallout radiation, which have proven very useful in evaluating the fallout shelter potential in the United States.

Calculation of shielding for initial radiation is more complicated than for fallout radiation because four components, namely, fission product gamma rays (FP), secondary gamma rays generated in air (AS), prompt neutrons (N), and gamma rays from neutrons captured in the structure (NG) must be considered. Under special circumstances other radiation such as prompt gammas or delayed neutrons may also be of interest. Much of the data base for procedures discussed here is given in an earlier paper by Spencer [3]; and the procedures have followed the pattern developed in that paper.

The role of neutrons is more complicated than that of gamma rays for at least three reasons: 1) neutron reflection from wall surfaces is a dominant, rather than perturbation effect; 2) neutrons give rise to capture gamina rays (NG) in the structure, and these are more penetrating than the neutrons themselves; and 3) the neutron source intensity relative to that of the initial gamma rays is a function of weapon design. Due to the importance of neutron reflections, additional procedures have been developed which are based

${ }^{1}$ Initial radiation is that which is emitted during the first minute after a detonation.

${ }^{2}$ Figures in brackets indicate literature references at the end of this paper. 
on the accumulated data and experience for enclosures and ducts. To take the secondary gamma rays produced in the structure into account, additional data for this component have been generated, on the general pattern of reference [3]. For relative source intensities we have utilized available data, beginning with that available in an important report by Auxier et al. [4]. Published and unpublished sources of shielding data used in INR computer codes are given in Appendix $A$.

\section{SOURCE DISTRIBUTION}

In order to compare various techniques for calculating shielding in structures, it is helpful to establish standard angular-energy distributions in the vicinity of the structure, for the different types of radiation. We have chosen $A S$ and $N$ distributions from a study [4] requested by the Radiation Shielding Subcommittee of the Advisory Committee on Civil Defense, National Academy of Science. These are presented together with the FP angle-energy distributions $[4,5]$ in Tables I-III. The polar angle in these tables is defined relative to the direction vector from source to detector.

We have also followed the recommendations of the same study to assume a ring source of bursts at a fixed angle of elevation. The rationale for choosing a ring source is that the direction of burst cannot be predicted beforehand - particularly if the building is likely to be exposed to more than one weapon. Therefore, a protection factor for a building is averaged over horizontal directions. The use of a ring source allows the averaging to be done before the protection factor is calculated. For buildings whose construction is similar on all sides, the protection is not likely to vary significantly from this average. An angle of elevation of $30^{\circ}$ was chosen as typical of low air bursts. In order to calculate the protection factor in a 
building, we start with the radiation dose in air. There is still some question as to whether the presence of the ground is important enough to be included in calculating this dose. Although the effect of the ground may be important in estimating the absolute dose, its impact on the protection factor, which is a ratio of doses, is small enough to ignore. The calculations reported here assume that the detector with reference to which the protection factor is estimated is located in a free air nedium with no groundair interface present.

In the calculations of reference [3], the asymmetry of the fission product source about the detonation point, due to cloud rise, was ignored. This aspect of those calculations has been criticized [6]; and there is general agreement that for barrier factors, at least, more precise calculations are required. These have been performed, and are routinely included below.

\section{APPROACH TO SHIELDING CALCULATIONS}

\section{A. General Approach}

The protection in a building against initial radiation is estimated in terms of a reduction factor IRF, which is defined as the ratio of the dose $D$ from initial radiation at a point in the structure to the dose $D_{0}$ from initial radiation at the reference point in free air. If the fraction of the free-air dose contributed by FP and AS gamma rays and by neutrons is denoted by $f_{F P}$, $f_{A S}$, and $f_{N}$, respectively, then the reduction factor is calculated from

$$
I R F=\frac{D}{D_{0}}=R_{F P} f_{F P}+R_{A S} f_{A S}+\left(R_{N}+R_{N G}\right) f_{N}
$$


where $R_{F P}$ and $R_{A S}$ are reduction factors for the FP and AS components of the gamma radiation, and $R_{N}$ and $R_{N G}$ are reduction factors for the neutrons and the secondary gammas generated in the structure.

We now consider approximate procedures for estimating the component reduction factors $R_{F P}, R_{A S}$, $R_{N}$ and $R_{N G}$. Since the approach is the same for all components, we drop the subscript in the following discussion.

The general approach which we have taken in developing shielding procedures can be described as follows. We start with the free field dose for each of the radiation components. We then consider the dose at a position on the exterior surface of the roof or one of the walls of a building. The ratio of this dose to the free field dose we call the mutual shielding factor, M. Next, we consider the dose at a point on the interior surface of the roof or wall, immediately opposite the point on the exterior surface. We call the ratio of these two doses a barrier factor, $B(X)$. Next we consider the dose at some arbitrary point inside the building, with no internal structure. The ratio of the dose at this point to that on the interior surface of the wall or roof is called the geometry factor, $G$, for that wall or roof. Finally, we consider the dose with any internal partitions or floors in place and call the ratio of this dose to that in the empty structure the attenuation factor, A. The reduction factor for each component, i.e., the ratio of the dose at an arbitrary point in the structure to the free field dose, is then calculated from the product

$$
R=M \cdot B\left(X_{e}\right) \cdot G\left(X_{e}, w\right) \cdot A\left(X_{i}\right)
$$

where $x_{e}$ is the thickness of an exterior wall or roof and $x_{j}$ is the thickness of an internal barrier. $A\left(X_{i}\right)$ may be the attenuation due to the combined 
effect of several floors and walls for any radiation component. The reduction factor at a point in the structure for any radiation component is obtained by summing the expression of eq (2) over the roof and exterior wall surfaces. In programming calculations in the INR codes some modifications of this simple product of four factors were necessary. These modifications will be explained in section IV.B.

B. Mutual Shielding Factor, M

This factor evaluates the effect of moving the detector from a free-air situation to an exterior surface of the building. It may include reductions in exposure due to the presence of nearby buildings. In the simple case of an isolated building, it is approximated for gamma rays by the integral of the free-air distribution over the hemisphere from which radiation is incident divided by the integral over all directions. For a roof, the partial integral is taken over the upper hemisphere; for a ring source incident on a wall, the integral is exactly one-half. The roof factor 0.85 has been used for both FP and AS gamma ray components [3].

The case of neutrons is treated somewhat differently, although it appears formally the same. Because the contribution from neutrons is not as highly concentrated along the line of sight between source and detector as is that from high energy gamma rays, our approach is that of reducing the overall source strength entering roof or side in accordance with the solid angle subtended by nearby shielding. This means the introduction of a cosine factor into the relevant integrals. Calculated in this way, the dose current entering one side of a building turns out to be 0.47 that of the dose current entering the roof.

In more complicated cases where neighboring buildings restrict the angles from which radiation can reach the detector point, the concept of cut-off angle is introduced. The source angular distribution for air-secondary gamma 
radiation is peaked in the downward direction at an angle of $30^{\circ}$ from the horizontal. For fission product gamma radiation the distribution is still peaked but somewhat more diffuse due to averaging over the cloud-rise time. Furthermore, the INR gamma-ray source energies are higher than for fallout, so that INR gamma radiation tends to preserve its original direction. The effect of this phenomenon is that the photon detector responds as if the walls of the building were being $x$ rayed with the source radiation. Therefore, we assume that cut-off angles for the mutual shielding factor can be determined by a line between the detector point and an important change in a neighboring building (e.g., the roof line of the neighboring building). For neutrons the above arguments are not valid. Instead, neutron transport is less sensitive to the original direction of motion of the neutron. The effect of a neighboring building is evaluated in terms of the cut-off angle measured from that building to a point on the exterior surface of the building in which the detector is located rather than to the detector location, itself. Whenever there is a cut-off angle introduced by the presence of nearby building, the factor $M$ in eq (2) is replaced by a difference of mutual shielding geometry factors which are functions of exterior cut-off angles. The use of figure 17 to determine these factors will be described under the Geometry Factor section.

\section{Barrier Factor, $B\left(x_{e}\right)$}

This factor is the ratio of dose at the inner surface of an exterior wall or roof to that at the outer surface of the same barrier. In order to generate the angular distribution of radiation from a ring source incident on a barrier, the distributions in tables I-III which are a function of the polar angle $\beta$ (see fig. 1) were averaged over directions of the compass $\phi$, rotated 
to a system in which the new polar angle $\theta$ or $x$ is relative to a line perpendicular to the barrier surface, and then weighted by the cosine of the new polar angle to obtain the current incident on the barrier surface.

Approximate barrier factors for initial gamma radiation were obtained by one-dimensional transport calculations for the rotated roof and wall sources in an infinite medium of concrete. In these calculations concrete is substituted for the air that is exterior to the barrier. This introduces an error of order $10 \%$ in the dose, but less in the reduction factor, which is a ratio. The error introduced by the substitution of a concrete backing for the interior of the structure, that is, behind the detector, is expected to be still smaller because gamma rays are reflected from other structural materials.

The barrier factors calculated for initial gamma radiation are shown in figure 2. As expected, the AS gamma rays are generally more penetrating than the FP gamma rays because they include higher energy photons. Furthermore, the two AS curves are rather similar. The two curves for FP gammas would also be similar due largely to the choice of a $30^{\circ}$ angle of elevation for the gamma ray sources. But cloud rise has the consequence of depressing the wall curve and raising significantly the roof curve, thus making the latter much less steep. The data from which these curves were derived were obtained using a gamma ray adjoint moments program written by G. L. Simmons [7], and a distribution construction program written by L. V. Spencer [8].

Barrier factors for neutrons and for the capture gamma rays which they produce in the structure are shown in figure 3. These data correspond to Snyder-Neufeld [9] dose weighting factors for the neutrons, and Henderson [9] weighting factors for the gamma rays. These were generated by ANISN calculations for the roof, and DOT calculations for the walls [9]. They are based on 
calculations for slabs and therefore do not include any neutrons reflected from behind the detector. The contribution from reflected neutrons is evaluated by a reflection factor added to the geometry factors (see section D.2).

\section{Geometry Factor, $G\left(X_{e}, w\right)$}

1. Unreflected component. The geometry factor is the ratio of the exposure at an arbitrary distance from the inner surface of an exterior wall or roof to the exposure at the surface: A cumulative integral over the angular distribution of radiation emerging from the surface is required to estimate this factor. Calculations used to approximate this integral for gamma rays, however, give the cumulative angular distribution over the incident radiation. The two integrals are equal only for the radiation not scattered in the barrier. But, in view of the fact that unscattered and small-angle-scattered components dominate the dose for the source energies and barrier thicknesses of interest, we believe that the calculated integrals represent an adequate approximation for this application. For neutrons, integrals were taken over angular distributions of emerging neutrons.

A polar reference axis for specifying the cumulative angular distribution of the incident radiation must be selected. For a ring source incident on a horizontal roof, the vertical direction is the obvious choice. Cumulative angular distributions are expressed in terms of the solid angle fraction w subtended by the roof. Figure 4 shows these geometry factors for the air secondary gammas. In this figure and in some of the following figures, as well as elsewhere in the text, thickness of barriers are given in units of pounds per square foot (psf) of concrete. The sharp rise in the curves for thin barriers shows the effect of the concentration of photons at $30^{\circ}$ angle of elevation. The higher values of the curves for thick barriers and small solid angle fractions indicate the increased importance of radiation traveling more nearly perpendicular to the roof slab. Similar curves for FP gamma radiation 
are shown in figure 5, and for neutrons and neutron-capture gamma rays (in the structure) in figures 6 and 7 , respectively. The single curve for neutrons is a good approximation for all thicknesses.

For radiation incident on a vertical wall, the choice of a reference direction is not so obvious. Figure 1 shows two possible directions: the vertical direction, normal to the roof, and the horizontal direction, normal to the wall slab. Since cumulative integrals over polar angles are correct only for circular source areas and cylindrical symmetry, one tries to choose the direction which most closely approximates this. We feel that most 1 arge buildings with story-heights small compared to wall-lengths can be better approximated by a cylindrical wall with a vertical reference axis rather than a series of four circular walls, each with a horizontal reference axis. The symmetry of the ring source about the vertical direction provides an additional reason for choosing a vertical axis as the reference direction. Geometry factors for walls are approximated by the product of two functions. The first function $G_{1}(X e, w)$, given in figures $8-11$ is an integral over the region of polar angles subtended by the walls of the structure. The second function, $G_{2}\left(X e, \phi_{0}\right)$, varies with the 1 imits on the azimuthal angle $\phi_{0}$ (see figs. 13-16) for each wal1. The sum of values of this function for each of the walls of a structure is therefore dependent on the shape of the building.

Geometry factors $G_{1}(X e, \omega)$ are plotted as a function of the solid angle fraction w subtended by the ceiling (or floor) rather than that subtended by the walls. Therefore, for increasing values of $w$ the geometry factors in figures $8-11$ decrease. Note that the horizontal scales in figures $8-11$ are semi-log scales in the quantity $(1-\omega)$. The curves for AS gammas show a steep slope near $\omega=0.5$, due to the concentration of photons at the $30^{\circ}$ 
angle of elevation. The corresponding curves for FP gammas are shown in figure 9, and for neutrons and capture gammas (in the structure) in figures 10 and 11 , respectively. Note again that figure 10 does not include reflected neutrons.

When the detector is on the same story as the radiating walls, a geometry factor for radiation from portions of the walls above the detector plane must be added to a geometry factor for portions of the wall below the detector plane (see fig. 12a). When the detector is on the story below, geometry factors nust be estimated for the solid angle fractions subtended by the ceiling of the higher story, and the floor of the higher story, and the two subtracted (see fig. 12b). A similar subtraction is required when the detector is on the story above the radiating walls.

Geometry factors $G_{2}(X e, \omega)$ for AS gamma rays and for a single wall are plotted as a function of $\sin \phi_{0}$ in figure 13. The curve for zero thickness in figure 13 is proportional to the angle $\phi_{0}$. The line for 36 pounds per square foot (psf) of concrete is nearly proportional to $\sin \phi_{0}$ and is therefore equivalent to the prediction for thick walls in the fallout methodology. ${ }^{3}$ The higher geometry factors for thickness greater than 36 psf show the effect of increased peaking in the angular distribution, relative to the direction perpendicular to the wall surface. The curves for FP gammas (fig. 14) are almost a duplicate of this set. Corresponding curves for unreflected neutrons and wall capture gammas are presented in figures 15 and 16 . The single curve that approximates the function $G_{2}$ for neutrons for all wall thicknesses is proportional to the azimuthal angle subtended by the wall.

${ }^{3}$ In the methodology for calculating fallout protection this information is not available and it is arbitrarily assumed that for thin walls the geometry factor is proportional to $\phi_{0}$ and for thick walls it is proportional to sin $\phi_{0}$, where $\phi_{0}$ is the azimuthal angle between a line perpendicular to the wall and a line drawn to one end of the wall. This implies that at the center of a rectangular building with thick walls, the relative contributions of the long and short walls is equal to the ratio of their lengths. 
The expression of the geometric effect as a product of a polar and an azimuthal factor was made possible by a remarkably good approximation of separability evidenced by the data. The assumption of separability was made in the fallout methodology only because of the lack of data on the azimuthai dependence. It was later supported by Monte Carlo calculations [10]. Current evidence, still somewhat limited, also points to this approximation as justifiable in the cases of unreflected neutrons and wall-capture gammas.

When the incident gamma radiation field is limited by the geometry of both the building in which the detector is located and an exterior structure, the product $M \cdot G\left(X_{e}, \omega\right)$ in eq (2) is replaced by a difference of geometry factors. For example, figure 12 shows a detector position for which the incident field of radiation through the first story wall is limited by the solid angle fraction $\omega_{u}^{\prime}$ defined by the first floor of the ceiling of the first story and the solid angle fraction $\omega_{u}^{\prime \prime}$ defined by the presence of an exterior structure. The combined interior and exterior geometry effects in this case are approximated by the expression

$$
\left[G\left(X_{e}, \omega_{u}^{\prime}\right)-G\left(X_{e}, \omega_{u}^{\prime \prime}\right)\right]
$$

This procedure is not applicable to neutrons and wall-capture gammas, however. For these radiations one simply applies a factor $M$ obtained from figure 17 , which records the part of the upper hemisphere not blocked off, in terms of an upper hemisphere free-field geometry factor for neutrons. This factor is applied equally to upper and lower hemisphere reduction factors.

2. Reflected component. The contribution from yamma rays reflected from structural material behind the detector is of the order of $10 \%$ and is neglected in these calculations. However, the contribution from reflected neutrons is of the same order as that from unreflected neutrons and must be taken into account. 
For many enclosures an adequate rule for this is simply to calculate the unreflected neutron reduction factor, including all contributing walls and roof, and multiply by a (total/unreflected) factor $\left(1+\rho_{0}\right)$ which we take here to be 3 . This assigns to the reflected neutrons twice the dose contributed by the unreflected components, a value obtained by several rather different calculations using Snyder-Neufeld dose weights. Problems arise when an important wall surface subtends a rather small solid angle fraction, as shown by $w$ in the sketch in figure 18. The sidewalls and endwall then act as in a closed duct, to contribute a dose attenuated by geometry and by one or more albedo factors. We then multiply the unreflected component $G_{u}$ directly from the given wall surface by a factor $\left(1+\rho+\rho_{e}\right)$. Here $\rho$ and $\rho_{e}$, tine contributions from sidewalls and endwalls, respectively, are evaluated for w and $\omega_{e}$, as presented on figure 18. We should note that this approach ignores variations in the length-to-width ratio of a source wall; but calculations have indicated that these reflection factors vary only weakly with this ratio.

In a building with many windows the reflected neutrons will not make such a large contribution. To account for this effect we have made the reflected contribution dependent on the relative window area on the story in which the detector is located. One then multiplies the reflected neutron components $\rho$ and $\rho_{e}$ by $(1-w)$ and $\left(1-w_{e}\right)$, respectively, where $w_{e}$ is the fraction of endwall solid angle subtended by windows, and $w$ is the fraction of sidewall solid angle subtended by windows, so that the detector does not receive reflected neutrons from a window. The INR codes assume a central detector location. Furthermore, for wall sources, $w$ is assumed to be zero, since the floor and ceiling are two of the "side walls," and $w_{e}$ is approxinated by FW, the fraction of wall perimeter occupied by windows. For roof sources or contributions from upper (or lower) stories, where the floor (or ceiling) is 
the "end wall," $w_{e}$ is assumed to be zero and $w$ is approximated by FW. However, in basements below grade, the full reflected contribution is assumed, regardless of the window configuration on higher stories.

\section{E. Attenuation Factor, $A\left(X_{j}\right)$}

This factor is a ratio of the exposure with interior structure in place to the exposure in an empty building. In the INR calculations it often does not appear as an explicit factor. "For all types of roof radiation the thicknesses of all horizontal barriers above the detector, including the roof, are added to obtain a total thickness $x_{0}$. The product of the barrier factor $B\left(X_{e}\right)$ and the attenuation factor $A\left(X_{j}\right)$ in eq (2) is replaced in the calculations by a table-lookup of the roof barrier factor $B\left(x_{0}\right)$. The variables of the geometry factor are $X_{0}$ and $\omega$, the solid angle fraction subtended by the roof. Similarly, for all types of wall radiation, the thickness of all vertical interior partitions is added to the exterior thickness to obtain a total thickness $X_{T}$. A single table-lookup is then used to obtain a wall barrier factor.

For gamma rays, the attenuation of radiation from walls of the next higher story through a ceiling to a detector, say, in the basement, is evaluated by an attenuation factor $A\left(X_{0}{ }^{\prime}\right)$. Figures 19 and 20 give the attenuation of AS gamma and FP yammas, respectively, from a ring source for different incident polar anyles $\theta_{0}$. Each curve contains information for the eneryy spectrum at that angle. In order to apply these curves to a basement detector, we could estimate the average angle to the upper story walls and interpolate for the corresponding value of $\cos \theta_{0}$ and the thickness of the ceiling. However, these curves were approximated in the INR codes by the tiwo roof curves from figure 2. The adequacy of this approximation is discussed in section V.C. 
For neutrons and secondary gammas the attenuation is accounted for by adding the thickness of the ceiling (or floor) barrier to the thickness of the interior and exterior walls of the upper (or lower) story to obtain the argument for the wall barrier factor.

\section{F. Overall Protection Factors}

A much-used concept in fallout shielding studies is that of the Protection Factor (PF). To apply this to initial radiations, one must choose one or more standard mixtures of the different source components. The difficulty of this is quickly seen in the variety exibited in figures 10-13 of Auxier et al. [4]. Nevertheless some patterns do emerge which may provide useful reference for this purpose.

Very high megaton (MT) detonations are apt to be based on energies provided largely by the fission process; and shielding at greater distances from the detonation becomes important. These aspects, together with the 1 MT data of reference [4], figure 12, suggest using a high MT reference reduction factor such as the following:

$$
I R F_{G}=0.5 R_{F P}+0.2 R_{A S}+0.3\left(R_{N}+R_{N G}\right)
$$

Where it is understood that $R_{N}$ always includes the wail capture gamma-ray component.

Similarly, low kiloton (kT) detonations can feature neutrons generated by fusion reactions, with only a limited fission component. The neutrons generate a substantial air secondary component, however. This is illustrated in figure 10 of reference 41, and suggests a representative combination such as the following, for low kT cases: 


$$
I R F_{N}=0.6\left(R_{N}+R_{N G}\right)+0.2 R_{A S}+0.2 R_{F P} .
$$

The more general problem of mixed cases should not be ignored, and hence we tentatively suggest even-balancing for an intermediate, or "other" reduction factor representation:

$$
I R F_{0}=\frac{R_{A S}}{3}+\frac{\left(R_{N}+R_{N G}\right)}{3}+\frac{R_{F P}}{3}
$$

This is consistent, more or less, with figures 11 and 13 of reference [4]. These three combinations, translated into reciprocals, can perhaps serve to cover any possible requirements for "IPF's." Note that by choosing three such representations, a full set of values can be used in combination, without loss of information about the three radiation components.

IV. DISCUSSION OF INR COMPUTER CODES

A. Limitations of Codes

The present version of the INR codes (INRG6 for gamma rays and INRN6 for neutrons) has several limitations, some of which may have to be modified in the future. 
1. Codes calculate contribution from roof and from walls of the same story, story above, and story below the detector location. Contributions from walls of stories more than once-removed from the detector are assumed to be negligible.

2. Codes calculate protection at a central location of each story. The concepts used for the central detector can be extended to off-center detectors, as is done in the PFCOMP code. The extension requires significant increase in coding because four solid angles are required for every solid angle calculated for the central detector. Unless inore experimental data or Monte Carlo calculations become available for comparison, this refinement does not seem justified.

3. A limited number of configurations of interior partitions are included. Interior partition configurations are limited to a rectangular central core or a central corridor, extending the length of the building.

4. Each story of a building must be approximated by a square or rectangle.

5. Windows are assumed to have the same configuration on opposite sides of a building.

6. Linear interpolation between tabulated points on linear or log scales is used. The number of tabulated points for barrier and geometry factors should be increased so that interpolation is more accurate.

7. The ceiling attenuation factor for AS and FP gamma rays is approximated by the roof barrier factor. The ceiling attenuation factor for AS and FP gamma rays should be made dependent on the average angle of incidence of radiation rather than approximating it by the roof barrier factor.

8. The contribution from windows of the story above is overestimated. A better calculation may require more input parameters. 
B. Description of Subroutines

INTRPB Calculates barrier factors for four walls and overhead barriers by interpolating on tabulated values

Input:

$X T A B(11)$ tabulated values of barrier thickness

$X(5) \quad$ array of barrier thicknesses for four walls and overhead, in units of pounds per square foot (psf) of concrete

$\operatorname{BTAB}(11,4)$ tabulated barrier factors for roof and walls for two types of radiation

Output

$B(5,2)$ barrier factors for air secondaries and fission product gammas (INRG) or neutrons and capture gammas (INRN) for four walls and overhead

Remark:

The number of tabulated values of barrier thickness is currently assumed to be 6 in the neutron code and 11 in the gamma-ray code.

INTRPG Calculates geometry factors $G_{1}$ and $G_{2}$ for four walls, and geometry factor $G$ for overhead, by interpolating on tabulated values.

For roof geometry factors linear interpolation on $\log G$ vs. $\log \omega$ is used. However, for side-wall $G_{1}$ geometry factors, linear interpolation on $\log G$ vs. $\log (1-w)$ is used. For side-wall $G_{2}$ geometry factors, linear interpolation on $\log G$ vs. $\log \sin \phi$ is used.

Common:

$\operatorname{ZTAB}(6)$ tabulated value of barrier thickness

$\operatorname{YTAB}(11,2)$ tabulated array of values of $\omega$ and $\sin \phi$

$\operatorname{GTAB}(6,11,6)$ tabulated array of geometry factors for walls and overhead.

Input:

$X(9) \quad$ array of barrier thicknesses with $X(n+5)=X(n)$, psf $Y(18,2)$ array of values of $\omega$ and $\sin \phi$ defining each surface 
Output:

$G(9,2) \quad$ geometry factors for air-secondary and fission product gammas (INRG) or neutrons and capture gammas (INRN) with four values of $G_{1}$, one value of $G$, and four values of $G_{2}$.

Remark:

The number of tabulated values of barrier thickness is currently assumed to be 6 in both neutron and gamma codes.

GEOM Calculates values of $\omega$ and $\sin \phi$ for four walls from input linear dimensions for story.

Input:

HI height of portion of wall above detector plane, ft

$\mathrm{XL} \quad$ length of story, ft

W width of story, ft

Output:

OM(4) solid angle fraction subtended by equivalent circular ceiling associated with each wall

SPHI(4) value of $\sin \phi$ for each wall

SECTOR Calculates values of the array Y (see INTRPG) for the upper and lower portions of a partial story (sector)

Input:

IL parameter indicating whether to neglect ( IL $=0$ ) or calculate ( $I L=1$ ) values of $Y$ for the lower portion of the wall.

HU height of portion of wall above detector plane, ft

HUR height of roof above detector plane, ft

HL height of portion of wall below detector plane, ft

$X L \quad$ length of story, ft

W width of story, ft 
Output:

$Y(18,2)$ array containing values of $\omega$ in the first column and sin $\phi$ in the second column. The first 9 entries are for surfaces above the detector plane; the remainder are for surfaces below the detector plane.

Subroutines called:

GEOM

INPUTT Input routine data storage for tabulated barrier and geometry factors

Input/Output:

IPR

OMTAB

SPTAB

Common:

$X T A B$

$B T A B$

ZTAB

GTAB

$\operatorname{OMRTAB}(17)$

$\operatorname{RTAB}(17,2)$ OMSTAB (17) print index: ( $I P R>0$ ), print all tabulated barrier and geometry factors

tabulated values of solid angle fractions

tabulated values of $\sin \phi$

tabulated values of barrier thickness

tabulated values of barrier factors

barrier thicknesses for which geometry factors are tabulated

tabulated values of geometry factors

tabulated values of solid angle fraction for duct data (INRN, only)

tabulated values of duct attenuation (INRN, only)

tabulated values of solid angle fraction for mutual

shielding (INRN, only)

$\operatorname{XMSTAB}(17,2)$ tabulated values of mutual shielding (INRN, only) 
TEST Calls in input data for building parameters

Input:

TITLE (20A4) Descriptive title for building

IW, ID, IPR, IMS, IP, HI, HS(>0), HT, HD, HR, FW, HIU, HIL, XL, W $(5 I 5,5 F 10.2 / 5 F 10.2)$

Indices

IW Window index

$\mathrm{IW}=0$ No windows

IW $=1$ Windows on all four sides

IW $=2$ Windows on two long sides

ID Detector index

$I D=0$ Sub basement

ID $=1$ Basement below grade

ID $=2$ Basement - partly above grade

ID $=3$ First story of multistory building

$I D=4$ Second or higher story

ID $=5$ Second or higher story, but immediately below roof.

$I D=6$ First story, immediately below roof.

IPR Print index

$I P R=0$ Suppress printout of input tabulations and some geometry factors

IPR > 0 Print this information

*TEST is replaced by CETE1 (for neutrons and secondary gammas) and CETE2 (for AS and FP gamma rays) in program written by R. Lyday for FEMA. His subroutines CHARLI and CECARD are used to relate input data in the SANDINR system to input parameters required by the INR codes.

** Code will overestimate contribution in this case if detector is below grade. For calculating geometry factor, code assumes grade level is at detector level. If detector is above grade, code does not calculate contribution from below detector plane and contribution will be slightly underestimated. 
IMS

Mutual shielding index

IMS $=0$ Set mutual shielding equal to 0.5 for walls, 0.85

for roof gamma rays, and 0.58 for roof neutrons.

IMS > D Determine mutual shielding from heights of

neighboring buildings.

IP Index for configuration of interior partitions

$I P=0$ No interior partitions

$I P=1$ Four-sided core configuration of interior partitions

$I P=2$ Central corridor extending the length of the building

Linear dimensions (Relative to floor of this story, in units of $f t$ )

HI Ceiling height

HS $(>0)$ sill height

HT Height of top of window

HD Detector height (Not actually used in INRG code, where test

is made on HL. Used for mutual shielding test in INRN code

HR Roof height

FW Fraction of perimeter occupied by windows

HIU Height of story above

HIL Height of story below

$\mathrm{XL} \quad$ Length of building

W Width of building

XLM(4F10.3) Length of first plane along each wall of building (not used in INRG code)

WM(4F10.3) Width of first plane in direction perpendicular to each wall of building

$H M(4 F 10.3)$ Height of SECOND plane on each side of building

After reading in these data, codes call subroutine INPUTT to read in tabulated shielding data. Codes then read in: 
Wall Thicknesses (psf)

XE(5E10.3) Thickness of each exterior wall $(L=1,4)$ and of roof plus intervening ceilings ( $L=5$ )

$X I(5 E 10.3)$ Thickness of each interior wall $(L=1,4)$

XUE(5E10.3) Thickness of each exterior wall of story above $(L=1,4)$

XUI(5E10.3) Thickness of each interior wall of story above $(L=1,4)$ and of ceiling $(L=5)$

XXLE(510.3) Thickness of each exterior wall of story below $(L=1,4)$

XXLI(510.3) Thickness of each interior wall of story below $(L=1,4)$ and of floor $(L=5)$

RFSTOR Calculates the reduction factor for the four walls and overhead of a story

Input: (Barrier thicknesses in psf, linear dimensions in $\mathrm{ft}$ )

IW index to indicate configuration of windows

HI story height

HIU height of story above

HIL height of story below

HS average height of window sills above floor

HT average height of top of windows above floor (HT>HS)

$X L \quad$ length of story

W width of story

$x(9) \quad$ array containing values of four wall thicknesses and overhead thickness, with $x(n+5)=x(n)$. Thickness includes that of intervening interior partitions.

$X U(9)$ array for thicknesses of four walls of story above and total overhead thickness $(X U(5))$, with $X(n+5)=X(n)$

$X X L(9)$ array for thicknesses of four walls of story below, with $x(n+5)=x(n)$

FW fraction of the length of the wall that is occupied by windows 


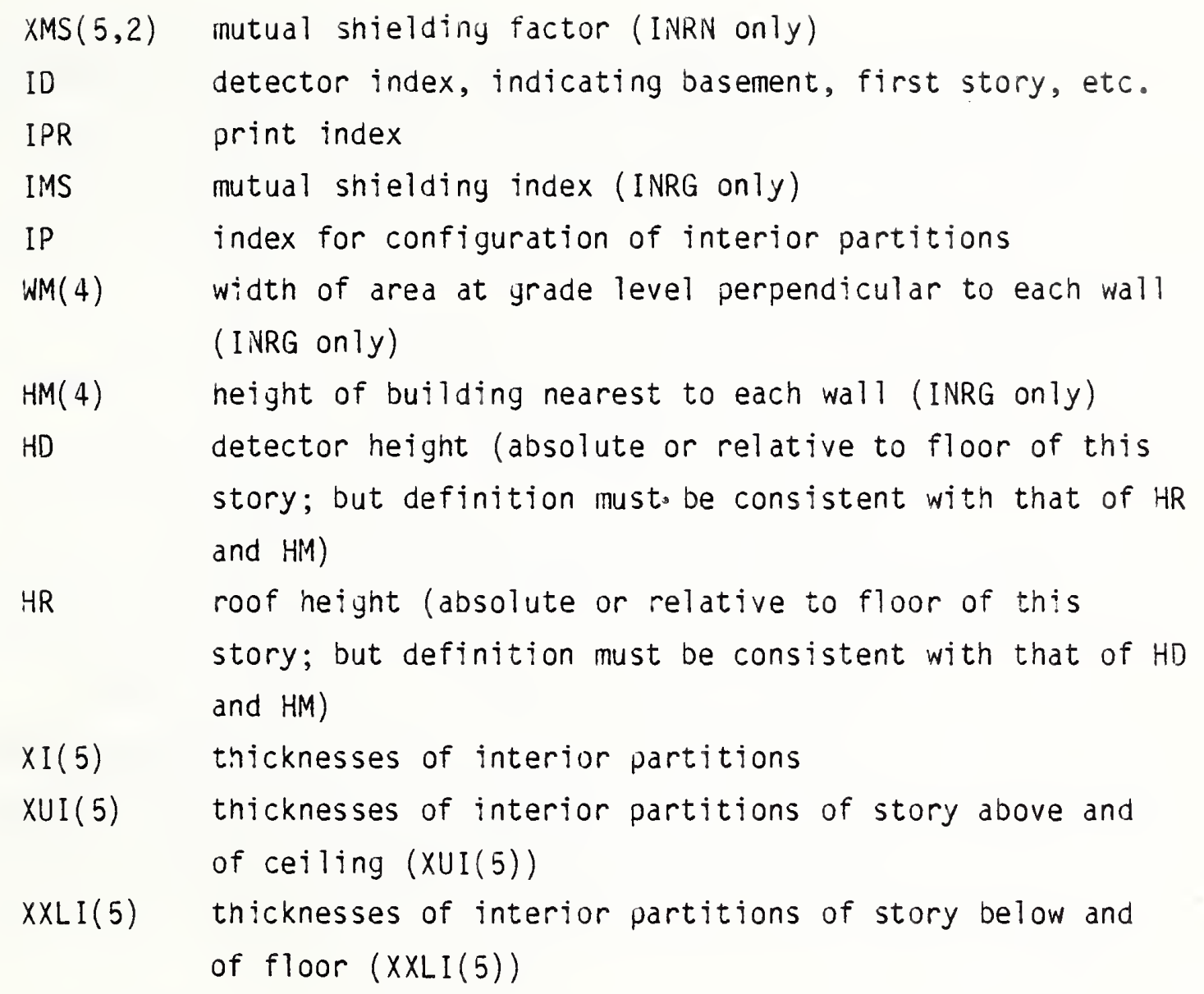

Output:

$\operatorname{RF}(5,2) \quad$ reduction factor array for four walls and overhead, for air-secondary and fission product gammas (INRG) or neutrons and capture gammas (INRN)

Subroutines called:

INTRPB

SECTOR

INTRPG

GMSHLD (INRG onTy)

INTRPR (INRN onTy) 
INTRPR Interpolates on tabulated reflection factors for neutrons to obtain a reflection factor for the "side" and "end" walls of the room. Here "end" refers to the surface opposite the one through which the radiation enters and "side" refers to the remaining four surfaces.

Input :

OMRTAB(17) list of solid anyle fractions at which reflection factors are tabulated

$\operatorname{RTAB}(17,2)$ reflection factors for 17 solid angle fractions for "side" walls ( $K=1)$ and "end" walls ( $K=2)$

TAUR(5) solid angle fraction subtended by the four walls $(I=1,4)$ and ceiling $(I=5)$. Values of TAUR are calculated in RFSTOR, assuming detector is centrally located, vertically as well as horizontally. Thus the solid angle fraction subtended by the "end" wall is always equal to that subtended by the source wall, and the same value is used for each of the two reflection factors.

Output:

RHO $(5,2)$ reflection factor for four walls $(I=1,4)$ and ceiling $(I=5)$, for "side"walls $(K=1)$ and "end" wall $(K=2)$.

NMSHLD (INRN only) Calculates the mutual shielding factor for neutrons incident on the roof and walls of a building. The solid angle fraction of open sky is calculated at the center of the roof and at exterior points at detector height at the center of each of the four walls. (For a detector below grade the exterior points are also below grade, although, physically, they should be at grade level or higher.) Mutual shielding factors are then interpolated from curves for either the roof or walls. A factor of 0.5 for the walls and 0.58 for the roof is included in the mutual shielding factor for neutrons. Reduction factors are multiplied by mutual shielding factors in the RFSTOR subroutine. 
Input: (in units of $\mathrm{ft}$ )

XLM(4) length of area at grade level parallel to each wall WM(4) width of area at grade level perpendicular to each wall (INRG only)

$X L \quad$ length of building

HM(4) height of building nearest to each wall (INRG only)

W width of building

HD detector height (absolute or relative to floor of this story; but definition must be consistent with that of HR and $H M$ )

$H R$

roof height (absolute or relative to floor of this story; but definition must be consistent with that of $H D$ and $H M$ )

Internal Variables:

TAUM(5) Solid angle fraction of open sky for each wall. Areas for calculating solid angle fractions are projected on to the horizontal plane at the height of the building nearest to each wall.

TAUMRF(5) Solid angle fraction of open sky for each quadrant of roof. Areas for calculating solid angle fractions are projected on to the horizontal plane at the height (HMAX) of the highest nearby building.

Output:

XMS $(5,2)$ Mutual shielding factor for walls $(J=1,4)$ and roof $(J=5)$, for neutrons $(I=1)$ and neutron capture gammas $(I=2)$. Mutual shielding factors for neutron capture gammas are assumed to be equal to those for neutrons in the current version of NMSHLD.

Subroutines called:

INTRPR

Remark: See Appendix $B$ for more detailed description of mutual shielding for neutrons. 
GMSHLD (INRG only) Calculates mutual shielding factors for gamma rays through roof and walls of building. As viewed from the detector, the nearest building limits the amount of open sky. For each side of the building the intersection on the wall of the plane formed by the nearer edge of the roof of a nearby building and the detector is determined (i.e., the edge of the "shadow"). Mutual shielding factors for sections of the walls below this intersection are set equal to zero. For example, if this intersection (shadow edge) is at a height halfway between the window sill and top, a ratio is formed of the contributions from above that intersection and from the whole window. This ratio -- the mutual shielding factor -- is applied as a correction to the window contribution. If the shadow intersects the roof, rather than the wall, then the intersection (instead of the real roof edge), determines the size of the effective roof on that side. A factor of 0.5 for the walls and 0.85 for the roof is included in the mutual shielding factor for both types of gamma rays. Corrections for mutual shielding are applied in the RFSTOR subroutine.

Input: (Linear dimensions in units of $\mathrm{ft}$, barrier thicknesses in psf)

$\begin{array}{ll}\text { WM(4) } & \text { width of area at grade level perpendicular to each wall } \\ H M(4) & \text { height of nearest building to each wall } \\ \mathrm{XL} & \text { length of building } \\ W & \text { width of building } \\ \text { HD } & \text { detector height. (Absolute or relative to floor of this } \\ & \text { story; but definition must be consistent with that of HR } \\ & \text { and HM.) } \\ \text { HI } & \text { height of the story } \\ \text { HL } & \text { height of portion of wall below detector plane } \\ \text { HIU } & \text { height of story above this one } \\ \text { HT } & \text { height of top of window } \\ \text { HUR } & \text { distance from detector to roof. HUR is set equal to } \\ & \text { HR-HD in the RFSTOR subroutine. }\end{array}$




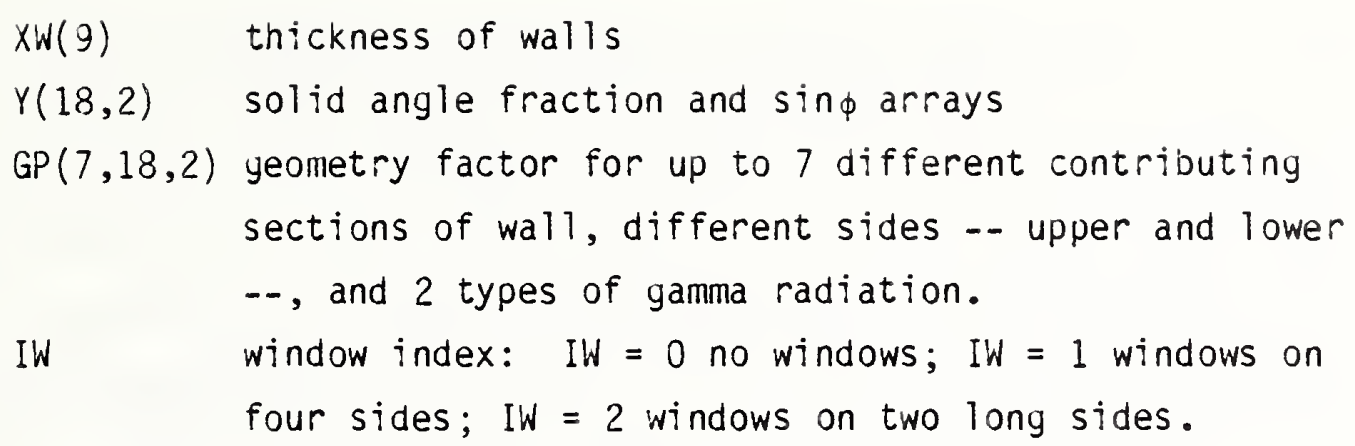

Output:

$$
\begin{aligned}
& \text { XMSW(4,5,2) mutuai shielding factor for four walls and roof for } \\
& \text { air secondary gammas }(M=1) \text { or fission product gammas } \\
& (M=2) \text {. Corrections for walls of same story }(J=1) \text {, } \\
& \text { windows of same story }(J=2) \text {, walls of story above } \\
& (J=3) \text {, and windows of story above }(J=4) \text {. }
\end{aligned}
$$

Subroutines called:

SECTOR

INTRPG

C. Listing of Computer Codes.

FORTRAN listing of subroutines of the INRG6 and INRN6 computer codes are shown in Appendix C. Data input for sample neutron and gamma programs are shown in Appendix D. Finally, output for the same sample programs are shown in Appendix $E$. 


\section{COMPARISON WITH MONTE CARLO CALCULATIONS}

A. Monte Carlo Calculations on Benchmark Structures

Since several approximations have been made in the derivation of eq (2) and in the determination of the component functions, it is necessary to check the results either with experiments or with more rigorous calculations. Experimental checks of approximate procedures for predicting fallout shielding were extensive. However, there have been no systematic experinents developed to either predict or check theoretical procedures for estimating protection from initial nuclear radiation. Therefore comparisons must be made with independent calculations.

The approximate procedures of eq (2) will be applied mainly to three dimensional structures with rectangular roofs and walls. Monte Carlo calculations probably offer the most promising approach for obtaining accurate and independent results for a small number of configurations.

Unfortunately we have available only one set of Monte Carlo calculations with which we can compare our calculated reduction factors. The Monte Carlo calculations considered here were performed by Beer and Cohen of MAGI [11,12] under subcontract to NBS and FEMA. Although the Monte Carlo method is a rigorous one, its application to any particular problem may contain errors due to poor sampling techniques or inadequate modeling of the geometry of the problem. Therefore, discrepancies between NBS approximate procedures and MAGI Monte Carlo calculations do not necessarily imply that the procedures are inadequate.

A series of structures of increasing complexity were selected as benchmark structures to test the adequacy of the approximate procedures. They were designed to approach in complexity a typical multi-story dormitory building. Cross section and elevation sketches of these structures are shown in 
figures 21 and 22. Figure 21 indicates a structure that contains a basement ceiling (elevation view), and windows on two sides (plan view). These structural details are given in table IV.

B. Combined Components

First we present a comparison of the overall protection factors calculated by NBS and MAGI for the high and low yield combination of components discussed in Section III.E. This comparison can be made only for structures 4 and 5 since MAGI did not calculate reduction factors for neutrons in structures 1 through 3.

Table VI shows reduction factors for the four radiation components and for overall reduction factors according to the weighting factors shown in eqs. (4) and (5) of Section III.F. Comparisons are made for structures 4 and 5 at central positions in the first story and basement. The first fact to note is that the first story provides protection factors of 2 to 4 , while basements provide protection factors of 6 to 20. Secondly, the NBS estimates of reduction factors are up to $40 \%$ higher than those of MAGI and are therefore conservative, in that they estimate less protection. The computer codes yenerated by NBS therefore seem to predict reasonable estinates of reduction factors. Reasons for discrepancies with the MAGI Monte Carlo calculations and possible improvements in the NBS computer codes are discussed in the following sections.

C. AS and FP Gamma Rays

Monte Carlo calculations were made by Beer and Cohen [11] to determine reduction factors for AS and FP gamma rays incident on the five benchmark structures. In a preliminary exercise the roof barrier for air-secondary and 
fission-product gammas was determined. Comparison of these results with those estimated from figure 2 is shown in table $V$. The agreement between the two methods for this simple configuration is within $10 \%$.

Now we turn to comparisons for the benchmark structures. Tables VII through XII give comparisons of reduction factors for AS and FP gamma radiations calculated by MAGI and NBS for centrally-located detectors $(x=y=0)$ in the five benchmark structures. We consider first, structure \#1. The comparisons shown in table VII indicate reasonably good agreement for the AS gamma radiation, but the NBS calculations for the FP gamma radiation are as much as $46 \%$ higher than the MAGI calculations. The discrepancy is probably due to the calculation of geometry factors, since the calculated barrier factors for the roof show only a few percent discrepancy. The NBS geometry factors may be high because of the approximation, discussed earlier, of integrating over the incident angular distribution rather than the emergent angular distribution.

Structure $\# 2$ includes windows. Since the contribution from windows involves merely an integral over portions of the source angular distribution, the two methods ought to agree well. The observed discrepancies for the basement are due to insufficient characterization by the computer codes of the geometry of the windows on upper stories. The code assumes erroneously that the windows of the upper story extend from the tops of the windows of the detector story to the top of the upper story, thus accounting for a larger window area than intended from the input data. Comparison of the contributions from the walls shows the same discrepancies as observed in Structure \#1.

The approximate procedures do not predict any differences in roof dose between structures $\frac{\| 1}{1}$ and $\frac{*}{\hbar} 2$, because of the presence of windows in structure \#2. The Monte Carlo calculations, on the other hand, seem to show about a $5 \%$ decrease in reduction factor because of leakage of gamma rays through the windows. 
In structure \#3, the main effect of the basement ceiling is to reduce the dose in the basement. Table IX shows that NBS calculation for the roof is still high, but that the wall results also differ by about $35 \%$. To examine the effect of the ceiling barrier we take ratios of the contributions calculated by MAGI for structures $\# 3$ and $\# 1$. We then compare these values with the NBS attenuation factors interpolated from figures 19 and 20 . Table $X$ shows the results. The agreement for the component from the roof is reasonably good. The agreement for radiation from the wall, however, is not as good. The main reason for this is that the barrier factor of the ceiling was originally made dependent on the average angle of incidence of the photons on the upper surface of the barrier. When the computer code was iritten, the roof barrier was substituted as a simplification. Table IX shows that the approximation results in a reduction factor from the walls that is lower by a factor of 1.9 for air secondaries and by a factor of 3.2 for fission product gammas. The approximation inade in the INR code is conservative and tends to overestimate reduction factors or underestimate protection.

Structure \#4 is similar to structure \#3 except that it contains windows. Comparisons of the contributions to a basement detector from the walls and windows of the first story calculated by the two methods are shown in table XI. Both calculations predict a lower wall contribution in structure \#4 than in \#3 because of reduced wall area. The window contribution calculated by NBS for the air secondaries and the fission product gammas is much larger than that calculated by Monte Carlo. This is the largest discrepancy in the comparisons we have considered. The attenuation in the basement ceiling as calculated from ratios of entries in tables VIII and XI is in reasonable agreement for the wall sources. Furthermore, the attenuation for window sources calculated for air secondaries by MAGI is $(.0098 / .0693)=.141$, not 
too different from the value of .165 calculated by MAGI for wall sources. However, the attenuation predicted for fission product gammas is $(.0010 / .0409)=.024$, considerably lower than the value of .065 calculated by MAGI for wall sources. Therefore, the MAGI results for windows are believed to be about a factor of 2.5 too low, reducing the discrepancy from a factor of 13 to 5.2 .

Figure 21 shows multistory structure \#5. Because of the many stories, the roof source is not expected to contribute to the dose on the first story or in the basement. However, since the ambient source radiation is directed downward, walls above the first story may be expected to contribute to the dose at these points. Table XII shows a comparison of the contributions from the first, second, and third story walls to detectors on the first story and in the basement. Both calculations indicate that for ceiling thicknesses of 57 psf, the first story is the major contributor. Contributions from higher stories increase the dose by about $1 / 3$ for AS gamma rays and are almost negligible for FP gamma rays. These increments would vary with the geometry of the building and the thickness of the ceilings. Agreement between the two types of calculations is good for the first story and, for the basement, a factor of 2 to 3 better than for structure \#4. This reinforces the argument that the MAGI calculations of the window contribution to the basement of structure \#4 may be low by a factor of 2.5 .

D. Neutrons and Secondary Gamma Rays

Under a later subcontract with NBS (March 1981) MAGI also made Monte Carlo calculations of reduction factors for neutrons incident on benchmark structure \#4. They tabulated reduction factors for both neutrons and for yamma rays produced by neutron interaction in the structure. These calculations were reported in MAGI-7072 [12]. Table XII shows comparisons for source neutrons entering through the roof and windows. 
MAGI also distinguished between reflected and unreflected components. Although there is some question of the MAGI's operational definition of the two terms, unreflected is intended to mean the contribution from neutrons (or gammas) which enter the room through the floor, ceiling or exterior walls and reach the detector before being reflected from a room surface. All others are reflected, including ganmas which were generated in a surface by neutrons entering the room.

For the roof source in Table XIII we find reasonable agreement for the sum of reflected and unreflected and for individual components. The agreement is also reasonable for basement detectors.

For the window source and first-story detector however, the NBS results are generally higher by a factor of 2. In this case, we believe that the unreflected neutron component may have been underestimated by MAGI. For example, they calculated .034 and .048 for the air-secondary and fission product source in structure \#2 (See Table VIII). Since the neutrons are even more isotropic than the FP gamma rays we would expect a greater contribution from neutrons. Therefore the unreflected contribution of .0566 calculated by NBS seems more reasonable than the contribution of .0266 calculated by MAGI. Furthermore, the reflected contribution calculated by MAGI is almost three times that of the unreflected - too high a ratio, in our opinion. We therefore believe that the MAGI calculation of the unreflected contribution is low by at least a factor of 2 .

For the window source and basement detectors the same problem exists. In this case, however, the problems is complicated by the attenuation in the ceiling barrier. But the attenuation factor for neutrons is less sensitive to the incident angle than for gamma rays. Therefore, even though the ceiling barrier factor for neutrons and secondary gammas is treated by "folding" the ceiling up against the outer wall and calculating the barrier factor for a roof source, the approximation is expected to be a good one. 
For the wall source and first-story detector the same comments apply as for the window source. For the wall source and basement detector the NBS unreflected neutron contribution is even more than a factor of 2 greater than that calculated by MAGI, but the reflected contribution is lower. The result is fortuitously close agreement for the sum of the two contributions both for neutrons and secondary gammas.

The combined contributions of all three sources are also shown in Table XIII. Since the contribution from the roof source dominates, the ratio of NBS results for all sources are similar to those for the roof source alone. Table XIII shows a similar comparison for Benchmark structure \#5. For the first story source and the first-story detector, we believe that the NBS reflected neutron contribution may be somewhat high because the code does not take into account the decreased reflection when the two walls adjacent to the source wall are replaced by windows. It does, however, account for the decreased reflection from windows in the wall opposite to the source wall. On the other hand, just as for the other structures, we believe that the MAGI calculation of the unreflected neutron component is too small. This can be demonstrated for the detector on the first story, in which case the estimate is particularly simple. The INR code gives a reasonably rigorous estimate for the unreflected neutrons, namely:

$$
R_{f}=0.58 G\left(\omega_{w}\right)
$$

where $G\left(\omega_{W}\right)$ is the geometry factor for the solid angle opening $\omega_{W}$ of the windows. This yields $R_{f}=0.196$, almost a factor of 2 greater than the MAGI value of .106 . 
For the basement, the MAGI values for the unreflected component are probably again too low, but the MAGI values for the reflected component are high, so that the sum of the contributions is consistent with those of NBS.

The contributions from stories 2-9 are also shown in Table XIV. For the first story detector the NBS values are consistently lower, probably because contributions from the third and higher stories are neglected in the INR code. The MAGI values for the basement detector give an idea of the underestimate of the NBS calculation.

Finally, the contribution from all sources are shown in Table XIV. The "bottom line" is that the NBS values for the reduction factors for neutrons and secondary gammas in a detector above grade are higher than the MAGI values by a factor of about 1.5 but probably more correct. For detectors in the basement the NBS value for the sum of the components is 0.8 times that of MAGI, that is, in rough agreement because of compensating estimates of reflected and unreflected contributions.

\section{CONCLUSIONS}

In summary, the approximate procedures developed for calculating protection from initial gamma radiation appear to be promisiny. Estimates of protection with a single ceiling slab in place have been compared with those from Monte Carlo calculations. Procedures for more complicated interior structure such as interior walls are available, but have not yet been compared with more accurate calculations.

The two areas in which the INR codes could be improved are the ceiling attenuation for AS and FP gamma rays, and the calculation of the contribution from windows in the story above the detector. 
$\underline{\text { References }}$

[1] L. V. Spencer, Structure Shielding Against Fallout Radiation from Nuclear Weapons, NBS Monograph 42, U.S. Government Printing Office (June 1962).

[2] C. Eisenhauer, An Engineering Method for Calculating Protection Afforded by Structures Against Fallout Radiation, NBS Monograph 76, IJ.S. Government Printing Office (July 1964).

[3] L. V. Spencer, Structure Shielding Against Initial Radiation from Nuclear Explosions, I. Attenuation of Air Secondary and Fission Product Gamma Rays, Nuc7. Sci. Eng. 57, 129-154 (June 1975).

[4] J. A. Auxier, Z. G. Burson, R. L. French, F. F. Haywood, L. G. Mooney, 'and E. A. Straker, Nuclear Weapons Free-Field Environment Recommended for Initial Radiation Shielding Calculations, ORNL TM 3396, Oak Ridge National Laboratory (Feb. 1972).

[5] L. G. Mooney and R. L. Swanson, Initial Nuclear Radiation Support Studies, RRA T7411, Radiation Research Associates, Inc., Ft. Worth, Texas (1974).

[6] M. Beer and M. O. Cohen, Effects of Ambient Field Specification on Initial Radiation Dose in Concrete Structures, Trans. Am. Nuc. Soc. 21, 545 (1975).

[7] G. L. Simmons, An Adjoint Gamma-Ray Moments Computer Code, ADJM/M I, NBS Technical Note 748, National Bureau of Standards (Feb. 1973).

[8] L. V. Spencer, "Plural-Series" Approximations of Functions, NBS J. Res., 76B, 91 (1972).

[9] G. L. Simmons and W. K. Hagan, Initial Nuclear Radiation Penetration Study, SAI01381 052LJ, Science Applications, La Jolla, California (1981).

[10] C. Eisenhauer and A. B. Chilton, Angular Distribution of Scattered Gamma Rays from a Fan Source, Trans. Am. Nuc. Soc. 14, 1 (June 1971).

[11] M. Beer and M. O. Cohen, Adjoint Monte Carlo Calculations of Initial Garmma Radiation Doses in Structures, Trans. Am. Nuc. Soc. 18, 377 (1974). (See also: M. Beer and M. O. Cohen, Initial Gamma Radiation Dose in Five Concrete Structures, Report Mr 7037, Mathematical Applications Group, Inc., Elmsford, N.Y., Nov. 1973).

[12] M. Beer, Monte Carlo Studies of the Shielding of Blockhouse Structures Against Initial Neutron Radiation, Mathematical Applications Group, Inc. Report No. MAGI-7072, Elmsford, New York (March 1981). 


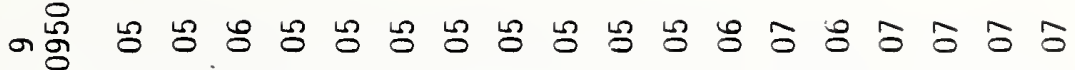
$=\quad$ 定i

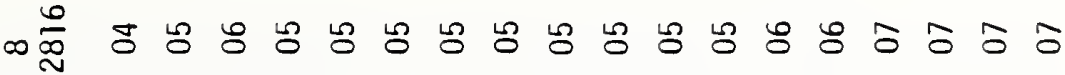

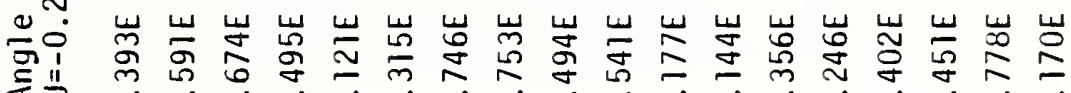

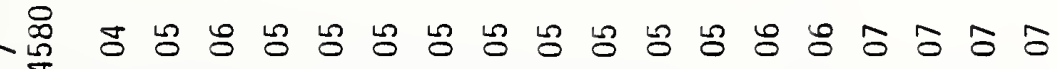

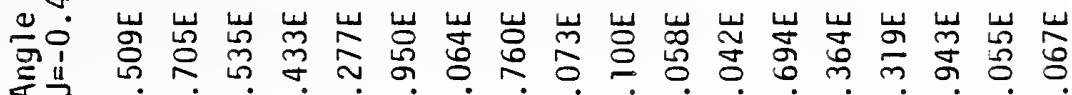

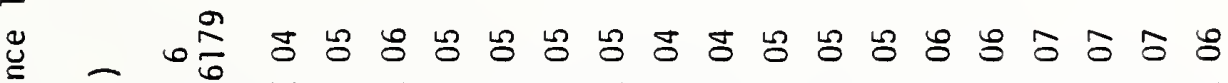

采 $+<\frac{1}{\Sigma}$ $\infty \dot{0}$

的总 旁

- 葛す

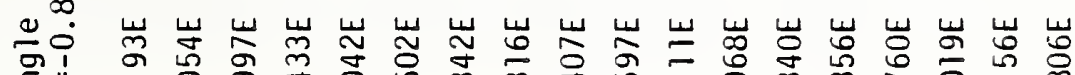

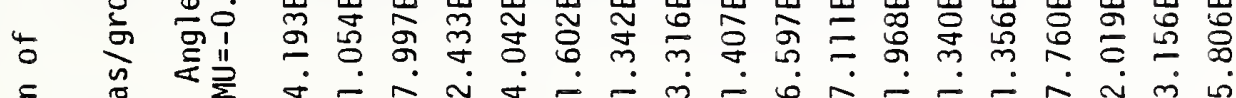

总产营

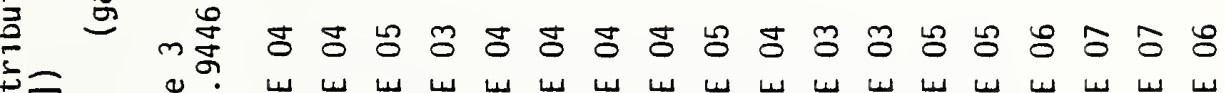

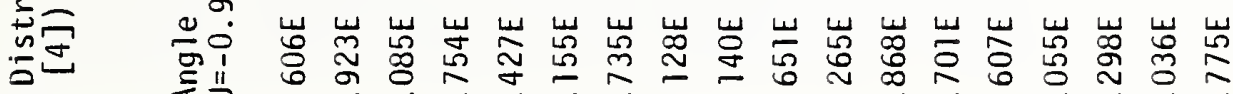
$\stackrel{\leftrightarrow}{\mathscr{E}}$

完苟

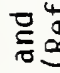

离.

$\geq$

王

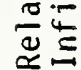

$\stackrel{\therefore}{\stackrel{0}{\circ}}$

$$
\text { - Oِ }
$$

๙

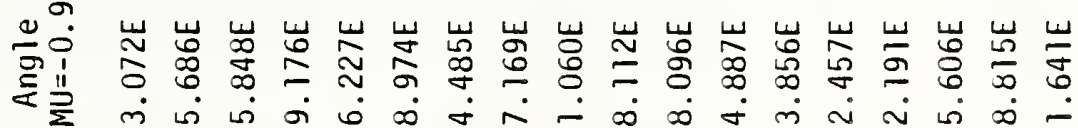

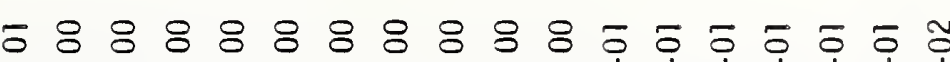

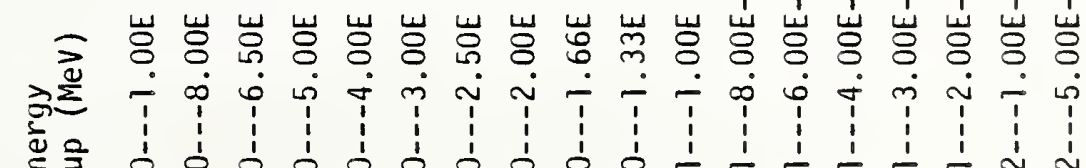
离产

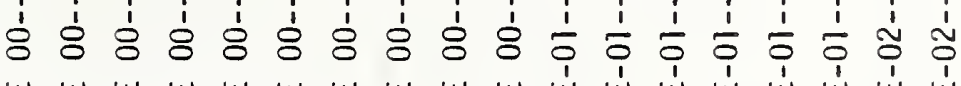

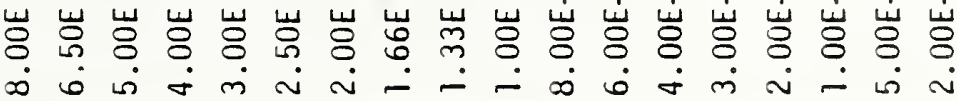




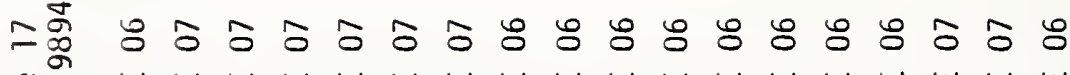

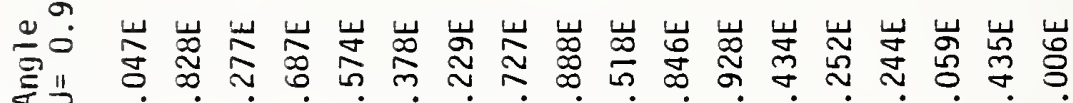

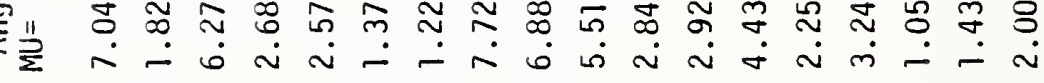

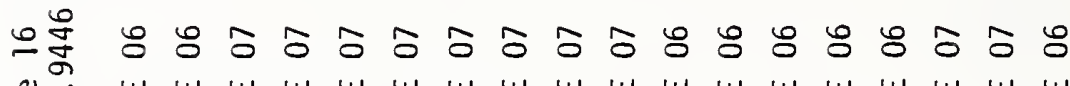

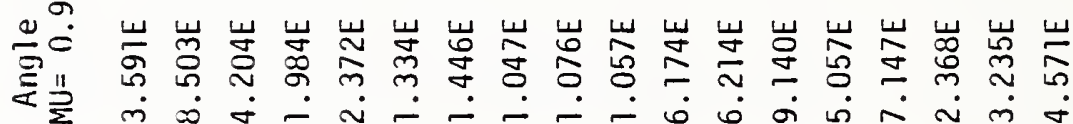

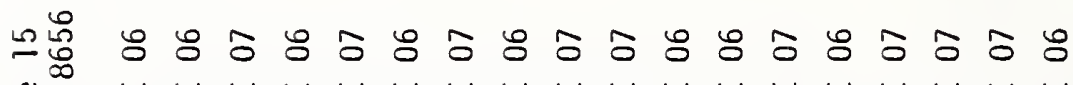

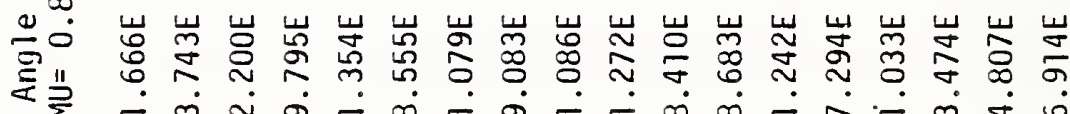

揭

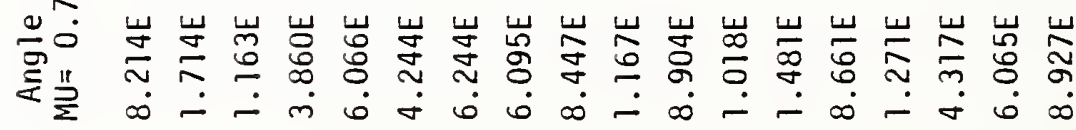

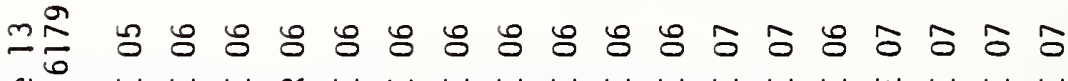

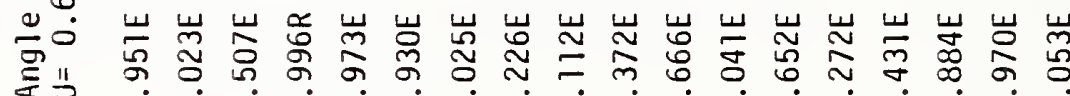

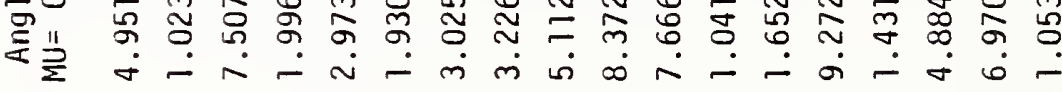

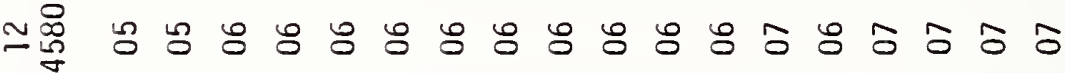

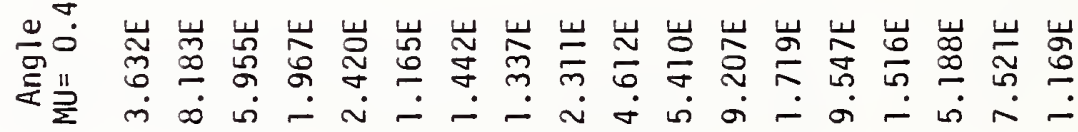

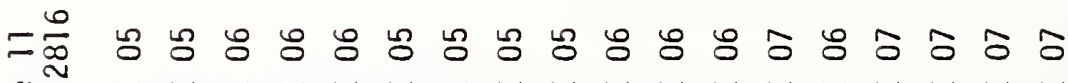

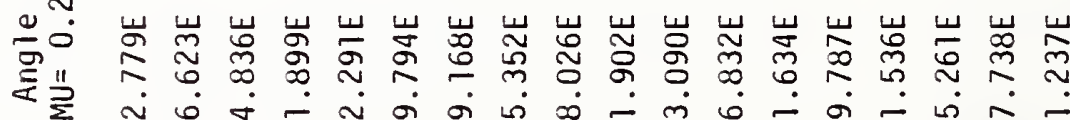

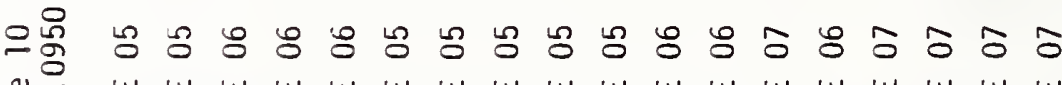

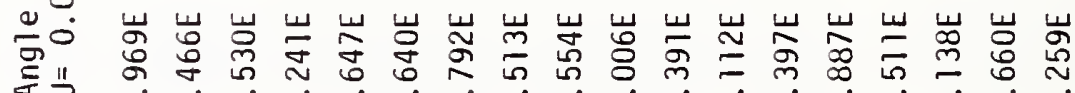
崖

б 8888888888

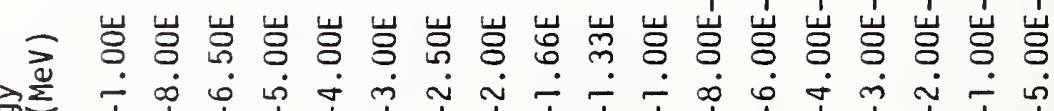

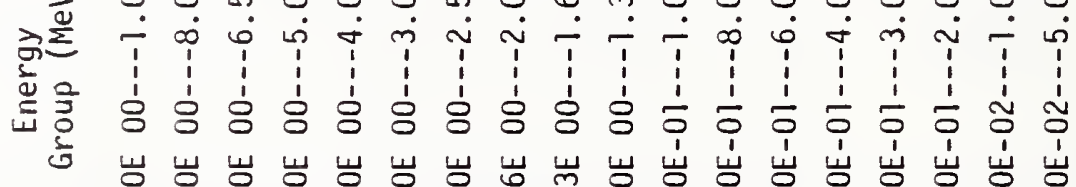

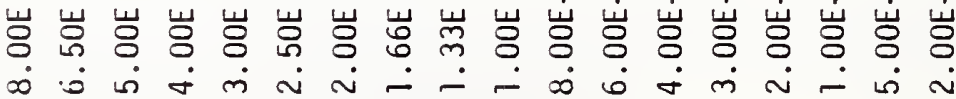


すิ ஏ 光

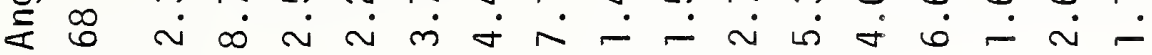

$\stackrel{\frac{2}{ \pm}}{\frac{1}{3}}$

$\stackrel{0}{\square}$

官

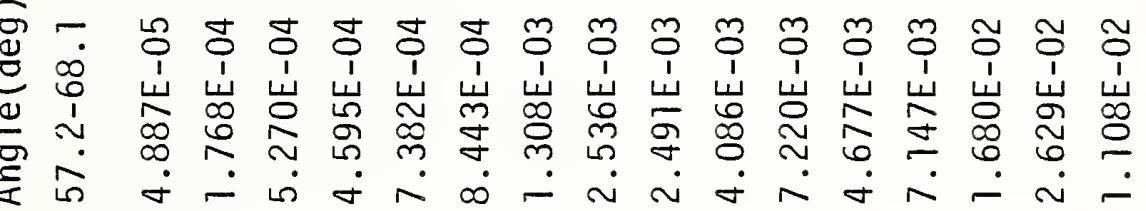

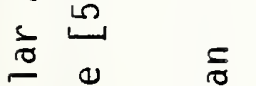

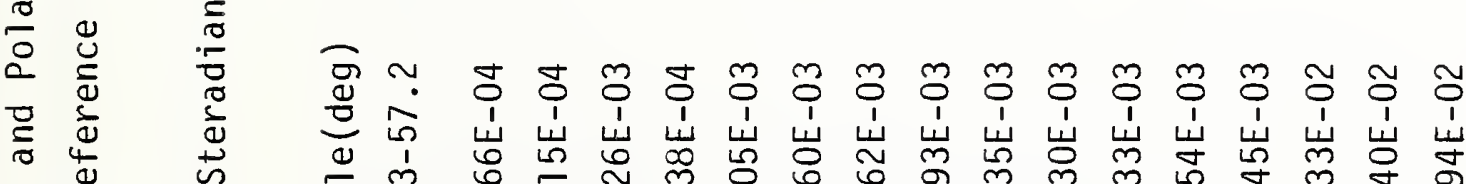

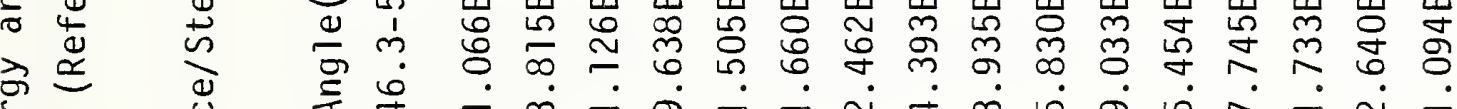
Фे

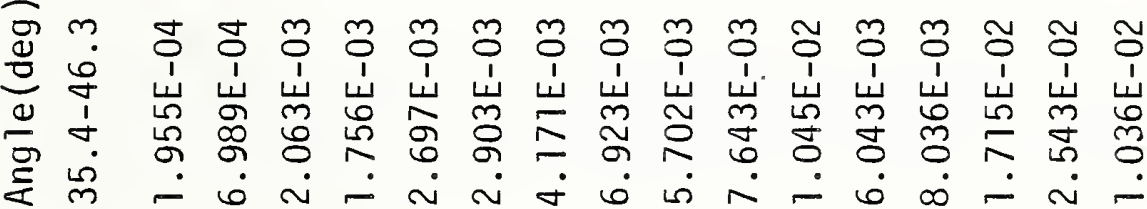

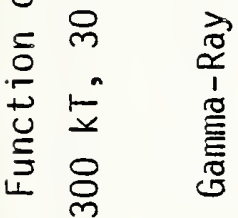

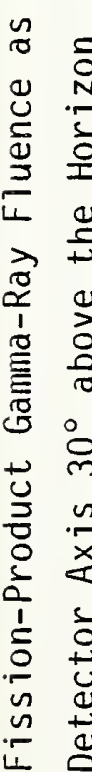

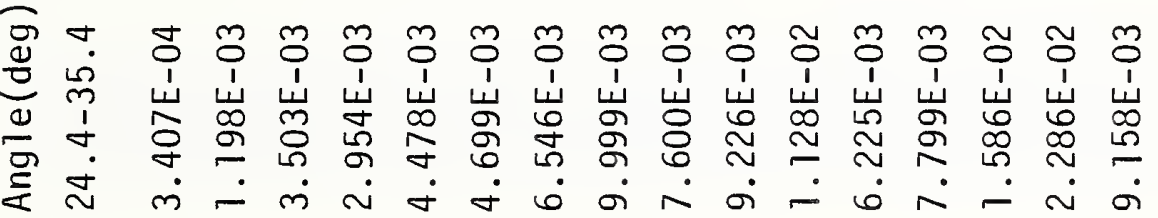

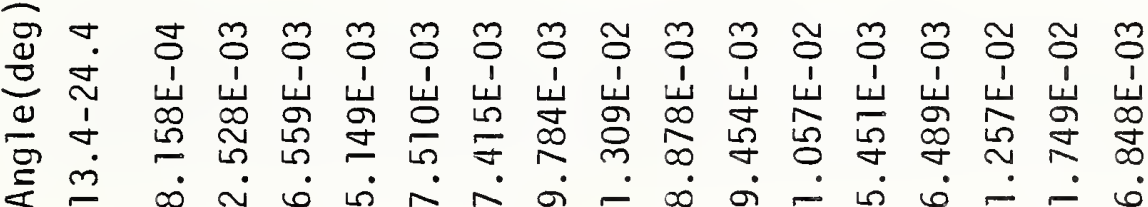

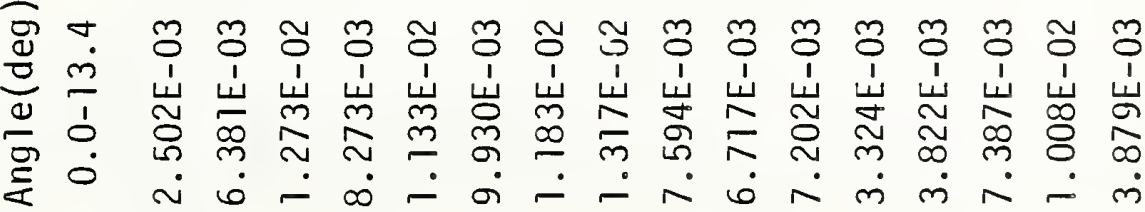

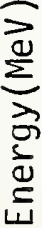

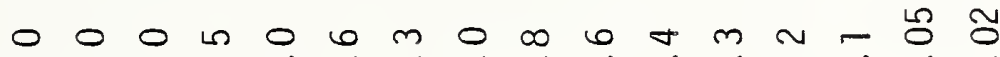

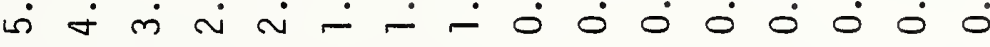

$\begin{array}{lllllllllllllllll}0 & 1 & 1 & 1 & 1 & 1 & 1 & 1 & 1 & 1 & 1 & 1 & 1 & 1 & 1 & 1 & 1 \\ 0 & n & 0 & 0 & 0 & 1 & 0 & 0 & m & 0 & \infty & 0 & \sigma & m & N & - & 0\end{array}$

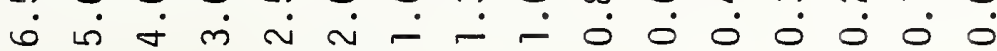




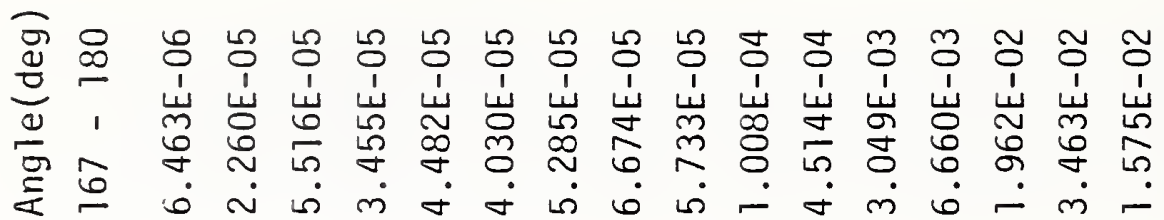

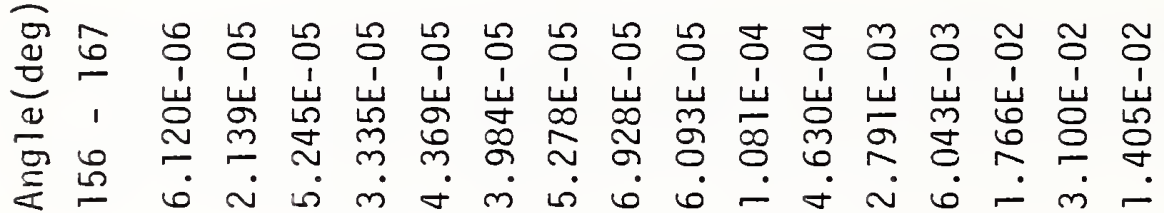

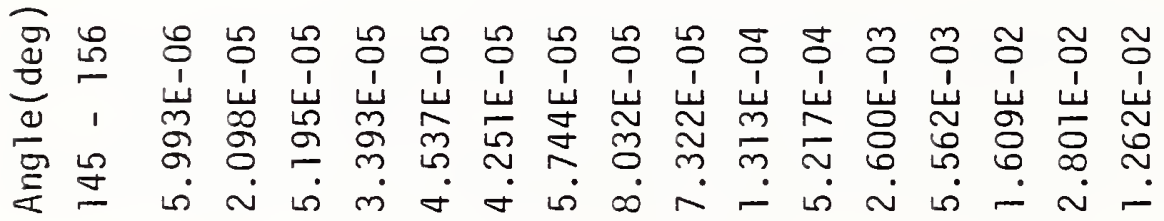

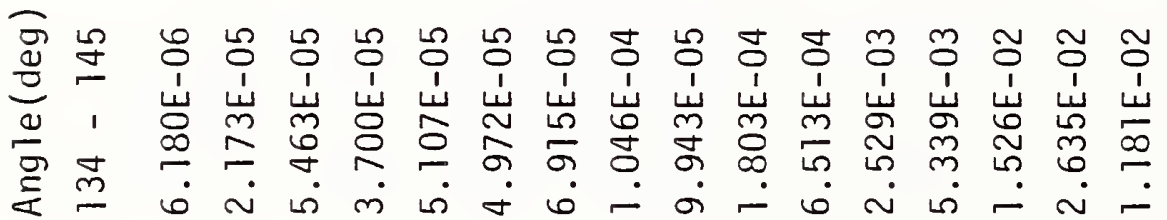

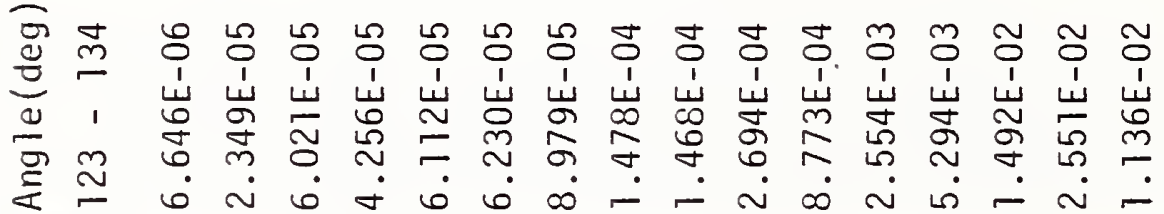

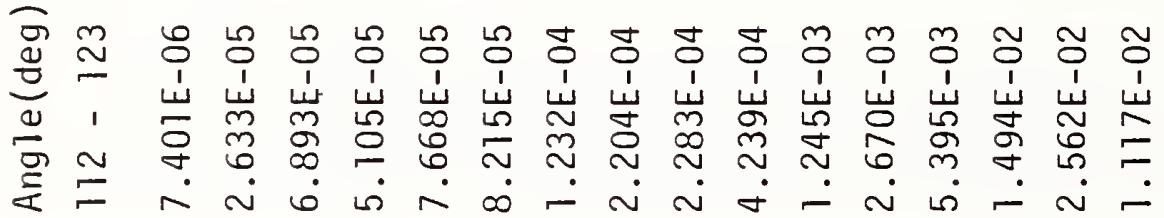

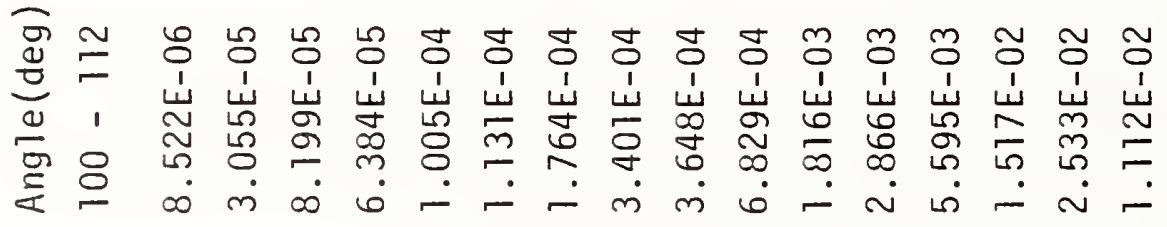

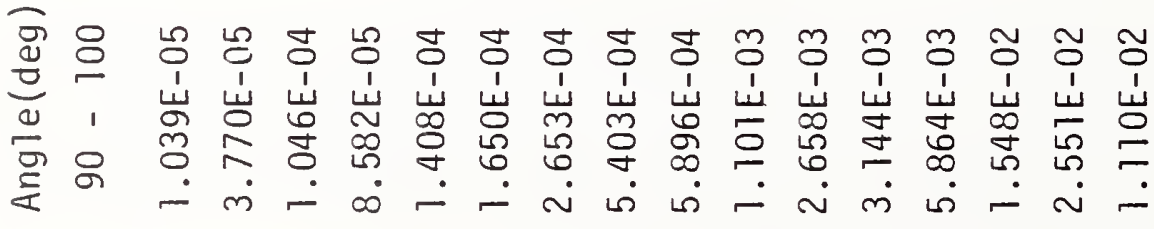

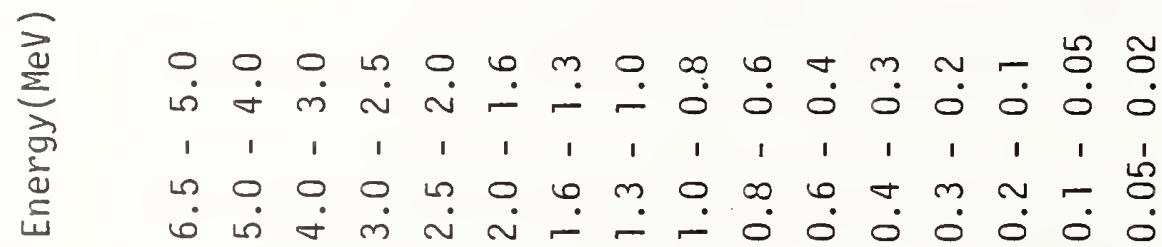


எ융 宁

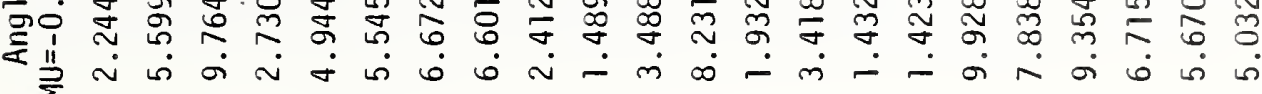

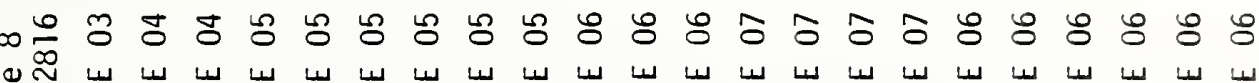

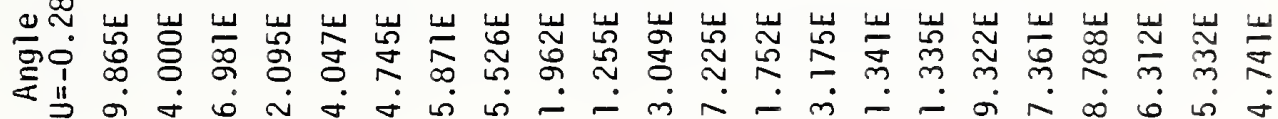

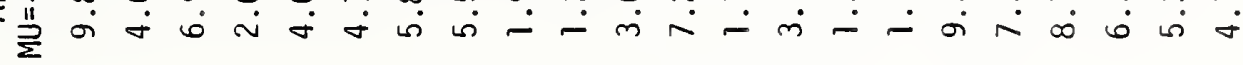

人店

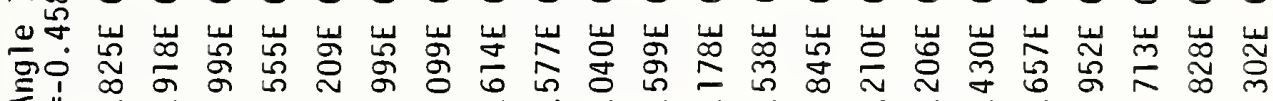
光

용 凹ర 常

융

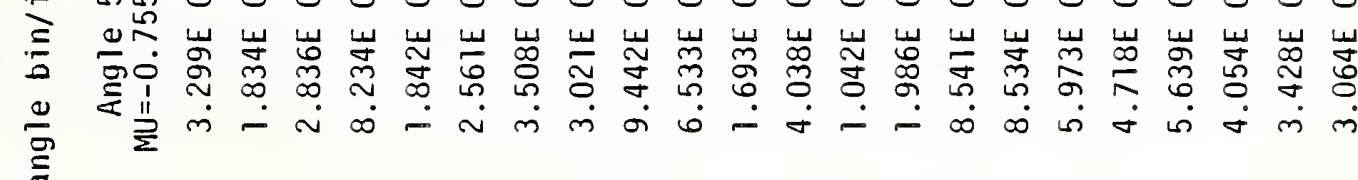

合

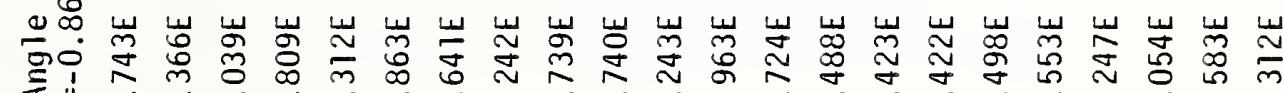
4

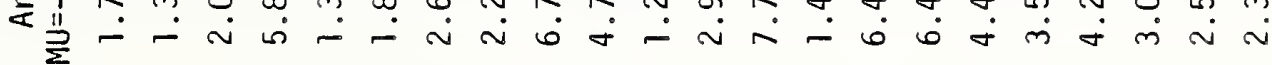

E m导の

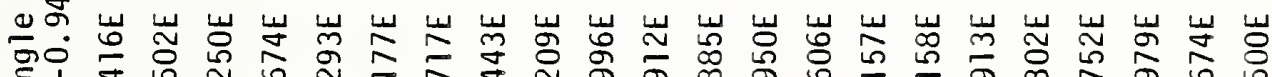

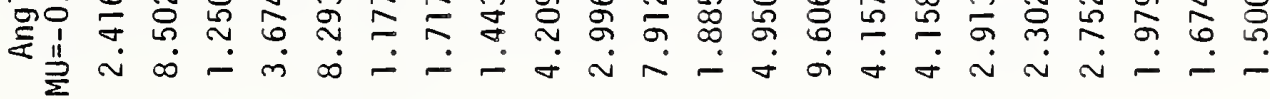

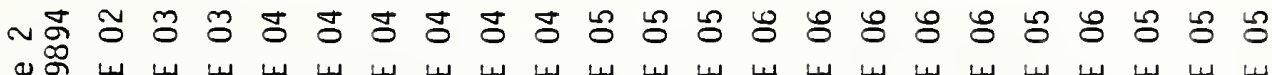

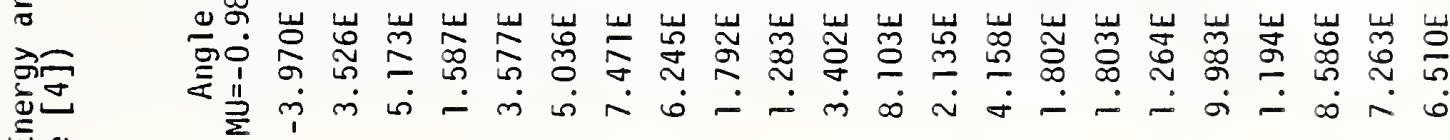
ए

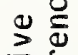
离离离 


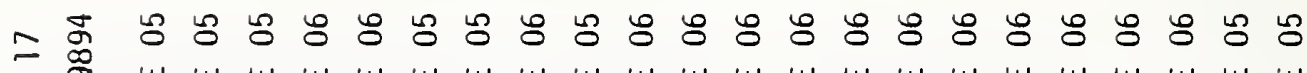

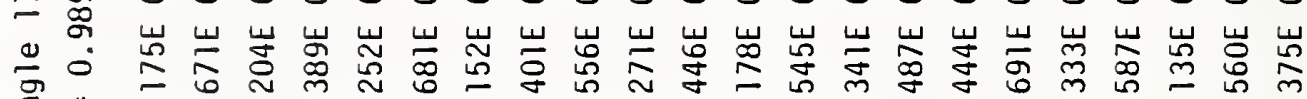

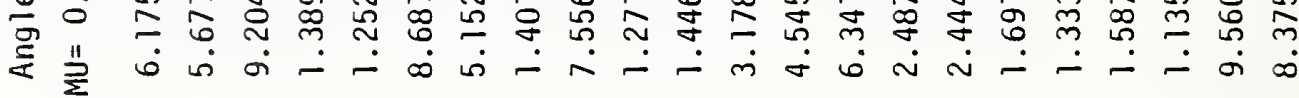

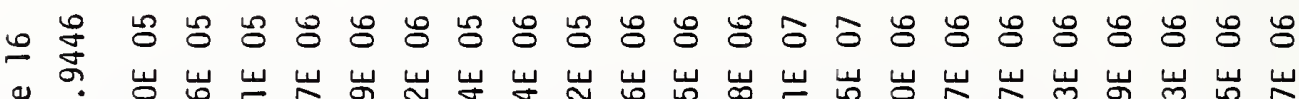

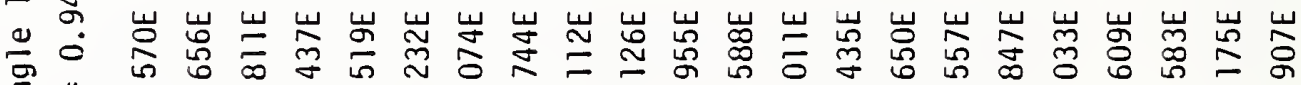

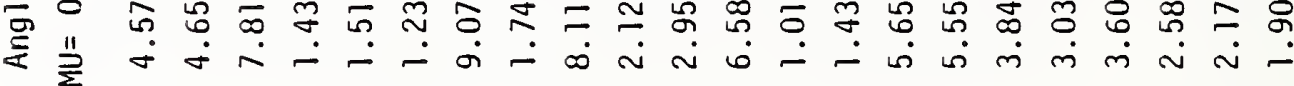

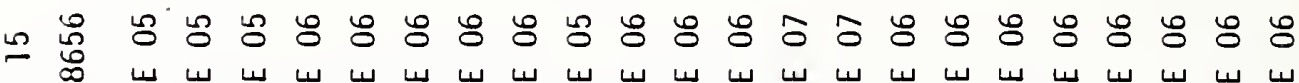

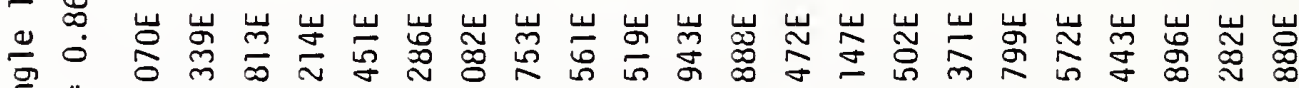
畕芝

ஏ 员 Ð 定

용 \& \&

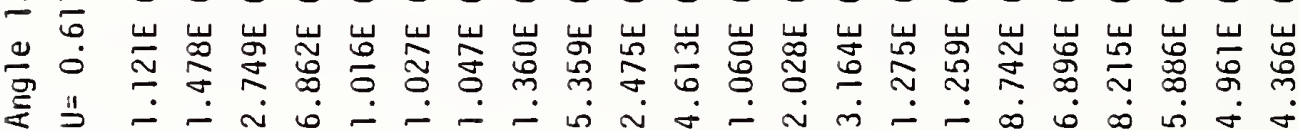

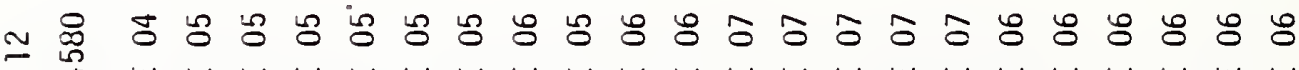

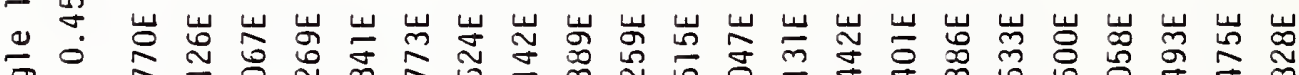

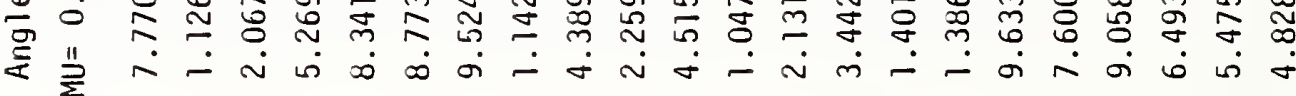
$=\underset{\sim}{\infty}$ 品 凹 界

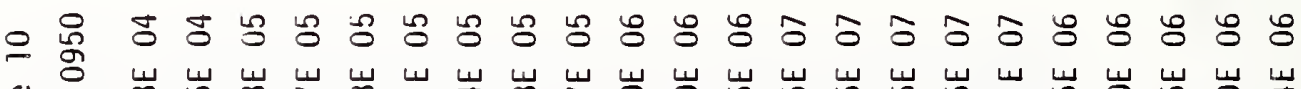

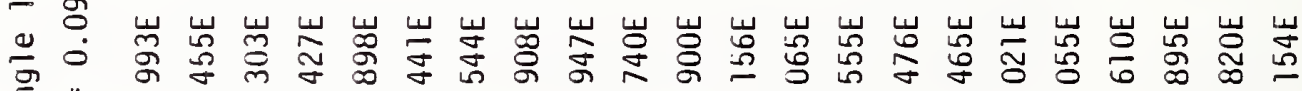
类 б ธ ธ

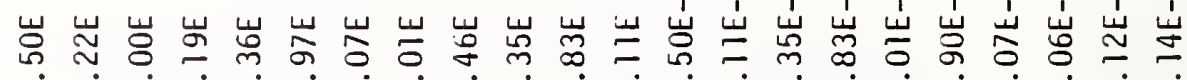
宓离

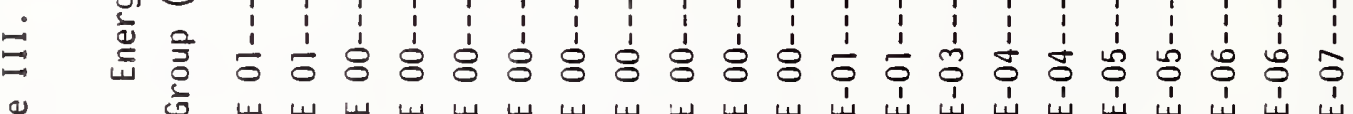
$\stackrel{\frac{0}{\circ}}{\circ}$

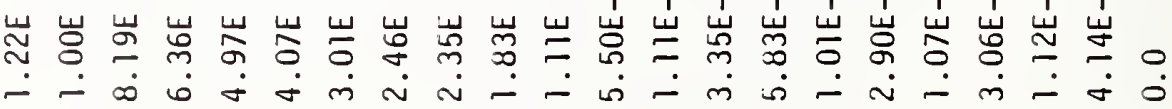


Table IV. Structural Details

$\begin{array}{ccc}\begin{array}{c}\text { Structure } \\ \text { Number }\end{array} & \begin{array}{c}\text { Thickness of } \\ \text { Basement Ceiling }\end{array} & \text { Windows ? } \\ 1 & 0 \text { psf } & \text { No } \\ 2 & 0 \text { psf } & \text { Yes } \\ 3 & 57 \text { psf } & \text { No } \\ 4 & 57 \text { psf } & \text { Yes }\end{array}$


Table V

Comparison of Roof Barrier Factors

$Z$ (psf) Air Secondaries

\begin{tabular}{rrrr} 
& MAGI & \multicolumn{1}{l}{ NBS } & RATIU \\
0 & 1.00 & 1.00 & 1.00 \\
10 & .72 & .80 & .90 \\
28 & .47 & .53 & .89 \\
57 & .27 & .28 & .96 \\
85 & .156 & .155 & 1.01
\end{tabular}

FP Gammas

\begin{tabular}{lcr} 
MAGI & \multicolumn{1}{l}{ NBS } & RATIO \\
1.00 & 1.00 & 1.00 \\
.58 & .63 & .92 \\
.31 & .33 & .94 \\
.153 & .145 & 1.05 \\
.075 & .071 & 1.07
\end{tabular}


Table VI. Comparison of Reduction factors for combined Components

Structure $\# 4$

First Story

\begin{tabular}{|c|c|c|c|c|c|c|}
\hline & & & & & High & Low \\
\hline & & & & & yield & yield \\
\hline & & & & & IRF & IRF \\
\hline & AS & $\mathrm{FP}$ & $N$ & $N G$ & (eq. 4) & $($ eq. 5) \\
\hline NBS & .305 & .208 & .485 & .096 & .258 & .451 \\
\hline MAGI & .298 & .173 & .339 & .060 & .256 & .334 \\
\hline Ratio & & & & & 1.0 & 1.4 \\
\hline
\end{tabular}

Basement

$\begin{array}{lllllcc}\text { NBS } & .234 & .128 & .1127 & .0343 & .155 & .161 \\ \text { MAGI } & .178 & .085 & .0814 & .0351 & .113 & .122 \\ \text { Ratio } & & & & & 1.4 & 1.3\end{array}$

Structure $\# 5$

$\begin{array}{lllllll}\text { NBS } & .242 & .260 & .490 & .082 & .350 & .444 \\ \text { MAGI } & .225 & .190 & .331 & .047 & .253 & .310 \\ \text { Ratio } & & & & & 1.4 & 1.4\end{array}$

Basement

$\begin{array}{lllllll}\text { NBS } & .073 & .0290 & .063 & .0122 & .052 & .066 \\ \text { MAGI } & .059 & .0102 & .069 & .026 & .045 & .056 \\ \text { Ratio } & & & & & 1.2 & 1.2\end{array}$


Table VII. Comparison of AS and FP Gamma-Ray Reduction Factors

\section{Structure $\# 1$}

(On first story at a height of 3 feet above the floor)

Air Secondaries

FP Gammas

$\begin{array}{ccccccc} & \text { Roof } & \text { Walls } & \text { Total } & \text { Roof } & \text { Walls } & \text { Total } \\ \text { NBS } & .232 & .053 & .285 & .123 & .043 & .166 \\ \text { MAGI } & .228 & .052 & .280 & .101 & .034 & .135 \\ \text { Ratio } & 1.02 & 1.02 & 1.02 & 1.22 & 1.26 & 1.23\end{array}$

(In basement at a depth of 9 feet below the basement ceiling)

$\begin{array}{lrrrrrr}\text { NBS } & .184 & .109 & .293 & .112 & .038 & .150 \\ \text { MAGI } & .156 & .091 & .247 & .083 & .026 & .109 \\ \text { Ratio } & 1.18 & 1.20 & 1.19 & 1.35 & 1.46 & 1.38\end{array}$


Table VIII. Comparison as AS and FP Gamma-Ray Reduction Factors

Structure $\# 2$

(On first story at a height of 3 feet above the floor)

Air Secondaries

FP Gammas

Walls and

Walls and

Walls Windows Windows Walls Windows Windows

$\begin{array}{lcccccr}\text { NBS } & .042 & .031 & .073 & .032 & .053 & .085 \\ \text { MAGI } & .0360 & .0340 & .070 & .0244 & .0480 & .072 \\ \text { Ratio } & 1.17 & 0.91 & 1.04 & 1.31 & 1.10 & 1.18\end{array}$

(In basement at a depth of 9 feet below the basement ceiling)

$\begin{array}{lcccccc}\text { NBS } & .068 & .119 & .187 & .025 & .088 & .113 \\ \text { MAGI } & .0664 & .0693 & .136 & .0209 & .0409 & .062 \\ \text { Ratio } & 1.02 & 1.72 & 1.38 & 1.20 & 2.15 & 1.32\end{array}$


Table IX. Comparison of AS and FP Gamma-Ray Reduction Factors

$$
\text { Structure } \# 3
$$

\begin{tabular}{lcccccc}
\multicolumn{9}{c}{ (In basement at a depth of 9 feet below the basement ceiling) } \\
\multicolumn{4}{c}{ Air Secondaries } \\
Roof & Walls & Total & FP Gammas & \\
NBS & .066 & .029 & .095 & Roof & Walls & Total \\
MAGI & .053 & .015 & .068 & .0312 & .0055 & .037 \\
Ratio & 1.25 & 1.93 & 1.40 & .025 & .0017 & .026 \\
& & & & 1.25 & 3.2 & 1.42
\end{tabular}


Table X. Calculated Gamma-Ray Attenuation Factors for Basement Ceiling

Structure $\# 3$

NBS

\begin{tabular}{cccc}
\multicolumn{2}{c}{ Air Secondaries } & & \multicolumn{2}{c}{ FP Gammas } \\
Roof & Walls & Roof & Nalls \\
.36 & .266 & .28 & .211 \\
.34 & .165 & .29 & .065
\end{tabular}

MAGI 
Table XI. Comparison of AS and FP Gamma-Ray Reduction Factors

\section{Structure \#4}

(In basement at a depth of 9 feet below the basement ceiling) Air Secondaries

FP Gammas

$\begin{array}{lcccccc} & \text { Walls } & \text { Windows } & \begin{array}{c}\text { Walls and } \\ \text { Windows }\end{array} & \text { Walls } & \text { Windows } & \begin{array}{c}\text { Walls and } \\ \text { Windows }\end{array} \\ \text { NBS } & .018 & .032 & .050 & .0036 & .0128 & .0164 \\ \text { MAGI } & .012 & .0098 & .022 & .0014 & .0010 & .0024 \\ \text { Ratio } & 1.50 & 3.3 & 2.3 & 2.6 & 13 . & 6.8\end{array}$


Table XII. Comparison of AS and FP Gamma-Ray Reduction Factors.

\section{Structure $\# 5$}

(On first story at a height of 3 feet above the floor)

Air Secondaries

Stories All

Walls: Story 1 Story 2 3-9 Walls

NBS

MAGI

$$
.165
$$

.077

.0

.242

.019

.225

0.0

1.08

1.88

1.30

.233

.179

.009

FP Gammas

Ratio 1.00

(In basement at a depth of 9 feet below the basement ceiling)

$\begin{array}{lllllllll}\text { NBS } & .073 & .0 & .0 & .073 & .0290 & .0 & .0 & .0290 \\ \text { MAGI } & .039 & .013 & .007 & .059 & .0080 & .0014 & .0008 & .0102 \\ \text { Ratio } & 1.87 & .0 & .0 & 1.24 & 3.62 & .0 & .0 & 2.84\end{array}$


Table XIII. Comparison of Neutron and Secondary-Gamma Reduction Factors Calculated by MAGI and NBS for Benchmark Structure \#4.

Roof Source

First Story Detector

\begin{tabular}{lccccccr} 
& \multicolumn{2}{c}{ Neutrons } & \multicolumn{2}{c}{ Secondary } & Gammas & \multicolumn{2}{c}{ Sum } \\
& MAGI & NBS & MAGI & NBS & MAGI & NBS & Ratio \\
Reflected & .0990 & .126 & .0302 & .0378 & .1292 & .164 & \\
Unreffected & .1117 & .124 & .00820 & .0108 & .1199 & .135 & \\
Sum & .2107 & .250 & .0384 & .0486 & .2491 & .299 & 1.2
\end{tabular}

Basement Detector

$\begin{array}{llllllll}\text { Reflected } & .0377 & .0322 & .0122 & .0097 & .0499 & .419 & \\ \text { Unreflected } & .0172 & .0318 & .0076 & .0114 & .0248 & .0432 & \\ \text { Sum } & .0549 & .0640 & .0198 & .0211 & .0747 & .0851 & 1.1\end{array}$

Window Source

First Story Detector

$\begin{array}{llllllll}\text { Reflected } & .0657 & .0852 & .00795 & .0255 & .0737 & .1203 & \\ \text { Unreflected } & .0226 & .0566 & .0 & .0 & .0226 & .0566 & \\ \text { Sum } & .0883 & .0818 & .00795 & .0255 & .0963 & .1975 & 2.0\end{array}$

Basement Detector

$\begin{array}{llllllll}\text { Reflected } & .0119 & .0175 & .00273 & .0060 & .0146 & .0235 & \\ \text { Unreflected } & .00432 & .0173 & .00477 & .00121 & .00909 & .0185 & \\ \text { Sum } & .0162 & .0348 & .00750 & .0072 & .0237 & .0420 & 1.8\end{array}$


Table XIII. (Continued)

\begin{tabular}{|c|c|c|c|c|c|c|c|}
\hline & & & Story & tector & & & \\
\hline & & rons & Second & y Gammas & & Sum & \\
\hline & MAGI & NBS & MAGI & NBS & MAGI & NBS & Ratio \\
\hline Reflected & .0246 & .0524 & .0113 & .01574 & .0359 & .0681 & \\
\hline Unreflected & .0152 & .0403 & .00222 & .00620 & .0174 & .0465 & \\
\hline Sum & .0398 & .0927 & .0135 & .0219 & .0533 & .115 & 2.2 \\
\hline
\end{tabular}

Basement Detector

$\begin{array}{llllllll}\text { Reflected } & .00915 & .00697 & .00554 & .00209 & .0147 & .00906 & \\ \text { Unreflected } & .00112 & .00688 & .00225 & .00392 & .00337 & .01080 & \\ \text { Sum } & .01026 & .01385 & .00779 & .00601 & .0181 & .0199 & 1.1\end{array}$

All Sources

First Story Detector

$\begin{array}{llllllll}\text { Reflected } & .189 & .264 & .0494 & .0790 & .238 & .343 & \\ \text { Unreflected } & .150 & .221 & .0104 & .0170 & .160 & .238 & \\ \text { Sum } & .339 & .485 & .0598 & .0960 & .399 & .581 & 1.5\end{array}$

Basement Detector

$\begin{array}{llllllll}\text { Reflected } & .0588 & .0567 & .0205 & .0178 & .0793 & .0745 & \\ \text { Unreflected } & .0226 & .0560 & .0146 & .0165 & .0372 & .0725 & \\ \text { Sum } & .0814 & .1127 & .0351 & .0343 & .1165 & .147 & 1.3\end{array}$


Table XIV. Comparison of Neutron and Secondary-Gamma Reduction Factors Calculated by MAGI and NBS for Benchmark Structure \#5.

Neutrons
MAGI NBS

Reflected
Unreflected
Sum

.157

.106

.263

.248

.196

.444

Reflected

Unreflected

Sum

.041

.012

.053

.032

.031

.063
First Story Source

Secondary Gammas

MAGI NBS

First Story

$\begin{array}{ll}.026 & .074 \\ .0 & .0 \\ .026 & .074\end{array}$

Basement Detector

$.011 \quad .0095$

$.006 \quad .0027$

$.017 \quad .0122$

2-9 Story Source

First Story Detector

$\begin{array}{lll}\text { Reflected } & .047 & .017 \\ \text { Unreflected } & .021 & .029 \\ \text { Sum } & .068 & .046\end{array}$

$.011 \quad .006$

$.010 \quad .002$

$.021 \quad .008$

Basement Detector

$\begin{array}{lll}\text { Reflected } & .0106 & 0 \\ \text { Unreflected } & .0054 & 0 \\ \text { Sum } & .0160 & 0\end{array}$

Sum
.0038

.0053

.0091
MAGI Total

$.183 \quad .334$

$.106 \quad .184$

.289 .518 .

Ratio

$.052 \quad .041$

$.018 \quad .034$

$.070 \quad .075$

1.1

$.058 \quad .023$

$.031 \quad .031$

$.089 \quad .054$

0.6

A11 Sources

First Story Detector

$\begin{array}{lll}\text { Reflected } & .204 & .265 \\ \text { Unreflected } & .127 & .225 \\ \text { Sum } & .331 & .490 \\ & & \\ & & \\ \text { Reflected } & .0516 & .032 \\ \text { Unreflected } & .0174 & .031 \\ \text { Sum } & .0690 & .063\end{array}$

$.241 \quad .345$

$.137 \quad .227$

$.378 \quad .572$

1.4

1.7

$.047 \quad .082$

Basement Detector

$\begin{array}{lllll}.015 & .0095 & .067 & .041 & 0.6 \\ .011 & .0027 & .028 & .034 & 1.2 \\ .026 & .0122 & .095 & .075 & 0.8\end{array}$




\section{LIST OF FIGURES}

Fig. 1. Angular coordinate systems: The angle $\beta$ is the polar angle with respect to the original source-detector line. The angular distribution from a point source is averaged over all azimuthal directions $\phi$ to form a ring source. Angular distributions are rotated to $(\theta, \phi)$ polar and azimuthal angles for radiation incident on the roof, and to $(\psi, \phi)$ polar and azimuthal angles for radiation incident on the walls.

Fig. 2. Initial gamma ray barrier factors.

Fig. 3. Initial neutron and wall secondary gamma barrier factors.

Fig. 4. Overhead geometry factor, air secondary gamma rays.

Fig. 5. Overhead geometry factor, fission product gamma rays.

Fig. 6. Overhead geometry factors, neutrons.

Fig. 7. Overhead geometry factors, wall capture gamma rays.

Fig. 8. Wall geometry factor $G_{1}$, air secondary gamma rays.

Fig. 9. Wall geometry factors $G_{1}$, fission product gamma rays.

Fig. 10. Wall geometry factor $G_{1}$, neutrons.

Fig. 11. Wall geometry factor $G_{1}$, wall capture gamma rays.

Fig. 12(a). Detector on same story as radiating walls: geometry factors for upper and lower solid angles are added.

12(b). Detector on story below radiation walls: geometry factors for upper solid angles are subtracted. Solid angle fractions such as $\omega_{u}^{\prime \prime}$ may be determined by exterior building. 
Fig. 13. Wall geometry factors $G_{2}$, air secondary gamma rays.

Fig. 14. Wall geonetry factors $G_{2}$, fission product gamma rays .

Fig. 15. Wall geometry factor $G_{2}$, neutrons.

Fig. 15. Wall geometry factor $G_{2}$, wall capture gamma rays.

Fig. 17. Mutual shielding geometry factors $i_{R}$ for roof and $i_{S}=m_{S} \frac{\sin \phi_{0}}{2}$ for walls.

Fig. 18. Neutron reflection factors o for sidewalls and oe for end walls.

Fig. 19. Data for estimating attenuation factors in ceiling, air secondary gamma rays.

Fig. 20. Data for estimating attenuation factors in ceiling, fission product gamma rays.

Fig. 21. Plan and elevation views of benchmark structure with basement ceiling and windows on two sides.

Fig. 22. Views of benchmark structure 5. Figures a) and b) represent elevation and plan views, respectively. Dots represent detector points. 

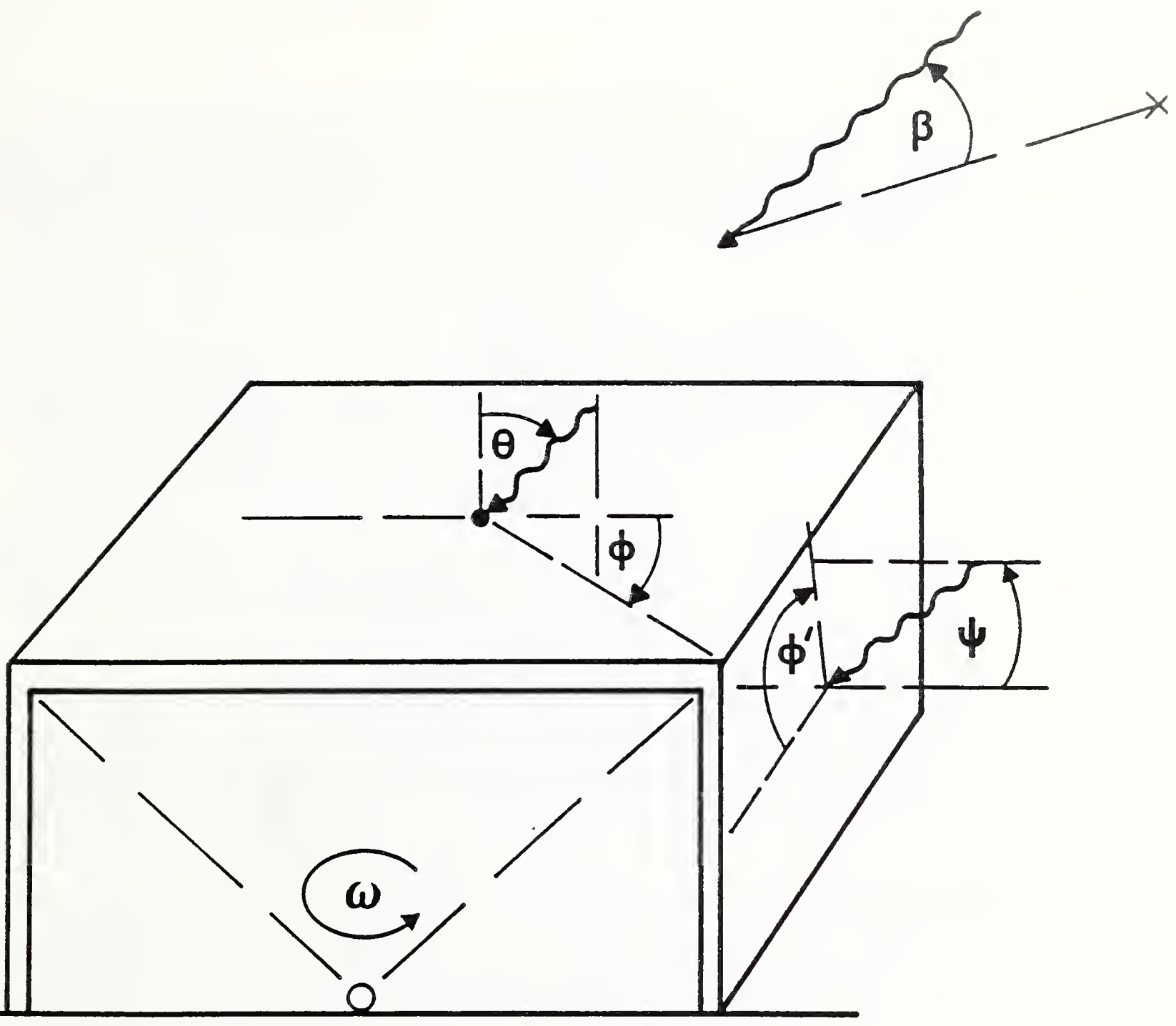

Fig. 1. Angular coordinate systems: The angle $\beta$ is the polar angle with respect to the original source-detector line. The angular distribution from a point source is averaged over all azimuthal directions $\phi$ to form a ring source. Angular distributions are rotated to $(\theta, \phi)$ polar and azimuthal angles for radiation incident on the roof, and to $(\psi, \phi)$ polar and azimuthal angles for radiation incident on the walls. 


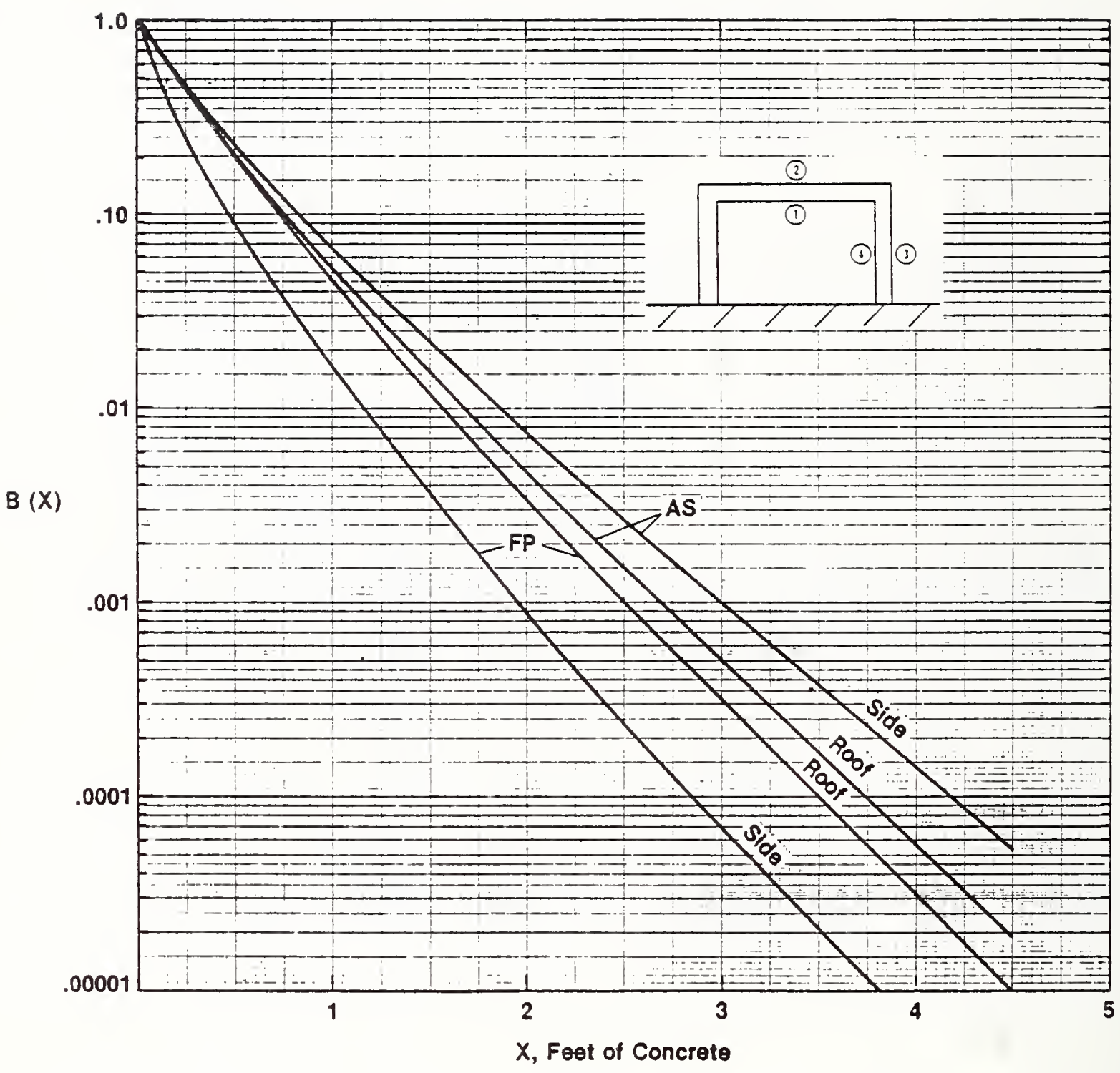

Fig. 2. Initial yamma ray barrier factors. 


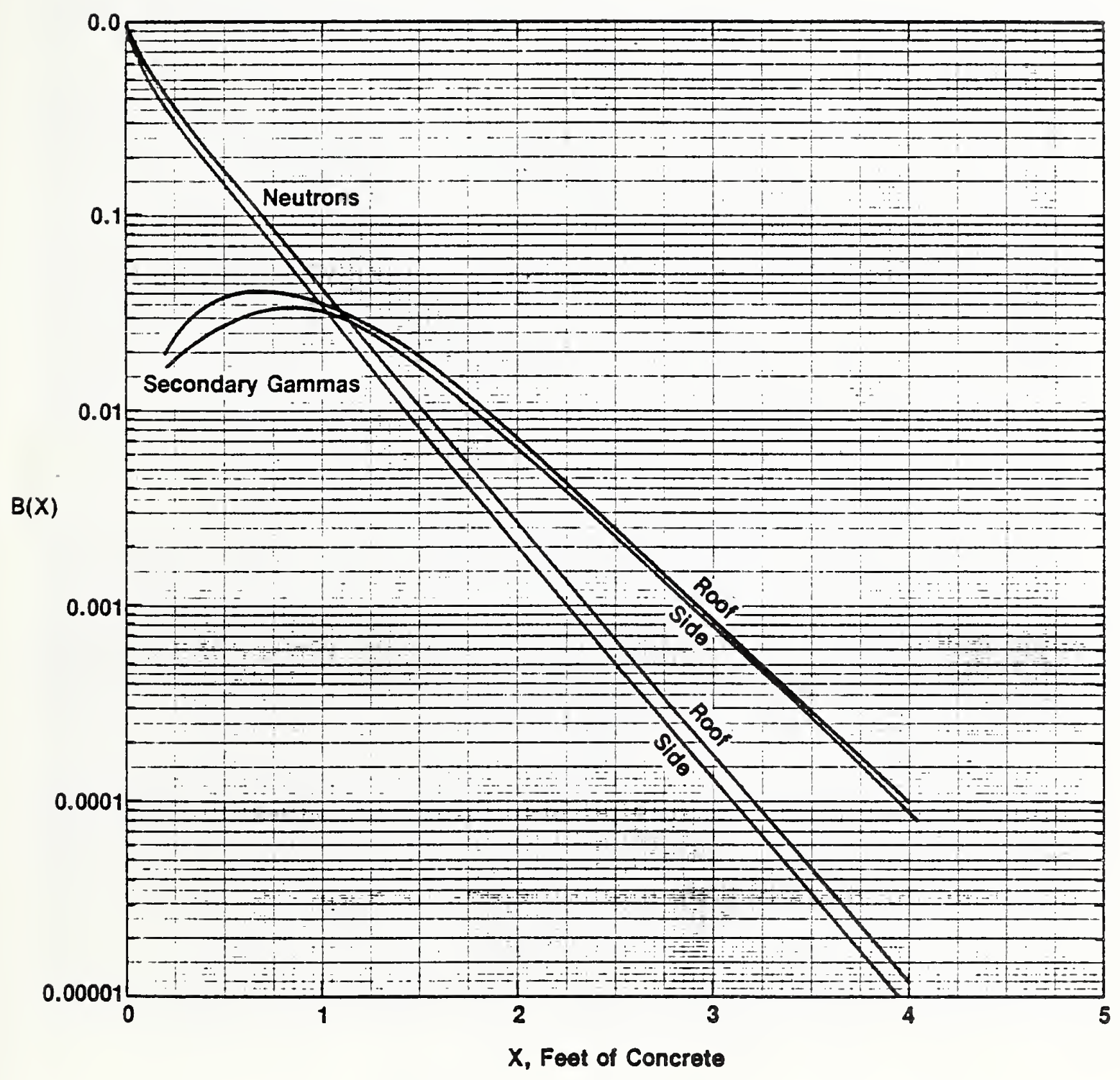

Fiy. 3. Initial neutron and wall secondary yamma barrier factors. 


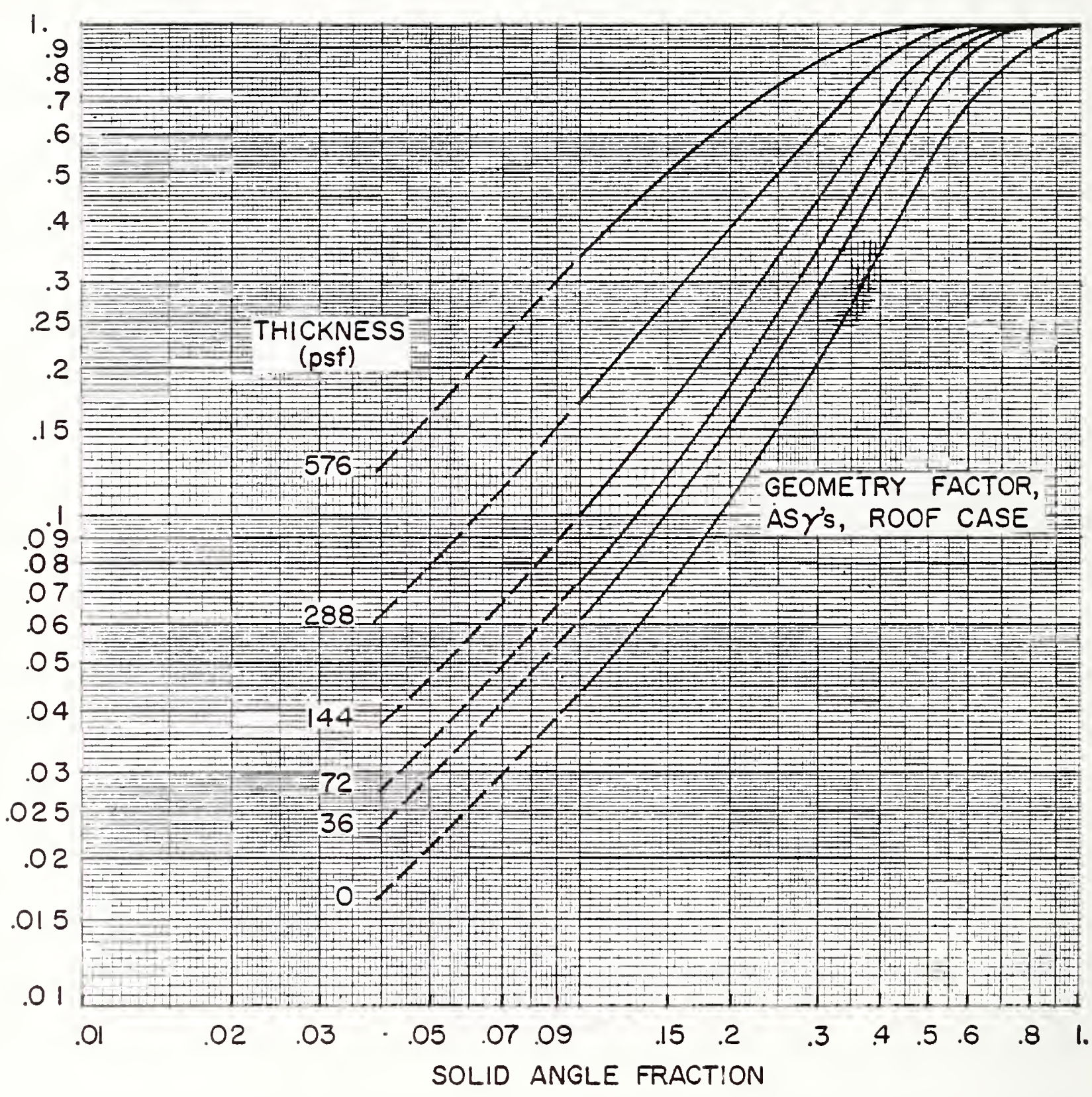

Fig. 4. Overhead geometry factor, air secondary gamma rays. 


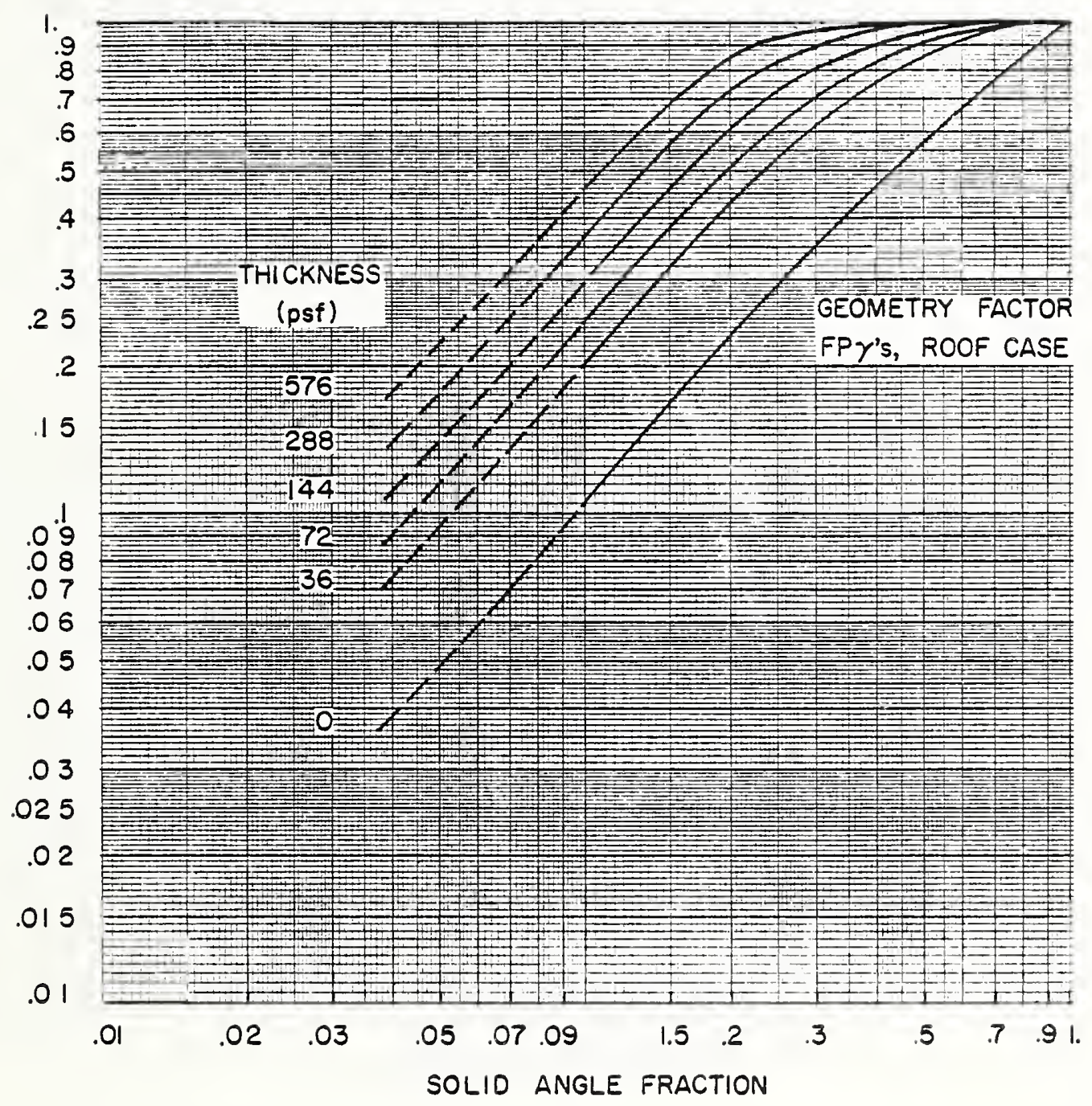

Fig. 5. Overhead yeometry factor, fission product gamma rays. 


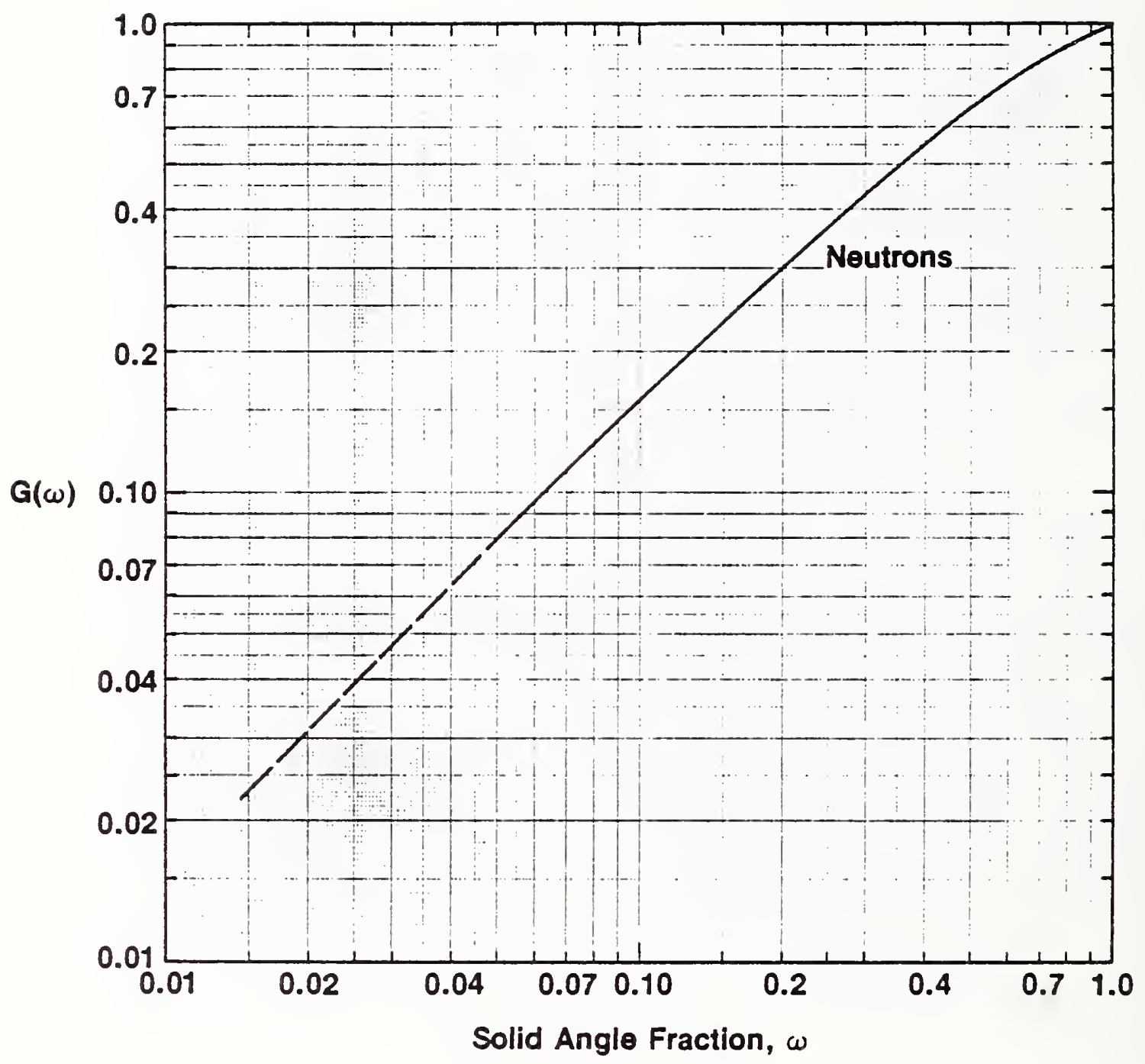

Fig. 6. Overhead geometry factors, neutrons. 


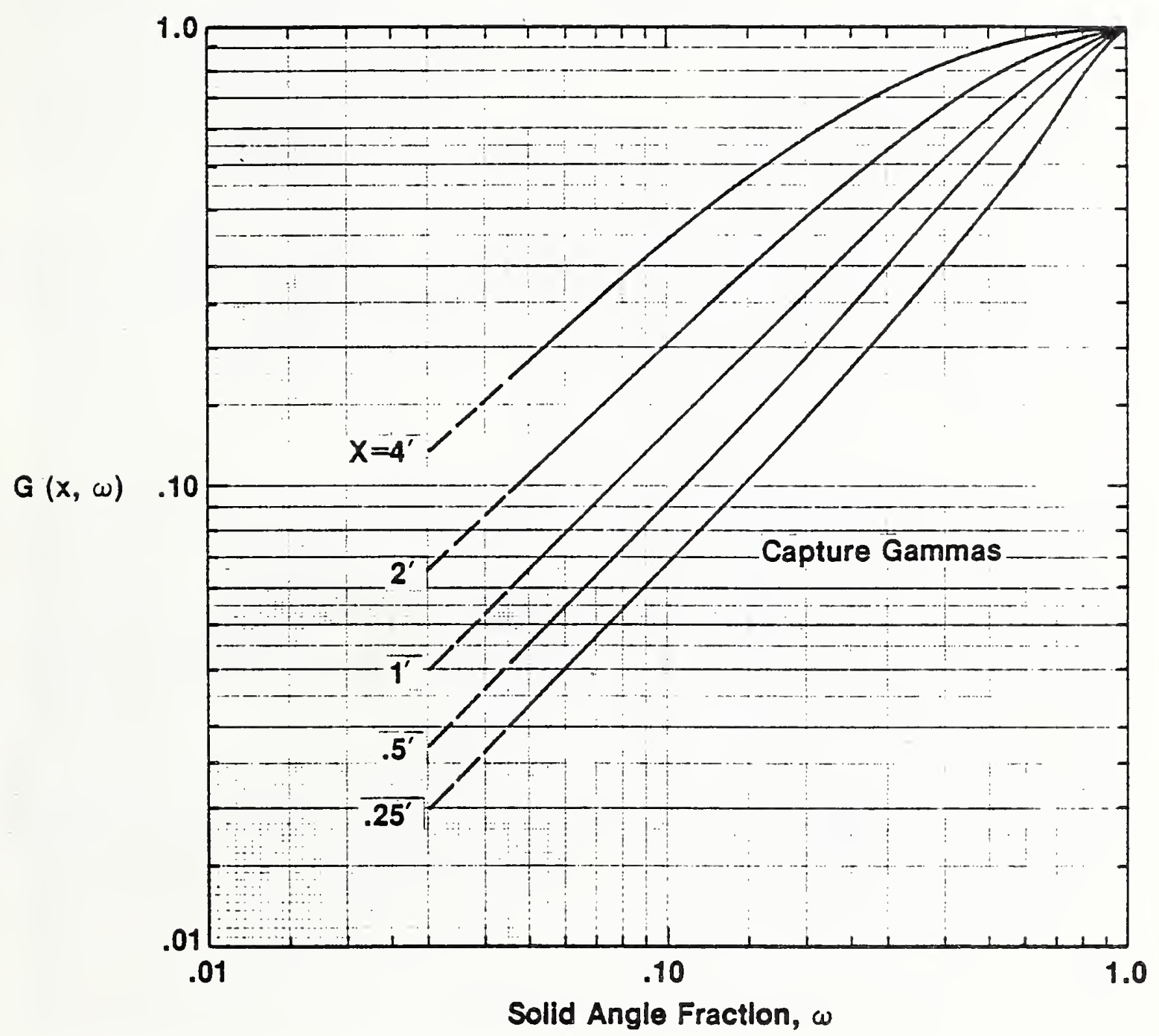

Fiy. 7. Overhead yeometry factors, wall capture yamma rays. 


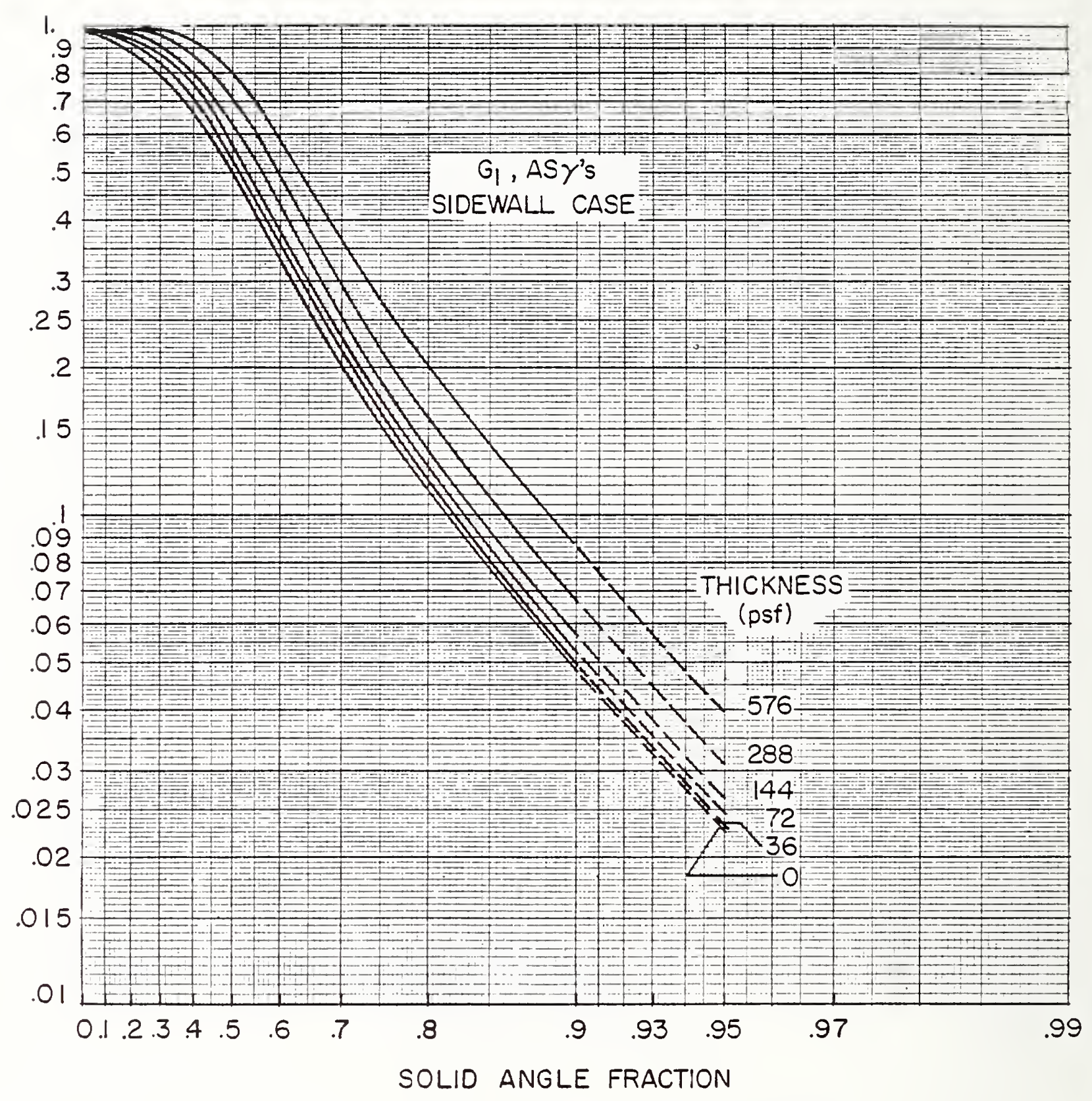

Fig. 8. Wall geometry factor $G_{1}$, air secondary gamma rays. 


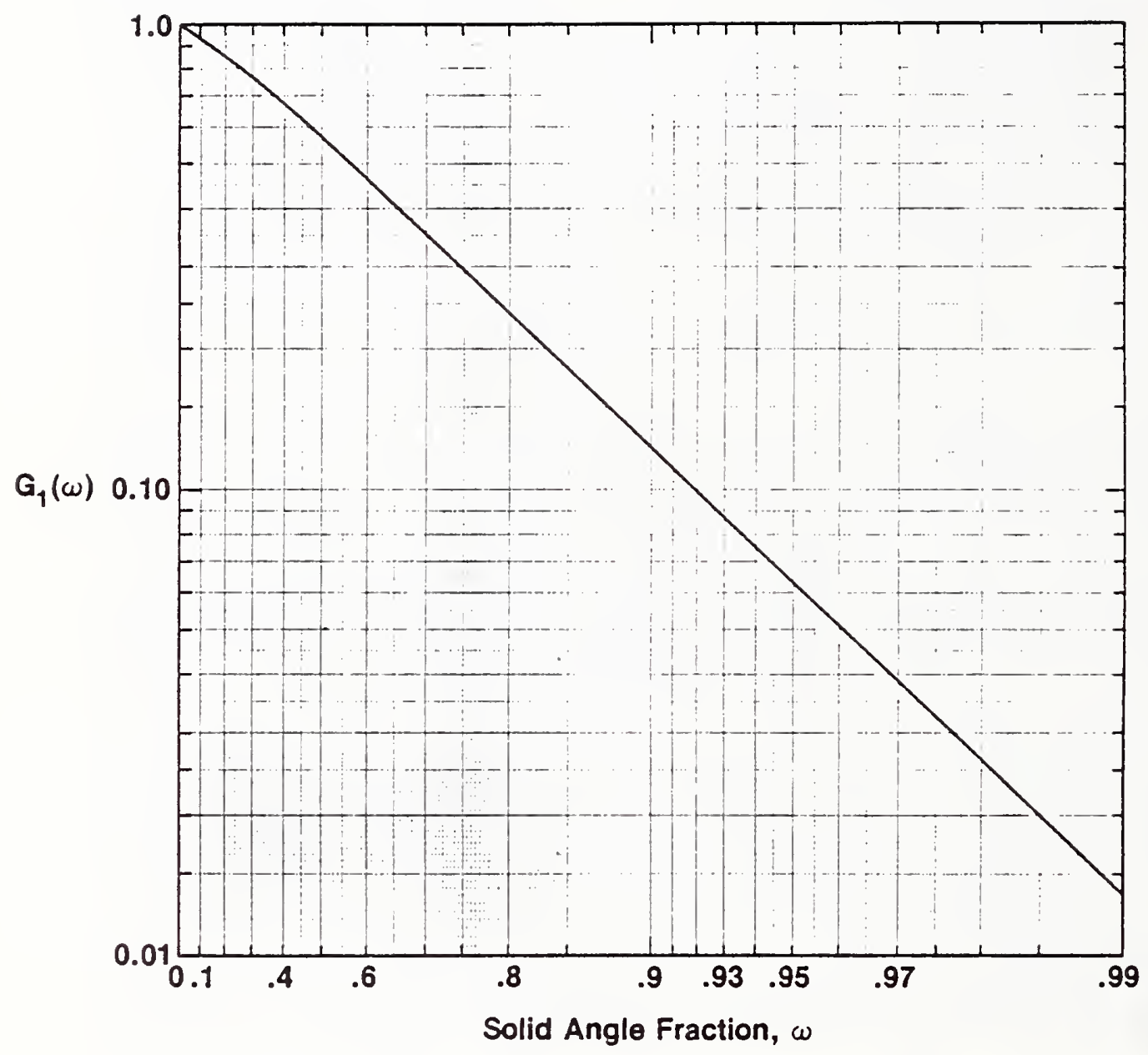

Fig. 10. Wall geometry factor $G_{1}$, neutrons. 


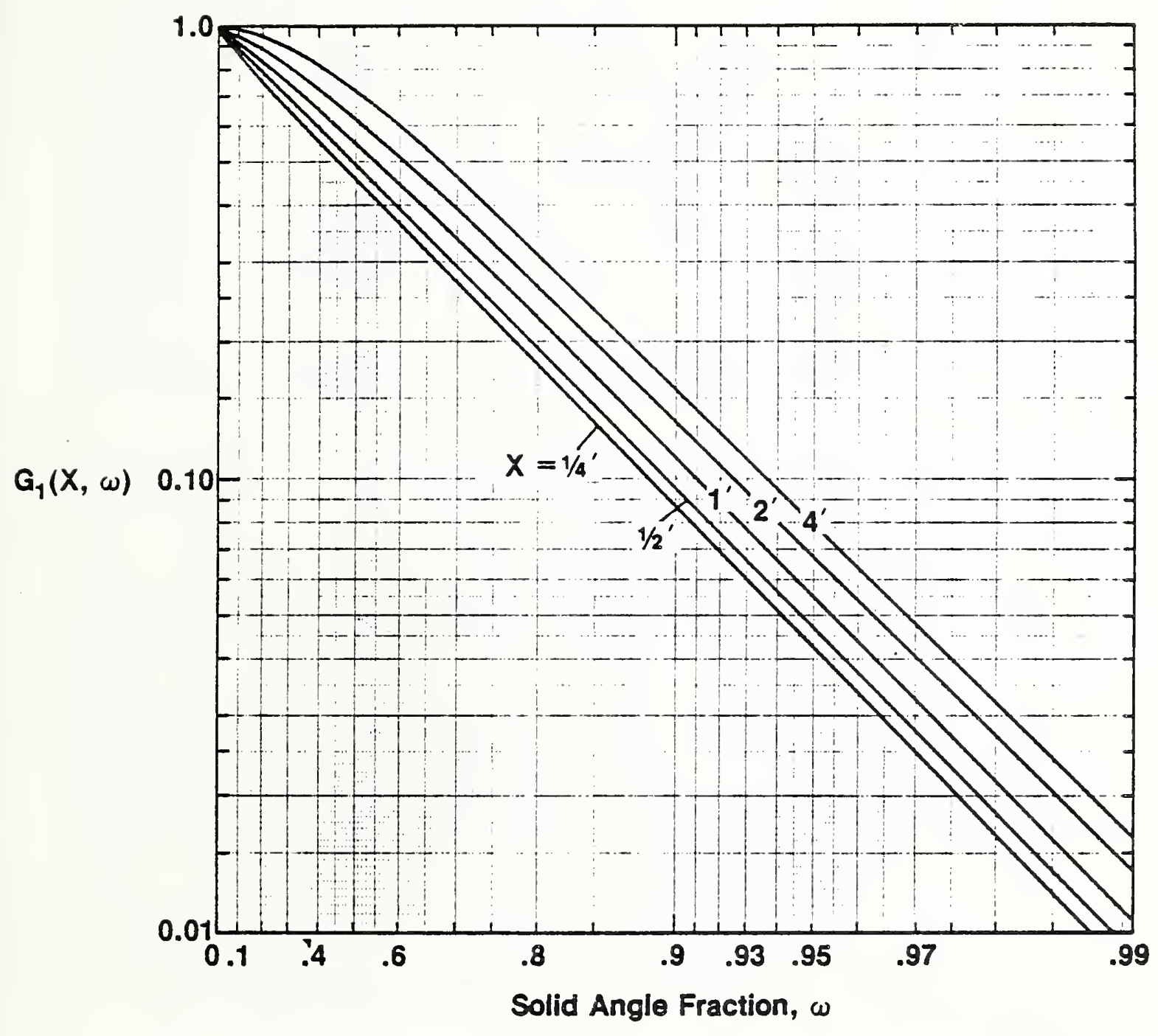

Fig. 11. Wall geometry factor $G_{1}$, wall capture yamma rays. 


\section{$G\left(\omega_{u}\right)+G\left(\omega_{l}\right)$}

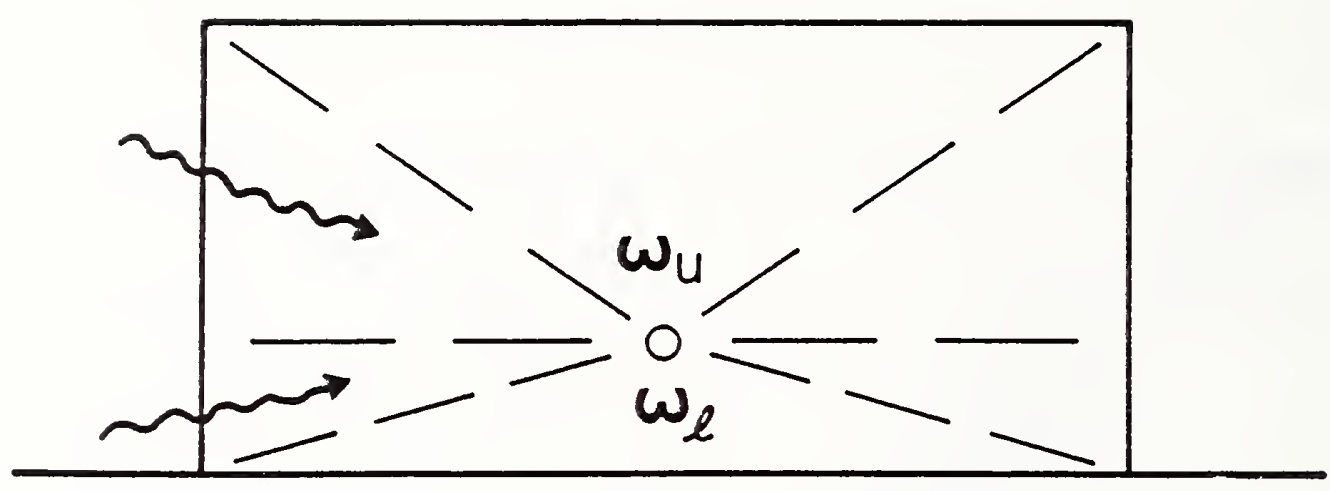

(a)

Fig. 12(a). Detector on same story as radiating walls: geometry factors for upper and lower solid angles are added.

$$
G\left(\omega_{u^{\prime}}\right)-G\left(\omega_{u}\right)
$$

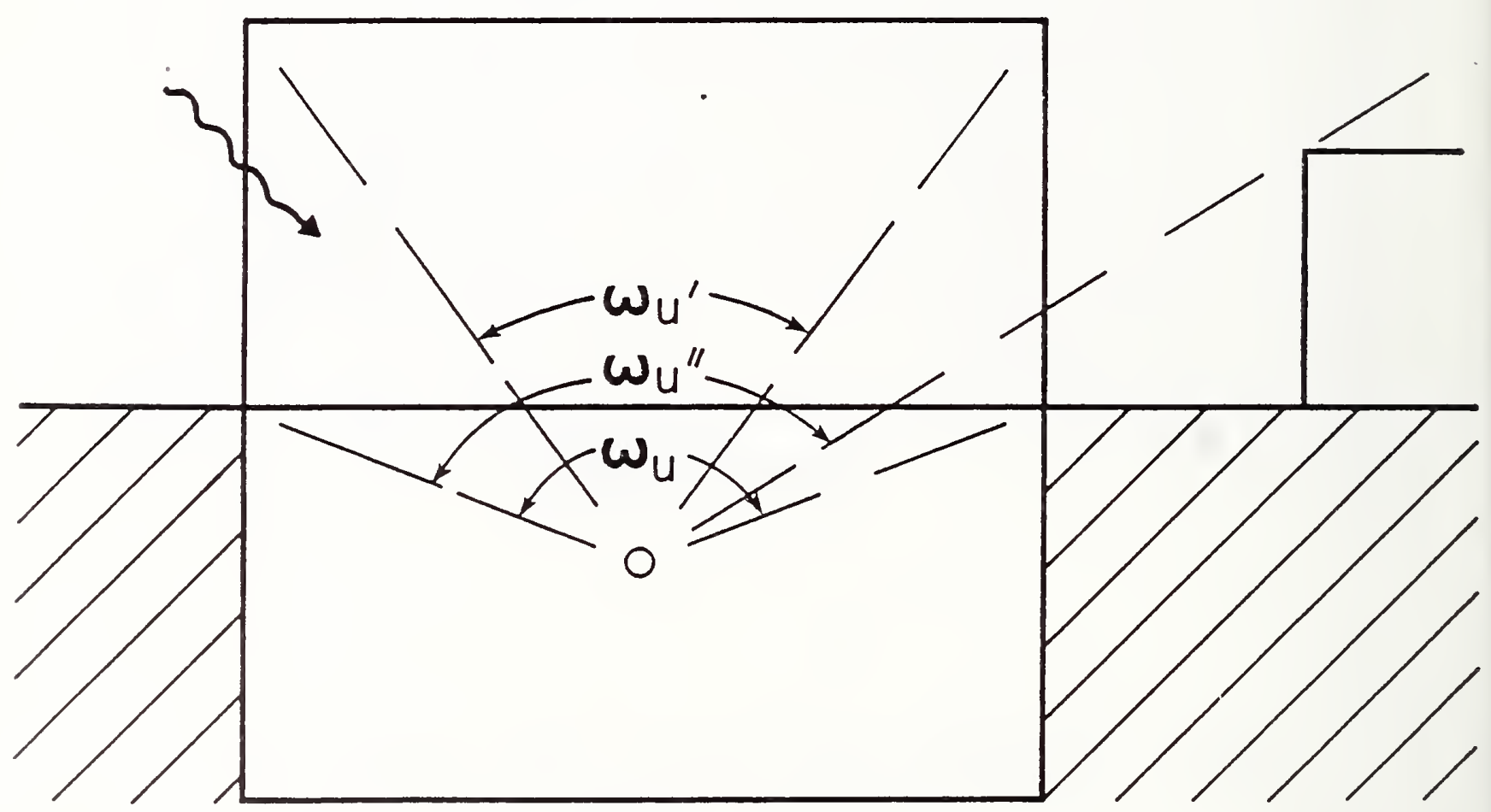

(b)

Fig. 12(b). Detector on story below radiation walls: geometry factors for upper solid angles are subtracted. Solid angle fractions such as $\omega_{u}^{\prime \prime}$ may be determined by exterior building. 


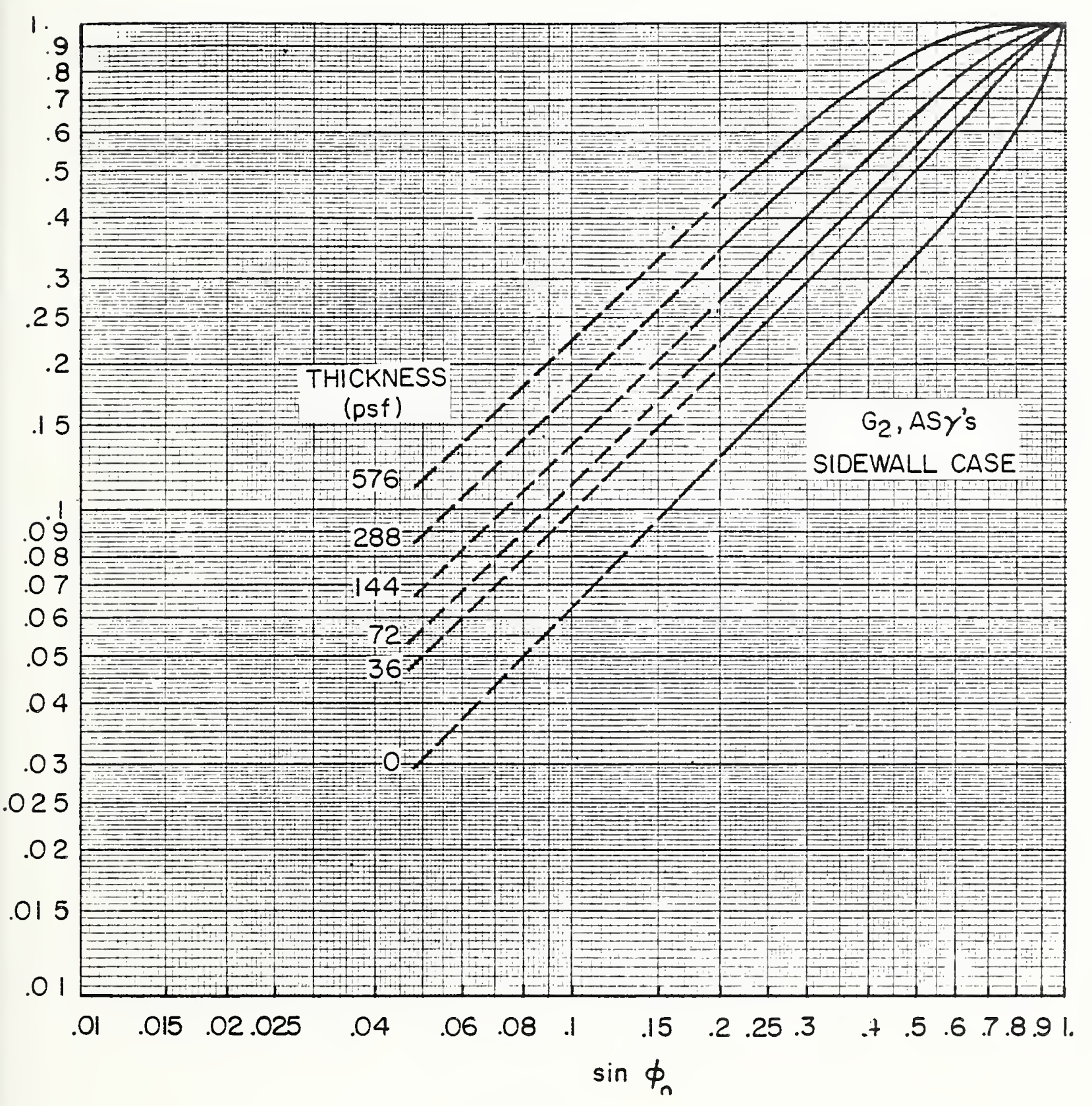

Fig. 13. Wall geometry factors $G_{2}$, air secondary gamma rays. 


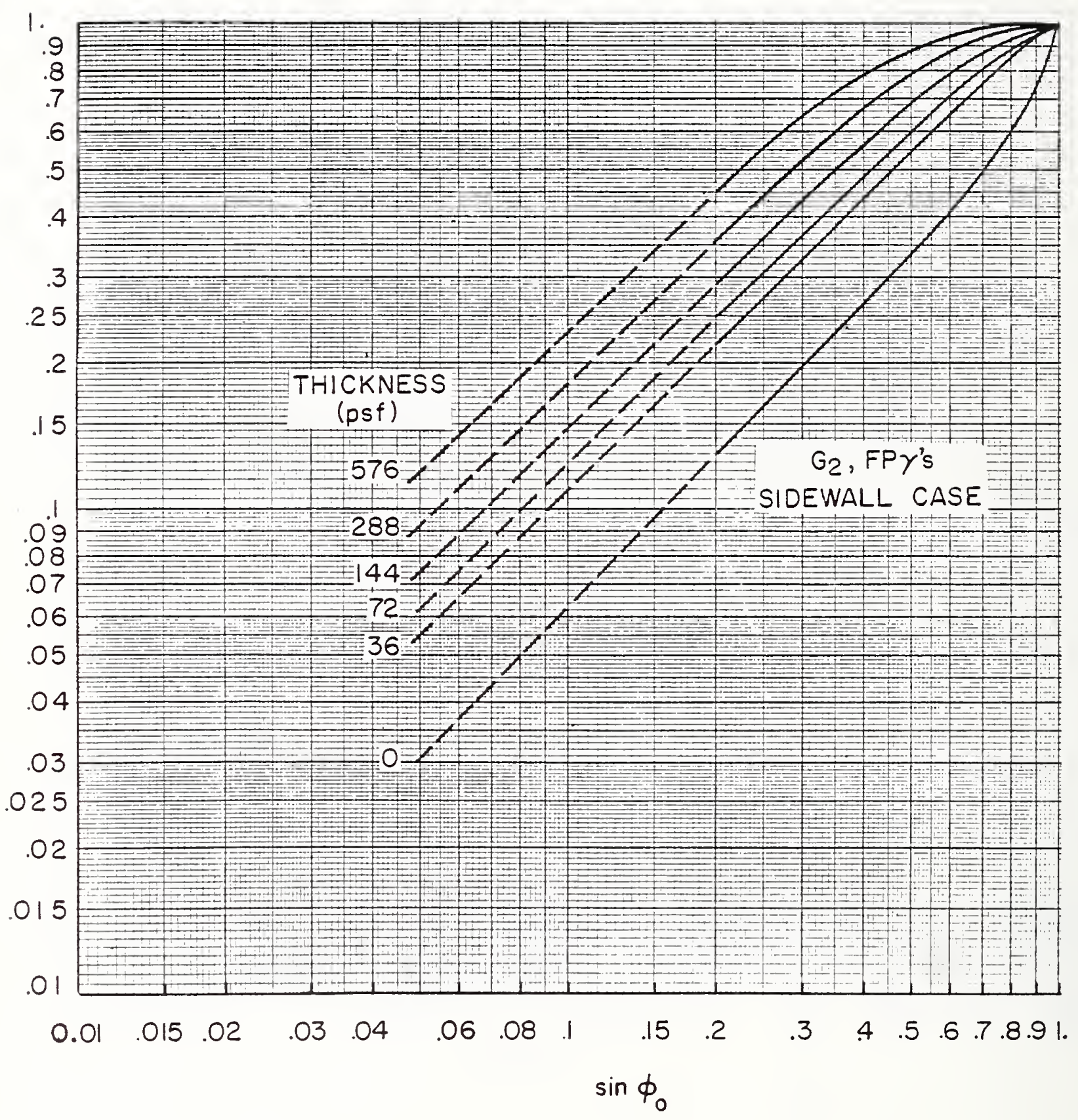

Fig. 14. Wall geometry factors $\mathfrak{G}_{2}$, fission product yamma rays. 


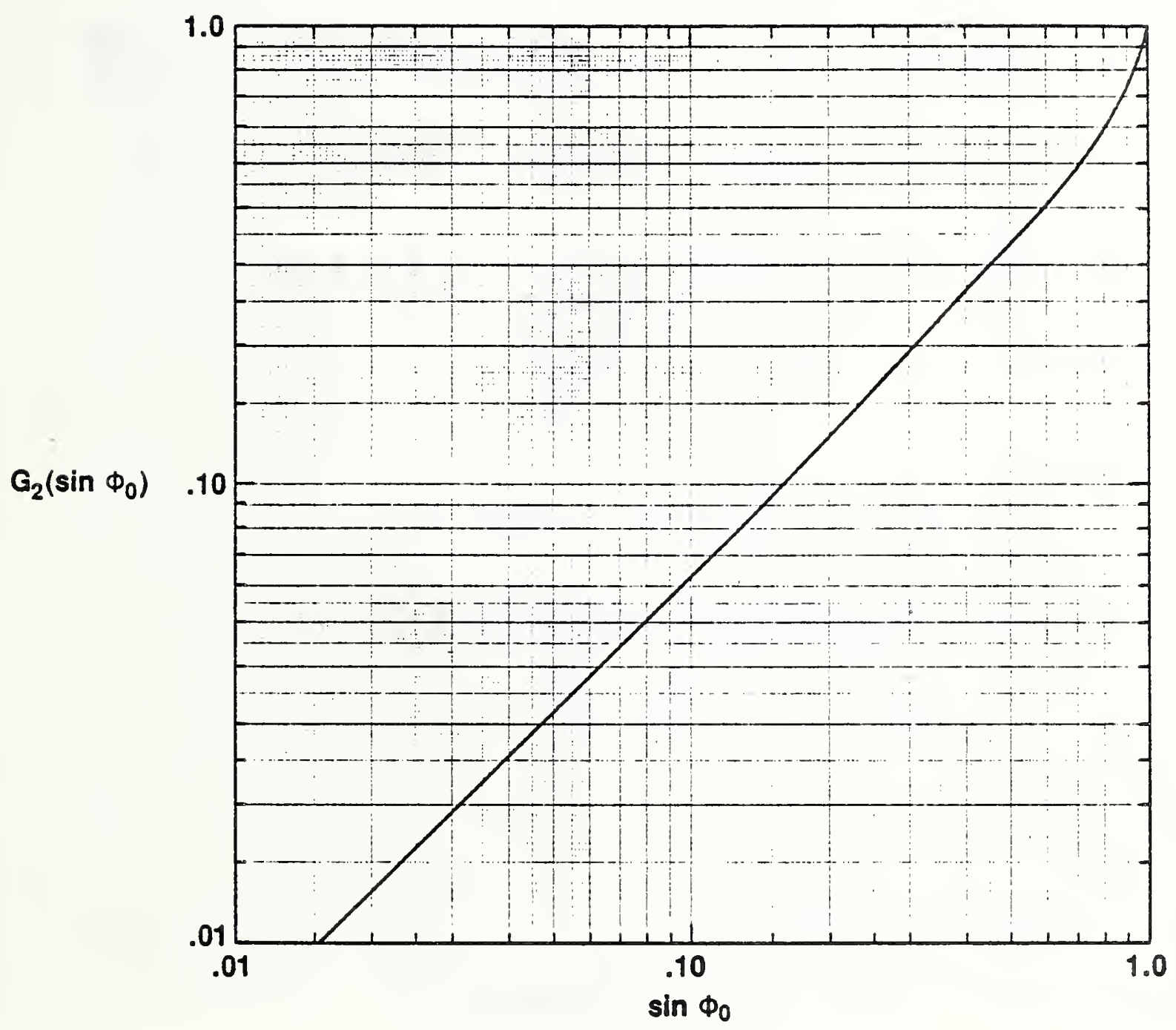

Fig. 15. Wall geometry factor $G_{2}$, Neutrons. 


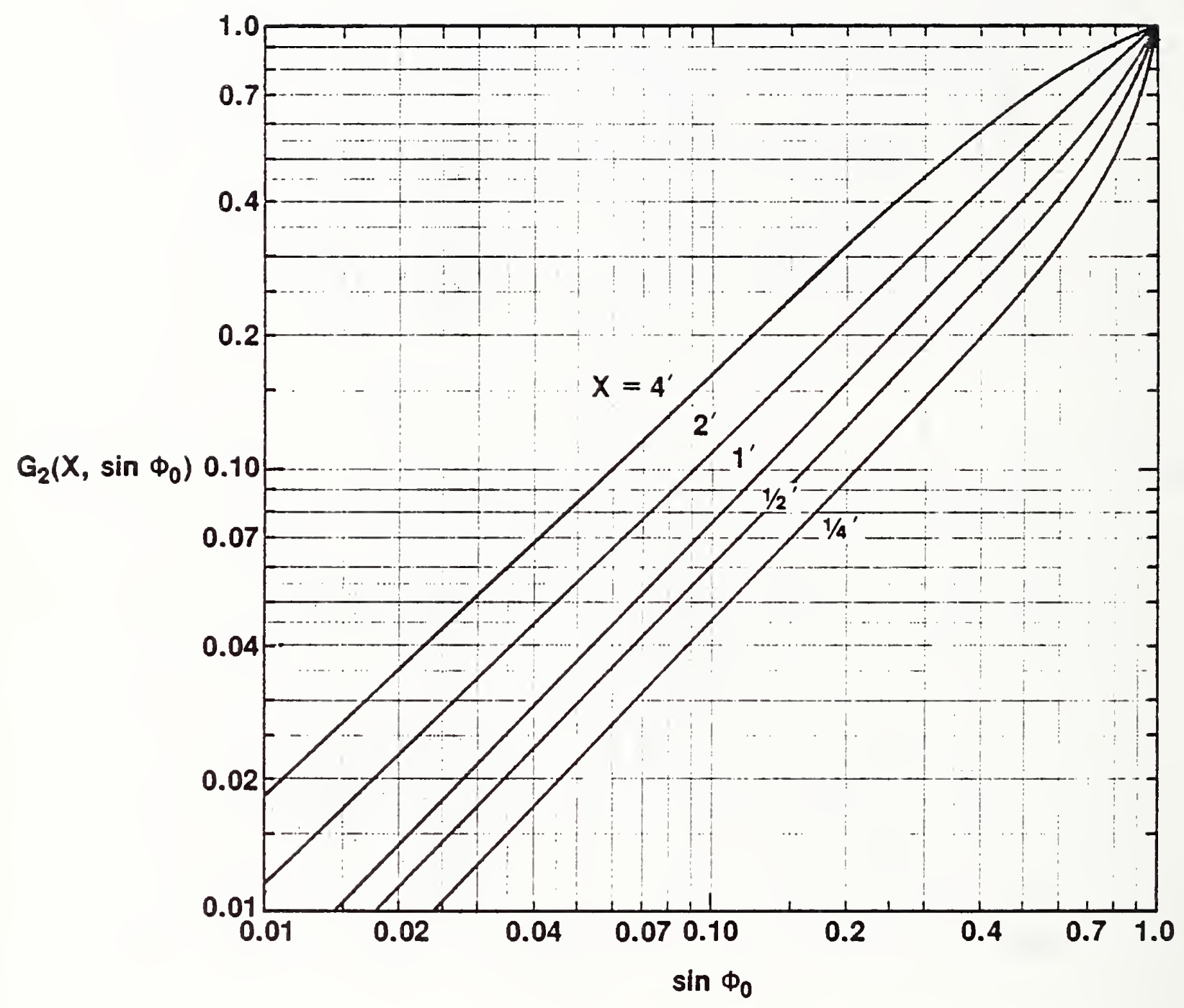

Fig. 16. Wall geometry factor $G_{2}$, wall capture gamma raus. 


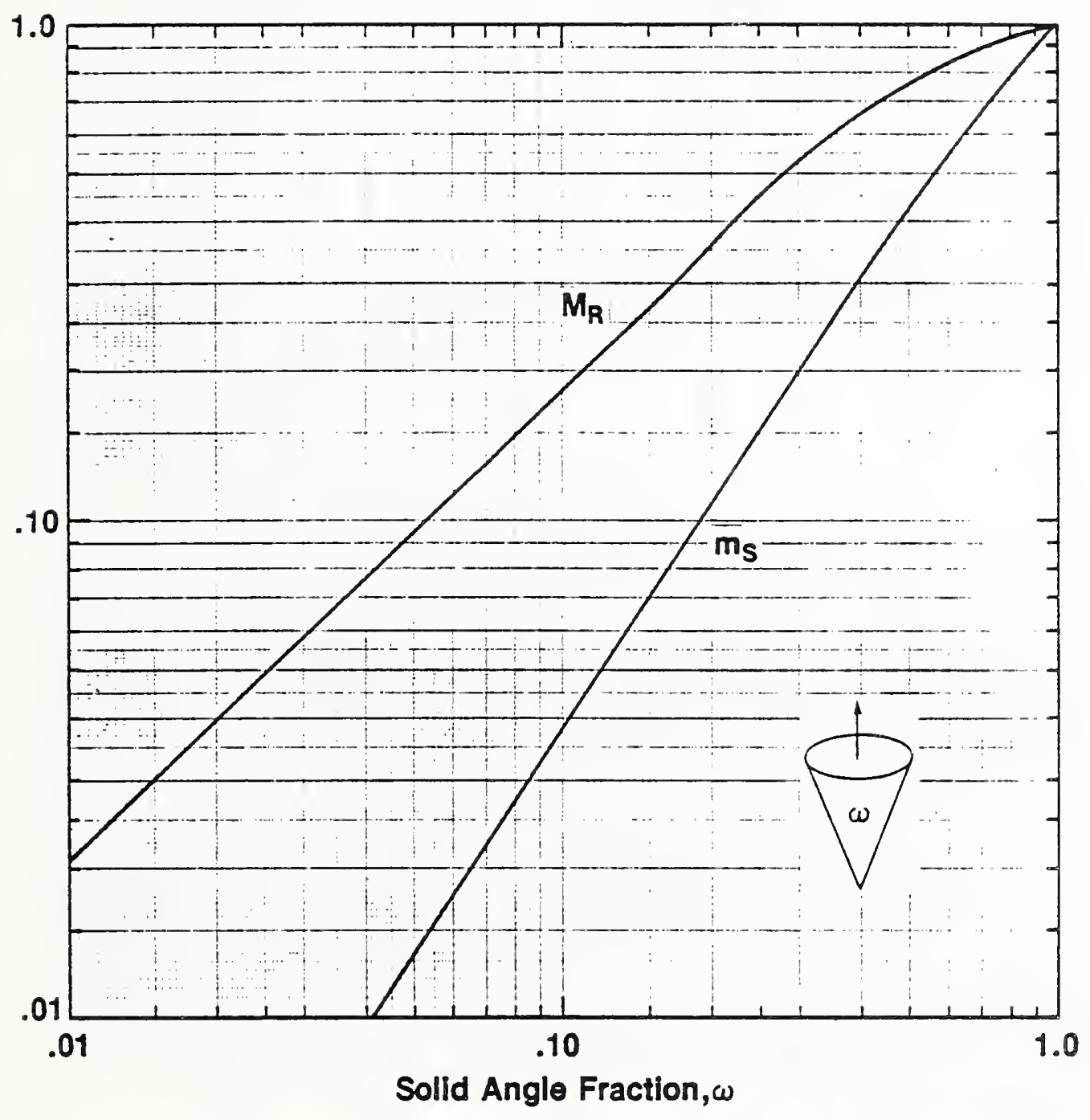
Fig. 17. Mutual shielding geometry factors $M_{R}$ for roof and $M_{S}=m_{S} \frac{\sin \phi_{0}}{2}$ for
walls. Data for mutual shielding estimates. 


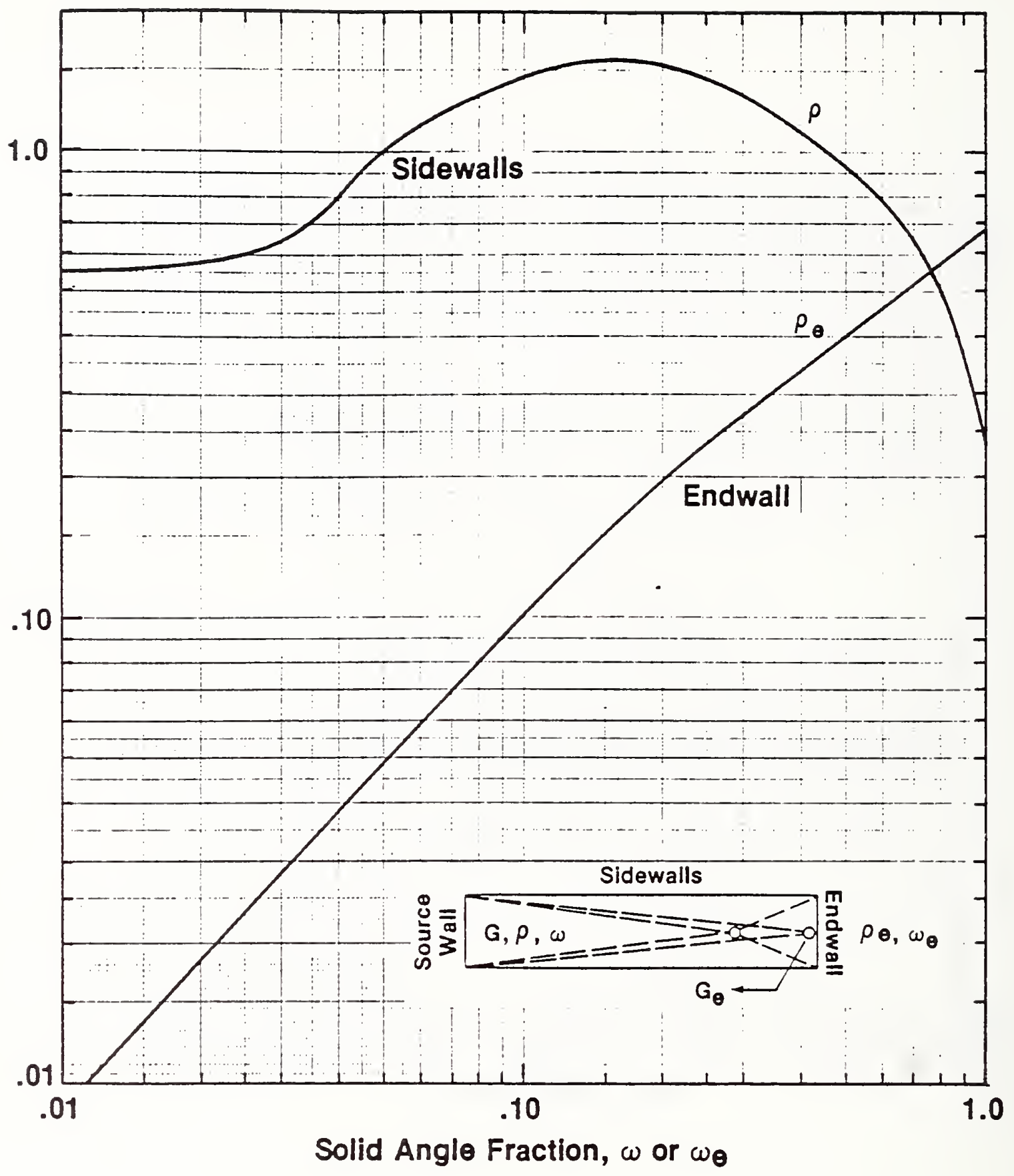

Fig. 18. Neutron reflection factors $p$ for sidewalls and $\rho_{e}$ for end walls. 


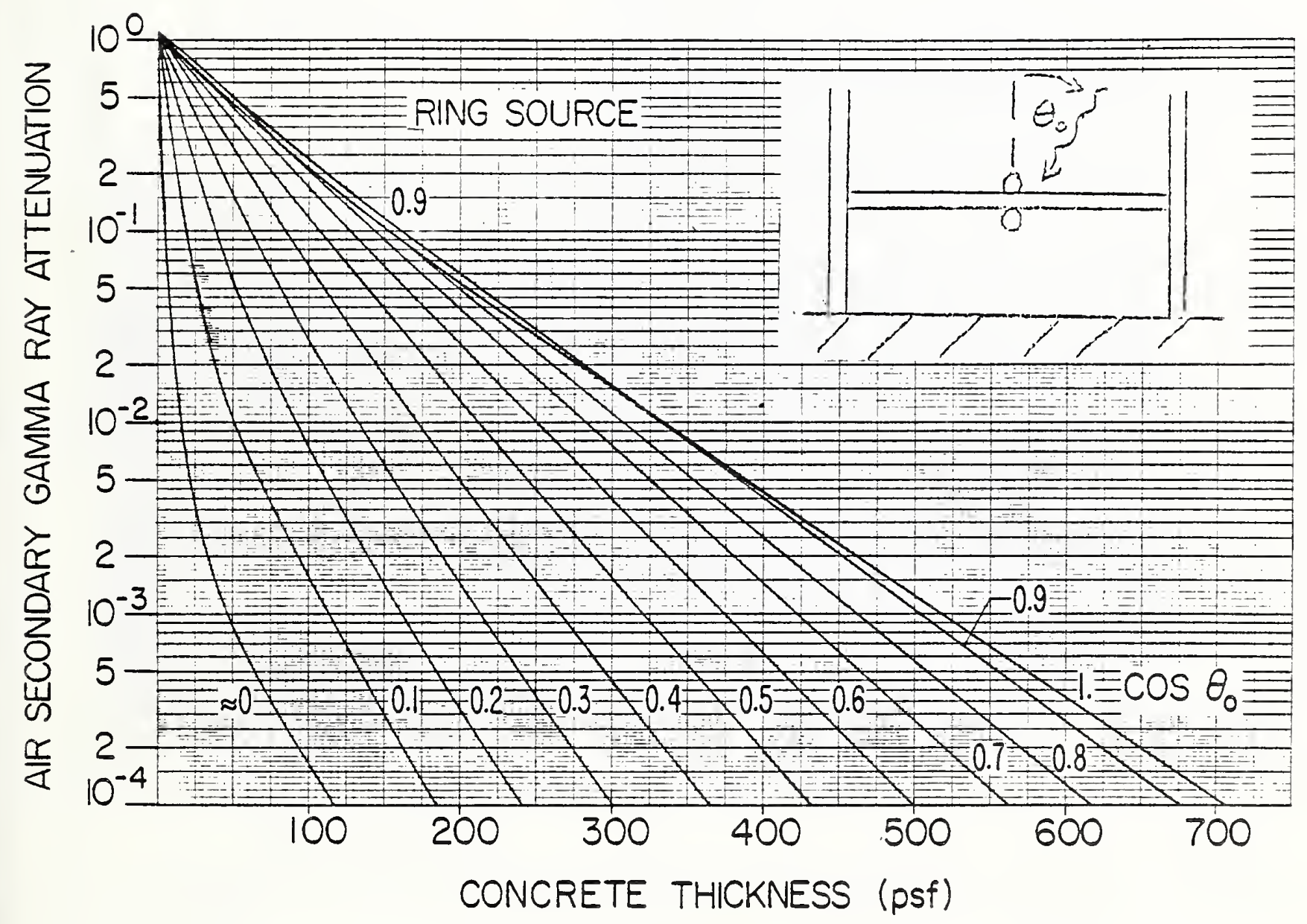

Fig. 19. Data for estimating attenuation factors in ceiling, air secondary gamma rays. 


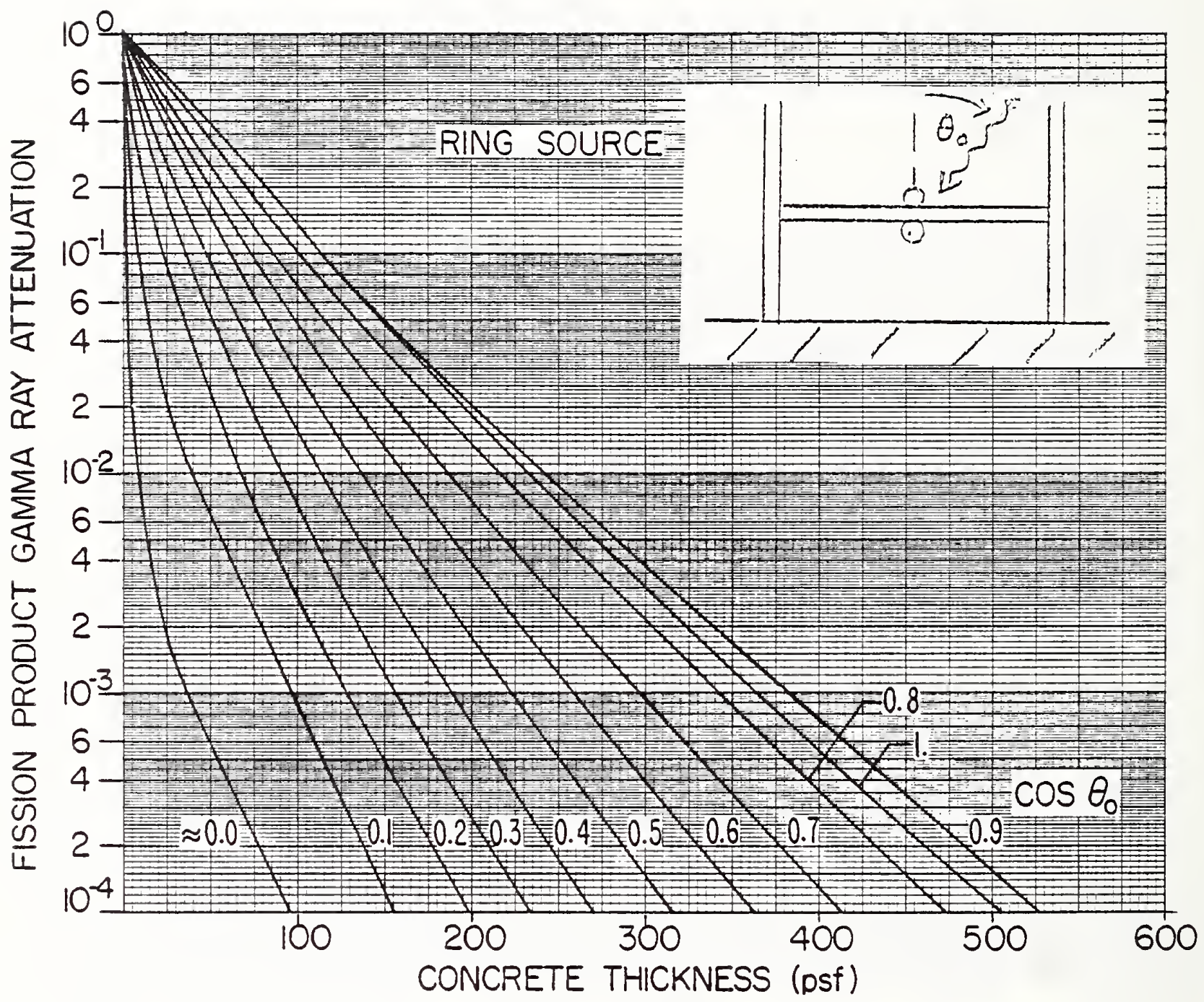

Fig. 20. Data for estimating attenuation factors in ceilirig, fission product gamma rays. 
(PLAN)
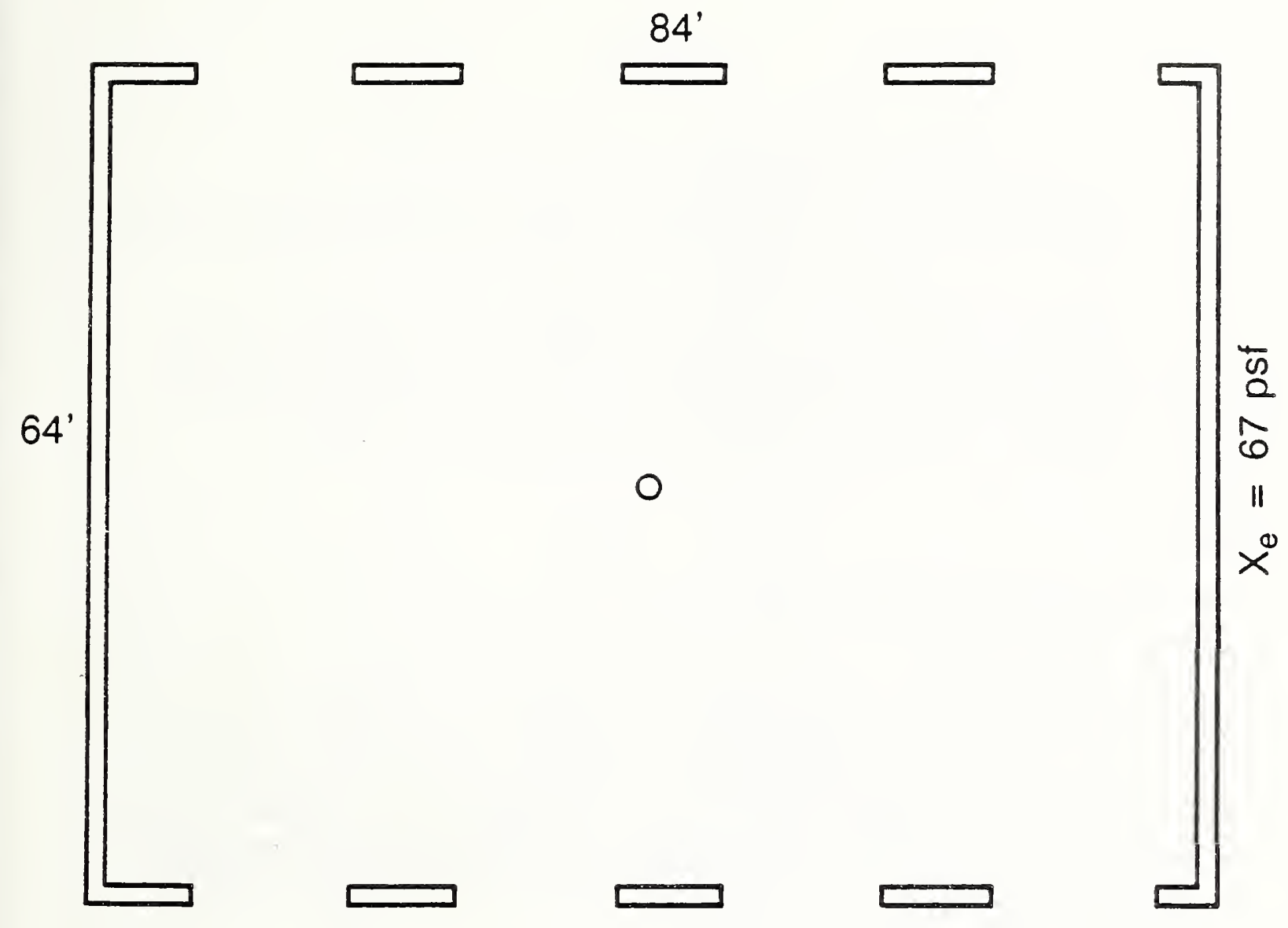

\section{WINDOWS 0.6 OF LENGTH}

(ELEVATION)

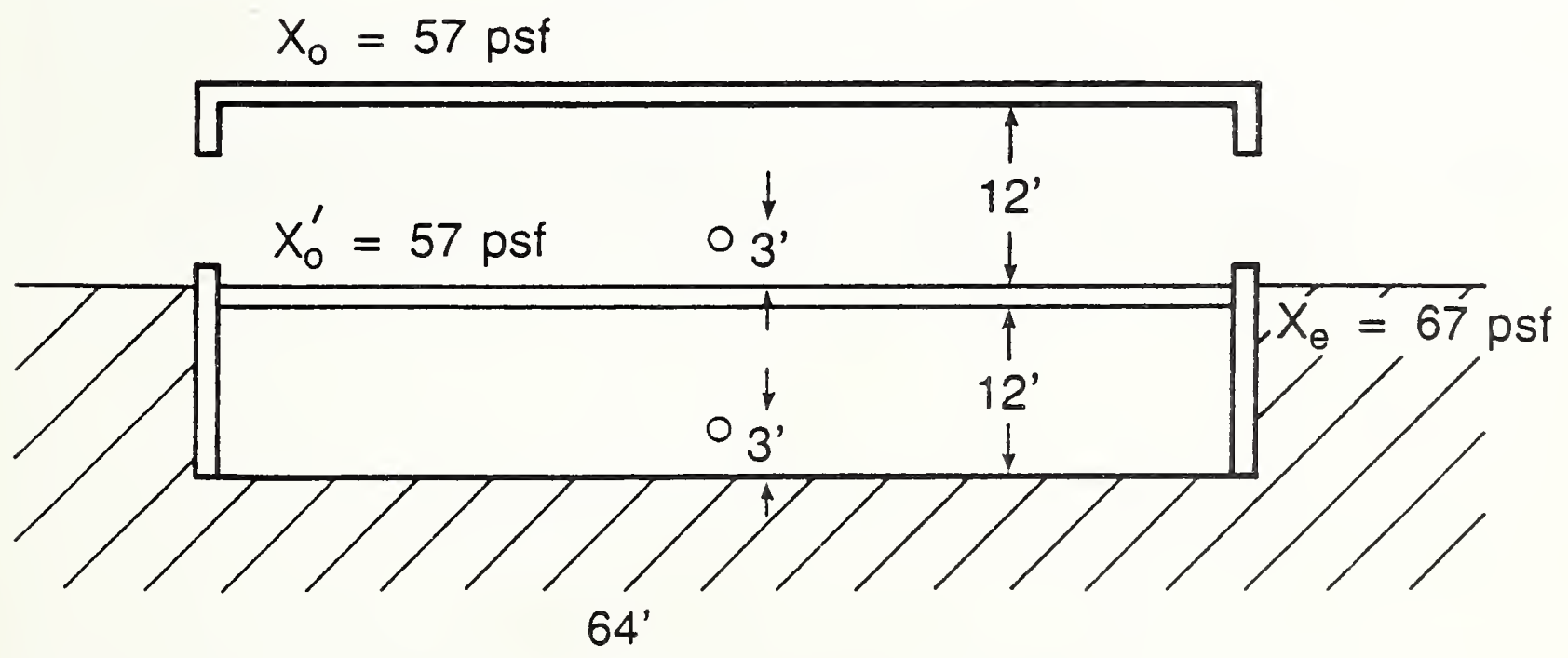

Fiy. 21. Plan and elevation views of benchmark structure with basement ceiling and windows on two sides. 


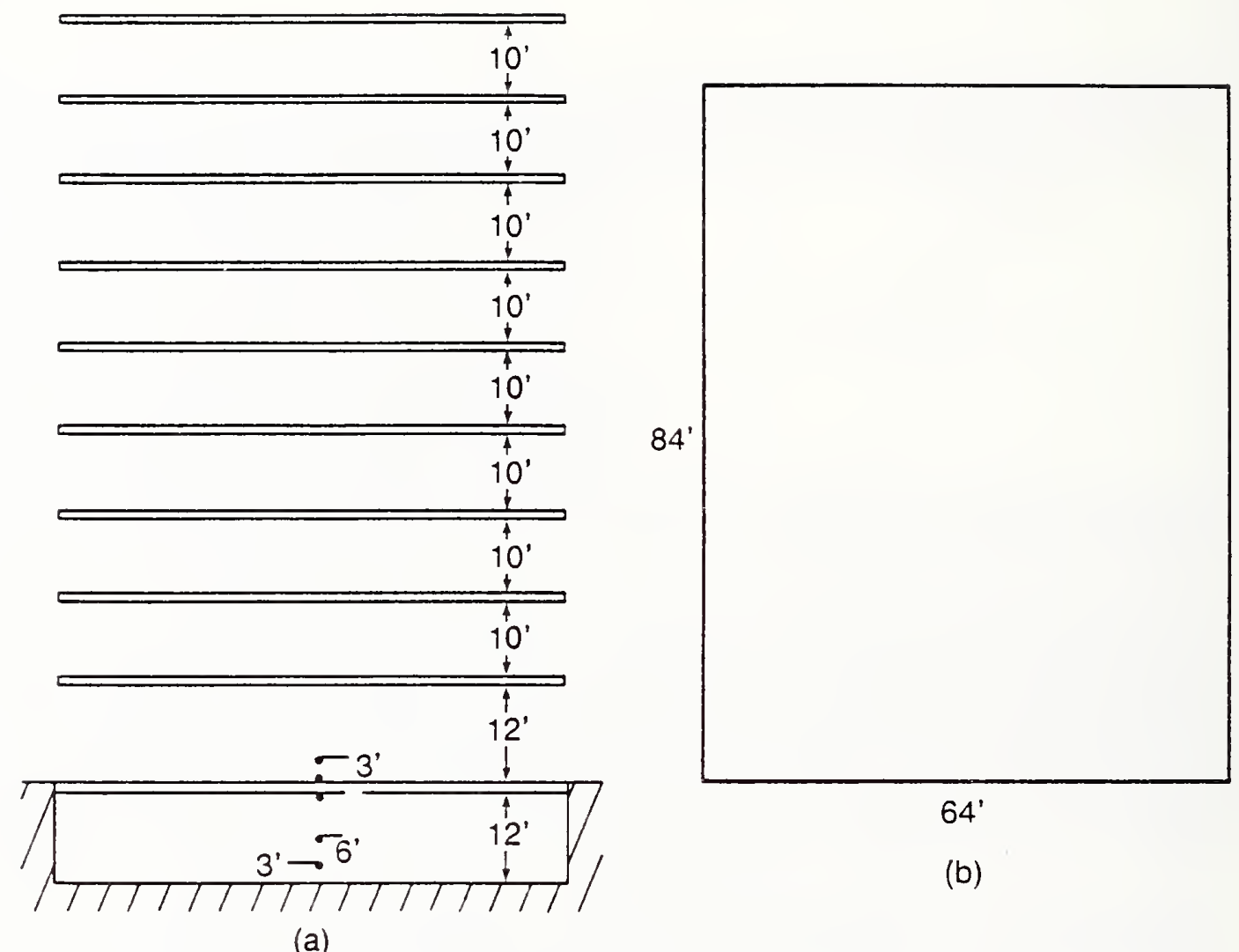

Fig. 22. Views of benchmark structure 5. Figures a) and b) represent elevation and plan views, respectively. Dots represent detector points. 
APPENDIX A

Sources of Data for INR Computer Codes

INRG5

Barrier Factors L.V. Spencer NSE 57, 129-154 (1975) Tabie X

Geometry Factors L.V. Spencer op cit, Tables XIV, XV, XVI, XVII, $X V I I I$, and $X X$

\section{INRN5}

Barrier Factors L.V. Spencer (unpublished) $1 \mathrm{ft}$ concrete $=146.6 \mathrm{pst}$ Geometry Factors L.V. Spencer (unpublished) Tables

Duct Reflection Factors L.V. Spencer (unpublished) Graphs

Mutual Shielding Factor L.V. Spencer (unpublished) Graphs $M_{R}, m_{S}$ 


\section{APPENDIX B}

TREATMENT OF MUTUAL SHIELDING FOR NEUTRONS

The present version of the code assumes that the mutual shielding factor for a wall or roof is determined by the $m_{s}$ and $M_{r}$ curves generated by Spencer (fig. 17). The solid angle subtended by open space in the upper hemisphere is determined for the exterior walls and the roof. A table-lookup for each solid angle is used to find some response for the walls $\left(m_{s}\right)$ or the response for the roof $\left(M_{r}\right)$.

The following steps are included in the subroutine NMSHLD:

1. If the mutual shielding input index IMS $\leqslant 0$ the mutual shielding factor for the walls is set equal to 0.5 and that for the roof is 0.58 .

2. If IMS > 0, solid angle fractions are determined for each of the four walls at a point at detector height on the outside wall. The solid angle fraction is calculated on the center line of a hypothetical horizontal area twice the size of the actual open horizontal area next to the side of the building. The field length is assumed to be symmetrical about the vertical plane perpendicular to the wall and including the detector point. The mutual shielding factor is set equal to $1 / 2$ of the solid angle fraction.

3. To determine the mutual shielding factor for radiation incident on the roof, the maximum height HMAX of nearby buildings is first determined. If the height on any side is less than the roof height, the distance to the nearest building is arbitrarily set at $1000 \mathrm{ft}$. Otherwise, the unobstructed solid angle is projected onto a horizontal plane at level of HMAX. In this plane the width $X$ of the clear field of view is determined by similar triangles, as shown in figure B.1. 


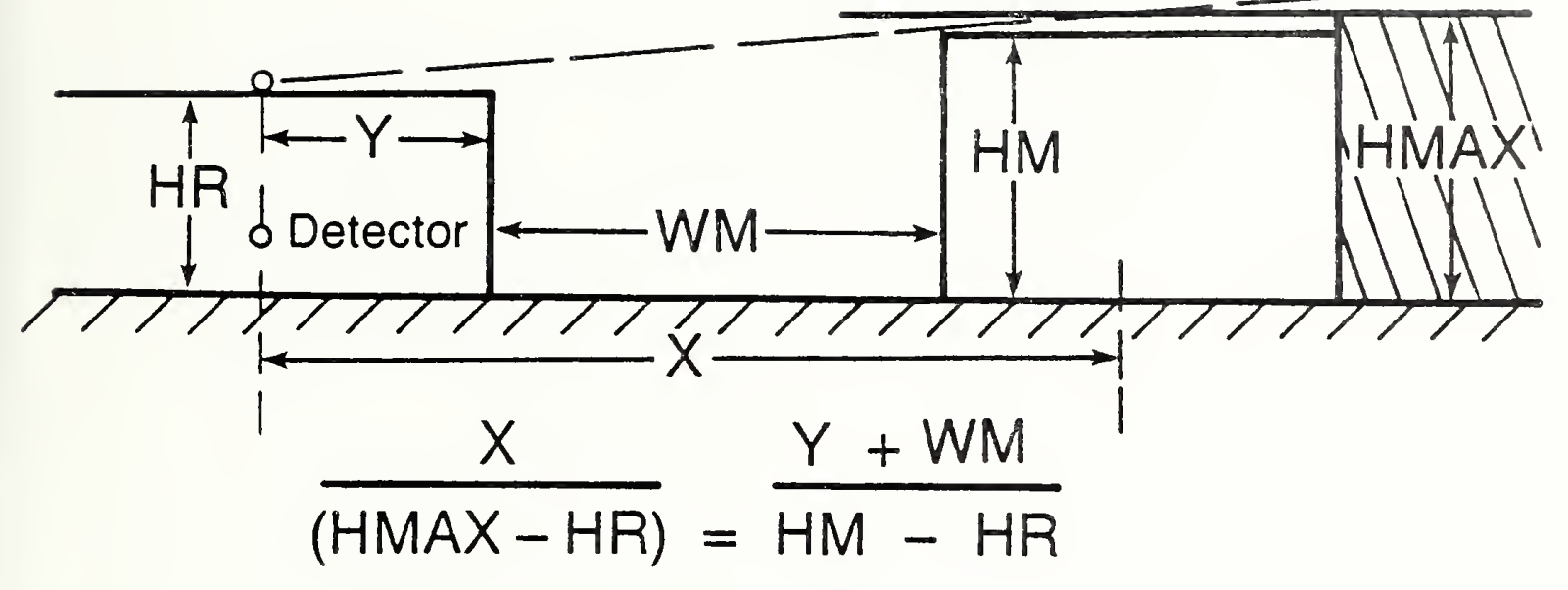

Fig. B.1

4. Solid angle fractions are then calculated for the four quadrants around the detector point on the roof, as shown in figure B.2.

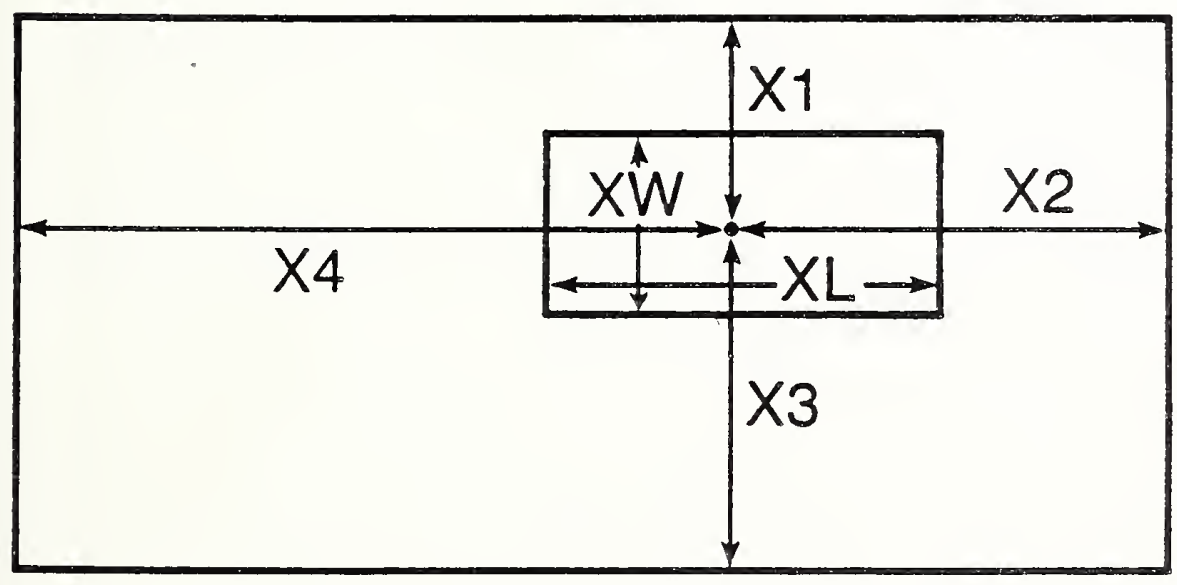

$\epsilon_{i}=X_{i} / X_{i+1}$

$\eta_{i}=\frac{(H M A X-H R)}{X_{i+1}}$

Fig. B.2

5. Response functions $m_{s}$ are then looked up (INTRPR) for solid angles subtended by detectors on each of the four sides of the building. These are multiplied by 0.5 . Response functions $M_{r}$ are looked up for each of the four quadrants surrounding the roof detectors. These four responses are averaged and multiplied by 0.58 to obtain the mutual shielding factor for the roof. 
APPENDIX C 
INRG 
SUBROUTINE SECTOK (IL, HL, HUR, HL, XL, $W, Y$ )

DIMENSION Y $(18,2), O M(4)$, SPHI (4)

$\zeta$

EXPRESSION FOR SULIO ANGLE SURTENEED EY A RECTANGLE

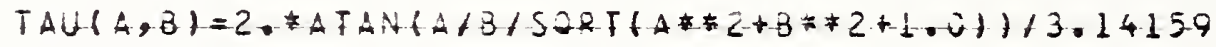

$H=H U$

CALL GEOM (H, XL, W, UH, SPHI)

C. SET UP Y ARRAY FREH VALUES GF GHEGA AND SIA PHI

DO $-20-J=1,4$

$J P=J+j$

$Y(7, H)=E,(9)$

$20 Y(J P, 2)=S P H I(J)$

C

equate fifth y value to solio angle fFaeticn subtendeu gy kOdF

$E P S=W / \times L$

$T Z P=2 . * H U R$

$E T A=T Z P / X L$

$Y(5,1)=F A U E P S, E F A)$

C TESF FO-SEE WHEFHER FE-CALEUH AFE Y ARRAY FER PORFION OF WALL

C L/TESTDETECTOR Plane $([L=1)$ oR EXIT (IL=0)

IF (IL.EO.C) GO TO $2 C O$

$H=H L$

CALL GEOM (H,XL, W, OM, SPHI)

CO $40 \quad J=1,4$.

$j 1=J+9$

$J 2=J+14$

$Y(J 1,1)=0,(J)$

$40 Y(J 2,2)=S P H I(J)$

C

CALGULAFE SOLIO AHGLE-FRAEFLEY SUZFEYQEE-ZY FLGQR (NOT USEO)

$T Z P=2 . \# \mathrm{HL}$

$E T A=T Z P / X L$

200 RETURN

$Y(14,1)=T A U(E P S, E T A)$

ENO 
SUBROUTINE GEOM (HI, XL, W, UN, SPHI)

OIMENSION

OM $(4)$, SPHI (4)

C expression fOR SOLID angle slitended ey a rectangle

$\operatorname{TAU}(A, B)=2$. ATAN(A/B/SGRT(A*2+8*2+1.0)/13.14159

C

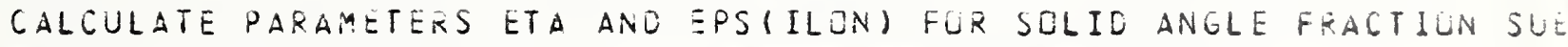
SUBTENDED BY EAEH ALL.

$00-4 \cdot J=1,4$

$T Z P=W$

IF (J.EQ.2.OR.J.EQ.4) TZP $=\times L$

$X L P=X L$

IF (J.EO.2. UF.J.EQ.4) XLP=W

$E T A=T Z P / X L P$

c calculate aziauthal half-angle fhe sletended by each wall PHI = ATAN $(X L / W)$

IF (J.EQ.2. [RR.J.EQ.4) PHI = ATAN(W/Xt)

WP $=2$ 2*HI

$E P S=W P / X L P$

C. REPLACE EACH HALL EY SECTECN OF CYLIOER WITH VERTIGAL AXIS THEL C

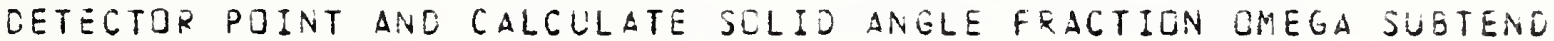
-ED EY EQLIVALENT CIRGULAR CEILING

DMAJ) $=1 .-1.5708 *$ TAUtEDS,ETAH-PHI

$40 \operatorname{SPHI}(J)=S I N(P H I)$

200 RETURN

END 
SUBRQUTINE INPUTT (IPR, GMTAB,SPTAE)

DIMENSION XTAB(11), STAB(11,4), ZTAB(6), OMTAB(11), SPTAE(11), GTAE(t,

$111,6), Y T A B(11,2)$

DIMENSION XLABEL(IO)

CQHACH XYAX,XTAB, SFAB,-ZIA- YTAZ, GTAE

DATA XLABEL $14 H G(X, 4 H O M) R, 4 H A S$,4HG(X, 4HOMIR, 4HFP ,4HG(X,,

$14 H O M) i, 4 H A S, 4 H G(X,, 4 H O M), 4 H F P, 4 H G Z(X, 4 H, S I N, 4 H)$ in $15,4 H G Z(X, 4 H$, ZSIN, 4HIWFPI

C

READ IN TABULATED BARRIER THICKNESSES

REAC $1, x T \perp 3$

- $0030 \mathrm{O}=1,11$

$30 \times T A B(I)=68.1 * X \operatorname{TAB}(I)$

C READ IN TABULATEO BARRIER faCtCFj

READ. i, ( $(B T A B(I, J), J=1,4), I=1,11)$

1. FCRMAT (BE-1C.3)

2 FCRMAT (1HO)

3 FGEMAT (IH)

5 FCKMAT $\left(3 x, 1 X T A B^{\prime}, 6 x, 1 B(x)\right.$ RAS', $5 x$, ' $5(x)$ FFP', $5 x, 1 B(x)$ NAS', $5 x, 1 B(x)$. IFPL1

7 FCRMAT (F10.3,1P4E12.3)

IF (IPR-EDOC) GQ-FE- 6 C

PRINT 2

PRINF 5

PRINT 2

PRINT 7, XTAE(I), (BTAO $(I, J), J=1,4)$

50 CONTINUE

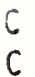

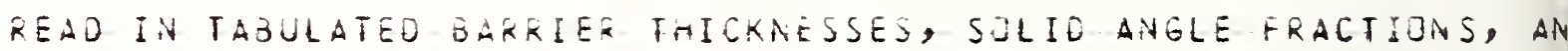
AND VALUES OF SIN PHI FCR gEUMETRY FACTORS

SO READ 110, ZTAB

READ I1O, GMTAB

READ 110, SPTAB

CMT $A B(1)=1 . O E-10$

$S P T A B(1)=1.0 E-10$

110 FCRMAT $(22 \mathrm{FG}, 4)$

READ IN TABULATED GEOMETRY FACTCRS

DO $150 \quad k=1,4$

IF $(K-2) 130,120,130$

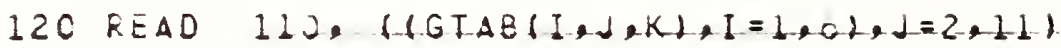

GO TO 140

130 KEAO 110, ( (GTAB $(I, J, K),[=1,6), J=1,11)$

140 UC $145 \quad I=1,6$

IF $\{K . L E .2)$ GTAB $(I, 1, K .1=1.0 E-10$

IF $(K . G T \cdot 2) \quad G T A B(I, 11, K)=1 \cdot C E-10$

$-I F-(K \cdot G F \cdot Z \cdot A N Q \cdot K \cdot L E \cdot 4)-G \cdot T+B(-I, 11, k)=1 \cdot 0 E-10$

145 CONTINUE

150 CONFINUE

DO $154 K=5,6$

READ 110, $((6 F A B(1, j, K), I=1,6),-1=1,0)$

OD $154[=1,6$

$00-15-2, \alpha=7,-1-1$

$153 \operatorname{GTAB}(I, J, K)=1.0 E-10$

154 GTAB(I,I,K) $=1.0 E-1 \mathrm{C}$

IF (IPR.EQ.0) GO TO 4 CO

PRINF 2 
PRINT I65

I 60 FORMAT $(23 \times, 1 \times(P S F)=1,0 F 10.0)$

162 FCRMAT $(50 x, 3 A 4)$

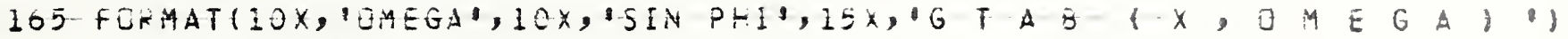
1)

DE $250 \quad x=1,6$

PRINT 2

$K i=3 \neq K-2$

$k 2=k 1+z$

PRINT 162, (XLABEL(I), I =KI,K2) .

PRINT $\dot{ }$

PEINT 100, $Z$ ITH

PR INT 3

$O C 250 \mathrm{~J}=1,1.1$

PRINT I7), OMTAB(J), SPTAB(J), (GTAE(I,J,K), I=1, 6 )

170 FURMAT (2F12.4,6F10.4)

250 CONTINUE

4 CO RETURN

END 
* inNer

SUBROUTINE INNER (IP, XE, XI,XUE, XUI, XXLE, XXII,Xm, XL, XXL)

OIMENSION XE( 5$), X I(5), X U E(5), X U I(5), X X L E(5), X X L I(5), X)(9), X U(9)$,

$1 \times \times L(9)$

C SET ROOF BAREIER THICKAESS EQUAL TO AE IS,, CEILING THICKNESS EQUAL TO XUI(5), ANO FLOCR THICKNESS EQUAL TO XXLI(S)

$X W(5)=x E(5)$

$X U(5)=X U I(5)$

$X X L(5)=X X L I(5)$

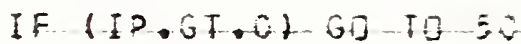

$0020 \quad L=1,4$

$X \times(L)=X \subseteq(L)$

$X \cup(L)=X \cup E(L)$

$20 \times X 1(L)=X \times L E(L)$

GO TO 200

50 IF-(IP.GF-.1]-GD-F5-10G

00 6O $L=1,4$

$X X f L=X E(L)+X I(L)$

$X U(L)=X \cup E(L)+X U I(L)$

$60 \times x(-1 t-1=x \times L E(L)+x \times L I(t)$

00 TO 200

$100-x+1+=x E(-i+x+1+1)$

$x w(3)=x w(1)$

$X *(2)=X E(2)$

$X w(4)=x_{N}(2)$

$X U(1)=X U E(1)+X U I(1)$

$X \cup(3)=x \cup(1)$

$x \cup(2)=x \cup E(2)$

$x \cup(4)=x \cup(2)$

$X X L(1)=X X L[(1)+x X L I ! 1)$

$X X L(3)=X X L(1)$

$x \times L(2)=x \times L E(2)$

$X X L(4)=X X L(2)$

200 RETURN

ENO 
*INTRPG

SUQROUTINE INTRPB-(XTAO,X, BTAE, E)

DIMENSION $X$ TAB $(11), B$ TAB $(11,4), \bar{B}(5,2), \times(5)$

C

RELAXATICN LENGTHS FOR EXTRAPULATION

$\stackrel{6}{C}$

RELATE K-ITYPE GF RAOIATIEN) ANO L TEAOEX CF HALL OR CVERHEAC

C TO PARAMETER JWHICH INEEXES GARFIER FACTOR TABLES

$10000250 \quad k=1,2$

80 250 $L=1,5$

IF $(K \cdot E Q .1 . A N D \cdot L \cdot E Q .5) \mathrm{J}=1$

$I F(K \cdot E Q \cdot I \cdot A N C \cdot L \cdot N E \cdot S) \quad J=3$

IF $(K, E Q \cdot 2 \cdot A N O \cdot L \cdot E Q . E) \quad J=2$

IF $(K, E Q \cdot 2 \cdot A N D \cdot L \cdot N E \cdot 5) J=4$

$200 \quad I=1$

$210 \quad I=I+I$

IF $(I . E 2.11)$ GO TO $22 \mathrm{C}$

IF $(X(L) \cdot L T \cdot X T A B(I))$ GO FO 220

GO TO 210

C

LINEAF INTERPOLATION ON $x$ ANO LOG OF BARRIER FACTOR

$220 B(L, K)=\operatorname{EXP}(A L O G(B T A B(I-1, J))+\operatorname{ALOG}(B T A B(I, J) / B T A B(I-1, J))$

$1(X(L)-X T A B(I-1)) /(X T A B(I)-X T A B(I-1)))$

250 CONTINUE

300 RETURN

ENO 
* INTRPG

SUBROLTINE INTRPG $(X, Y, G)$

DIMENSION ZTAÓ( 6$), Y T A B(11,2), G T A B(6,11,6), Y(18,2), G 1(11,6), X(9)$,

$1 \in(9,2), X T A B(11), 8 T A E(11,4)$

COYMCN XYAAX,XTAB, BTAB, ZTAE, YTAB, GTAB

$\epsilon$

RELATE M (TYPE UF RAOIATIEN) AND L (INOEX OF WALL CR OVERHEAO)

TO-PARAMETER-K WHIEH INEEXES-GEQMETRY FAETOR TAELES

De $450-4=1,2$

$00 \quad 450 \quad L=1,9$

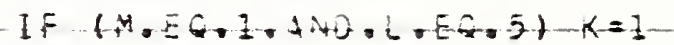

IF $(M, E Q \cdot 2 \cdot$ IND.L.EQ.j) $K=2$

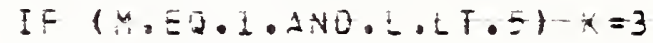

IF (M.EE.2.AND.L.LT.E) $\quad x=4$

IF $(M \cdot E Q .1 . A N D \cdot L \cdot G T .5) \quad k=5$

IF $(M \cdot E Q .2 \cdot A N O \cdot L \cdot G T \cdot 5) \quad k=6$

C

INOEX I FQR T'WO NEAREST BARRIER THICKNESSES

$I=1$

$110-I=I+1$

IF (I.EQ. 6$)$ oO TO $26 C$

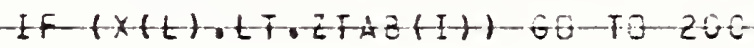

GC TC 110

200 I $X=I$

IN $=I-1$

C DETERMINe if VARIAELE IS CHEGA (K.LE.4) JR SiN PHI (K.GT.4)

If $(K-4) 320,320,330$

$320 K I=1$

GU TC 350

$330 \mathrm{KI}=2$

C

IHQEX J-FOR-FWG HEAREST-GMEGA-ER SIV PHI-VALUES.

$350 \mathrm{~J}=1$

$360 \mathrm{~J}=\mathrm{J}+\mathrm{I}$

IF $(Y(L, K I), L T, Y T \Delta B(J, K I))$ GO TO $3 C 0$

$300+2=7$

GO TO 360

$J I=J-1$

C TWD-WAY INTERPOLATION DN GEOMETRY FACTORS

$390 \quad 00400 \mathrm{~J}=\mathrm{J} 1, \mathrm{~J} 2$

$c$

LINEAR INTERPOLATION ON BARRIER THICKNESS $X$ AND LOG OF

$\mathrm{C}$

GEOMETRY FACTERS

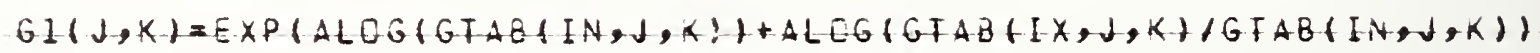

$I *(X(L)-Z T A B(I N)) /(Z T A B(I X)-2 T A B(I N)))$

400 CONTINUE

C

LINEAR-INTEXPOLATIEN ON LQG Y AHE-LOG GF-GEQMETRY FACTORS

IF $(K \cdot E 0.3 \cdot C R \cdot K \cdot E Q \cdot 4), G E-T Q-425$

$G(L, M)=E \times P(A L O G(G I(J 1, K))+A L O G(G I(J 2, K) / G I(J 1, K)) \# A L O G(Y(L, K I))$

$1 Y F A B(-11, K-I+1+A L G G(-F F A O H J Z, K-1)+Y-A D(J 1, K-I)))$

GC TO 450

c

FOR $K=3$ ANO $K=4$, INTERPCLATE JN LOG(1-GMEGA) 
$425 Y I=1 .-Y(L, K I)$

IF $(Y I \cdot L T \cdot 1 \cdot O E-10) Y Y=1.0 E-10$

$Y I=1 .-Y T A B(J 1, K I)$

IF $(Y 1 \cdot L T \cdot I \cdot O E-1, U) \quad Y 1=1.0 E-1 \hat{U}$

$Y Z=1 .-Y T A B(J 2, K I)$

IF $(Y 2 \cdot L T \cdot 1 . O E-1 C) Y .2=1.0 E-1 G$

$G(L, M)=E X P(A L O G(G)(J I, K))+A L O G(G)(J 2, K) / G I(J 1, K)) A L O G(Y I / Y I) / A L D G$ $1(Y 2 / Y 1))$

450 CONTINUE

RETURN

END 
PROGRAM TEST (INPUT, DUTPUT, TAPEE=INPUT, TAPEO=OUTPUT)

DIMENSICIV XTAB $(11), B T A B(11,4)$,

YTAB $(11,2)$,

OIMENSION ZTAB(6), OMTAE(11), SPTAB(11), GTAB $6,11,6)$

OIMENSION RF $(5,2), X U(9), \times X L(9)$

OIMENSION XLM(4), WM(4),HM(4),XE(5),XI(5),XUE(5),XUI(5),XXLE(5), $-1-X X L I(-5),-I I L E+2 C)$

COMMON XMAX,XTAB,BTAB, ZTAJ,YTAB, GTAE

- I FERHAT HEEIG.3

2 FORMAT (IHO)

3 FCRMAT (IH)

4 FORMAT $\left(5 X, ' X^{\prime}, 7 X, 1 B(X) A S^{\prime}, 8 X,{ }^{\prime} B(X) F P !\right)$

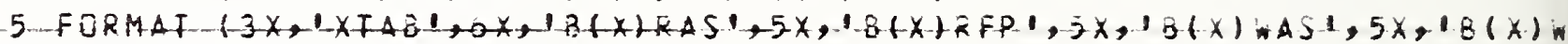
IFP')

6 FERMAT- $(1 \mathrm{H}+1$

8 FCRMAT (F10.3,1PZE12.4)

9. FORMAT $(20 A 4)$

R.EAD $(5,9)$ TITLE

-W WITE- (t, 6$\}$

WRITE $(6,2)$

WRITE $(6,9)$ TITLE

READ $(5,10)$ I, IO, IPR, IMS, IP,HI,HS,HT,HO,HR, FW, HIU,HIL, XL, W

WRITE (E, 10) IH,ID, IPR, IMS,IP, HE, HS, HT, HQ, HR, FW, HIU, HIL, XL, W

10 FORMAT $(5 I 5,5 F 10.2 / 5 F 10.2)$

40 FEAQ-45,-XE

PRINT 45, XLi4

REAQ 45, , W

FRINT 45, WM

REAC- $45, H M$

PRINT 45, H.M

45 -FORMAT- (4FIG.3)

CALL INPUTT (IPR, OMTAB,SPTAB)

OO $50 \mathrm{~J}=1,-11$

$Y T A B(J, 1)=C M T A E(J)$

$50 Y T A B(J, 2)=S P T A B(J)$

READ $(5,1)(X E(L), L=1,5)$

WRITE $(5,1)(X E+t), t=1,5)$

READ $(5,1)(X I(L), L=1,5)$

WRITE $(6,1)$ (XI $(L), L=1,5)$

$X M A X=581$.

READ $(5,1)$ (XUE (L), L $=1,5)$

WRITE $(t, 1)(X \cup E(L), L=1,5)$

READ - $(5,1)(X \cup I(L), L=1,5)$

WRITE $(6,1)(X \cup I(L), L=1,5)$

READ $(5,1)(\times \times L E(L), L=1,5)$

WRITE $(6,1)(\times \times L E(L), L=1,5)$

READ $(5,1)(\times \times L I(L), L=1,5)$

WRITE $(6, I) \quad(X X L I(L), L=1, j)$

CALL _ INNER (IP, XE, XI, XUE, XUI, XXLE, XXLI, X, , XU,XXLI

CALL RFSTOR (I $W, H I, H I U, H I L, H S, H T, X L, W, X, X U, X X L, F N$,

IID, IPR, IMS, IP, WM, HM, HO, HR, XI, XUI, XXLI, RF)

1000 STOP

END 
SURROUTENE RFSTOR-(IH, HI, HIU, HIE, HS, HT, XL, H, X, XU, XXL, FW,

IID, IPR, IMS, IP, WM, HM, HC, HR, XI, XUI, XXLI, RFI

DIMENSION XTAB(II), BTAE(I1,4), Y $(1 E, 2), Y T A B(11,2), 6(9,2), X(9)$

DIMENSICY ZTAB(S),

GTAB $(0,11,6), B(5,2)$

OIMENSIEN EP $(7,1 \mathrm{C}, 2), x$ M $(9)$

DIMENSION XMSG(4,E, 2), KF (5,2), F(4), XU (9), XXL(9), BU(5,2), BL(E, 2)

DIMENSION $X I(5), X U I(5), X X L I(5), X X(9), 3 I(5,2), 3 U I(5,2), E L I(5,2)$

COMMON XMAX, XTAB,BTAB, ZTAB, YTAB, GTAE

TAU(A,子) $=2$. ATAN(A/B/SQRTHA*Z+3*2+1.01)/3.14159

1 FCRMAT (IHI)

2 FORMAT (IHO)

3 FORMAT (IH)

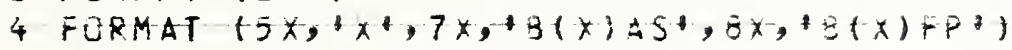

8 FERMAT (FLC. $\hat{3}, 1$ 1PELIL.4)

9 FORMAT (F10.0,3F10.4)

DO $50 \quad M=1,2$

CL 5 j $j=1,18$

DO $50 \quad k=1,7$

$50 G P(K, J, M)=C .0$

CALCULATE DARRIER FACTORS FGK FOUR NALS ANO OVERHEAC

CALL INTRPB $(X T A B, X, E T A B, O)$

CALL INTRPB (XTAB,XU,BTAB,BU)

CALL INTRPE (XTAB,XXL,BTAB,BL)

IF (IP.EQ.O) GO TO 6 C

CALL INTRPE (XTAB,XI, ETAB,EI)

CALL INTRPB (XTAB,XUI,ETAB,BUI)

CALL-IATXRZ XXFA3,XXLI, BFAE,BLI\}

GO TO 75

$600070 \quad k=1,2$

$0070 \quad L=1,5$

$B I(L, K)=I \cdot 0$

$\operatorname{EUI}(L, K)=1.0$

70 BLIfLOKT $=1.0$

75 CONTINUE

PRINT-2

PRINT 2

PRINT 4

PRINT 2

DO $80 \mathrm{~L}=1,2$

80 PRINT $8, \quad X(L),(B(L, K), K=1,2)$

PRINT 2

DO $81 L=1,5$

81 PRINT 8, $X U(L), f B U(L, K), K=1,2)$

PRINT 2

D.C $82-L=1,5$

82 PRINT $8, \quad X X L(L),(B L(L, K), K=1,2)$

PRINT 2

DO $83 \quad L=1,5$

83 PRINT $8, \quad x I(i),(3 I(t, k), k=1,2)$

PRINT 2

$-00-84-t=1,-5$

84 PRINT 8, XUI $(L),(B \cup I(L, K), K=I, 2)$

PRINT 2

DO $85 \mathrm{~L}=1,5$

85 PRINT $8, \quad x \times L I(L),(B L I(L, K), K=1,2)$

C SET PARAMETEXS fll, FOR FRACTION GF PERIMETER JCCUPIED Gy

C INDOWS

C IW=C NO WINOJWS, IW=1 WINOOWS ON $A L L$ FOUR SIOES, IW=2 WINOOWS 93 
DC $300 \quad L=1,4$

IF $(I H . E Q .0) \quad F(L)=0.0$

IF $(I N . G T . C) \quad F(L)=F W$

IF (IW.GF.1.ANQ.t.EQ.Zt $F(t)=0.0$

IF $(I W . G T \cdot 1$. AND.L.E2.4) $F(L)=0 . C$

3 CO CONTINUE

$x \ln (5)=x(5)$

\begin{tabular}{|c|c|}
\hline LOGP & $O N K$, \\
\hline$C$ & $K=2$ NINOCN HALLS OF SAME STORY \\
\hline E & MI ZOEAS-OF - SAHE STORY \\
\hline C & $K=4$ WALLS OF UPPER STORY \\
\hline$c$ & $K=5$ NDE WS GF UPPEF-SFJRY \\
\hline C & $K=6 \quad W A L L S$ OF LONER STORY \\
\hline
\end{tabular}

DO $450 \quad k=1,7$

C

FOR NO WINOJWS, CALCULAFE CNLY FER K=1,4, ANG

$310 \mathrm{HU}=\mathrm{HI}-3$.

$H L=3-$.

IF $(K \cdot N E \cdot 1 \cdot A N D \cdot K \cdot N E \cdot 4 \cdot A N D \cdot K \cdot N E \cdot 6)$ GC TO 450

GO-TO $33 \mathrm{C}$

C - SET DETECFER-HEIGHT TE SILL HEIGHF UNEESS THERE ARE NO WINOQWS

C (IN=O), IN WHICH CASE SET IT EQUAL TC 3 FT

$320 \quad H C=H T-H S$

$H L=H S$

IF (K.EO.I) HU $=H I-H S$

330 IF $(K . E Q .4 \cdot O R \cdot K \cdot E Q .5) \cdot H U=H E+H I U-H S$

IF $(K . E Q .0 .0 R \cdot K . E Q .7) \quad H L=H S+H I L$

IF $(K \cdot E O \cdot I) H U R=H R-H Q$

$I L=C$

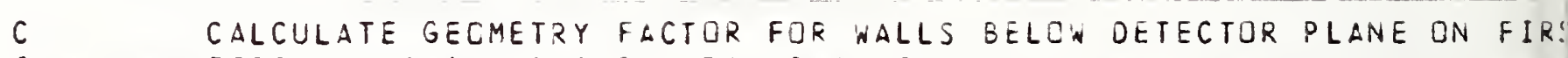

C

FIRST-PASS $I K=1$ L THRU IOQ $4201-L Q Q P$

IF $(K \cdot E C \cdot 1 \cdot O R \cdot K \cdot E Q \cdot 6 \cdot O R \cdot K \cdot E O \cdot 7) I L=1$

DO $340 \quad L=1,4$

$L P=L+5$

$X X(L)=X(L)$

$x x(L)=x I(L)$

$x \times(L P)=x I(L)$

$x(L P)=X(L)$

$340 \times \ln (L P)=x(L)$

IF $(K-4) 345,341,243$

$34100342 L=1,4$

$L P=L+5$

$X W(L)=X \cup(L)$

$X X(L-)=X U I\{L)$

$X X(L P)=X \cup I(L)$

$342 \times(L P)=X U(L)$

GO TO 345

-343-IF (K.NE-6) GE-TZ -345

DO $344 \quad L=1,4$

$L P=L+5$ 
$x \times(L P)=x \times I(L)$

$344 \times X(L P)=X \times L(L)$

383 FUKMAT (I $5,7 F 10.3)$

345 IF - F INE-2.C) 60 TO 330

IF $(K-3) 380,340,340$

340 IF (K.HE.3.AND.K.NE. J.ANG.K.NE.7) GE TO 300

C

IF $(I N . G T . I)$ GO TO 350

DC $348 \mathrm{~L}=1,4$

$L P=1+5$

$X *(L P)=X X(L)$

$348 \times \cup(L)=X \times(L)$

G] TO 3 a

$350 \times(1)=\times \times(1)$

$x^{\prime}(2)=x(2)$

$x(3)=x \times(3)$

$x w(4)=x(4)$

DO $370 \quad L=1,4$

$L P=L+5$

$370 \times(L P)=X N(L)$

$c$

CALCULATE Y ARRAY

$3806 A L L$

381 FGRMAT $(2 F 10.3)$

6

calculate geonetry facturs above detectir plane

CALL

INTRPG $\left(X_{M}, Y, G\right)$

IF $(K, G T \cdot 1 \cdot A N O \cdot K \cdot L T \cdot G)$ GE-FO 285

C Calgulate gegMetry facters gelow oetector plane

DO $382 \quad 1=1,4$

$L P=L+9$

DO $382 M=1,2$

$382 G P(K, L P, M)=1 \cdot-Y(L P, I) * 3$

385 CD $390 \quad t=1,9$

DO $390 \quad M=1,2$

$390-G P(K, L,+M)=G(t, M)$

IF (IPR.EQ.0) GO TO 450

PFINT-3

OC $515 L=1,9$

IF (L.EQ.-1) PRINT 520

IF (L.EQ.6) PRINT 521

IF $(L, L E .5) \quad L=1$

IF $(L . G T .5) \quad J=2$

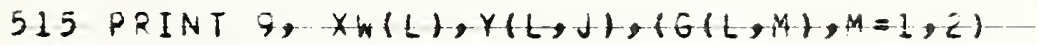

PRINT 410, GP

410 FORMAT $(7 . F 10.4)$

4 SO CONTINUE

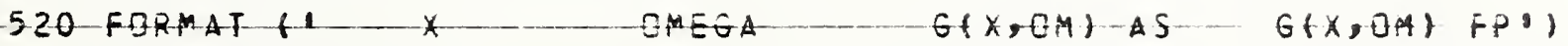

521 FORMAT $(1$ SIN PHI G2(X,SIN) AS G2(X,SIN)FPI)

IF (IMS) $5130,2150,518$

$5150 \quad 00 \quad 517 \quad M=1,2$

DO $517 \mathrm{~J}=1,4$

DO $516 \quad L=1,4$

$516 \times M S G(J, L, M)=0.5$

$517 \times M S G(J, 5, M)=0.85$

GO TO 500

518 CALL GMSHLD (WM,HM, XL, W, HO, HI, HIU,HS, HT, HUR, X, Y, GP, IW, $1 \times M S G)$ 
500 DO $551 \quad 4=1,2$

C

CALCULATE REDLCTICN FACTOR FOR RCGF

$530 R F(5, M)=B(5, M) \neq G P(1,5, M)$

$R F(5,4)=2 F(5,4)+x, 45 G(1,5, M)$

If $(I O . E Q . C)$ GD TO 551

C

CALCULATE REDUCTICN FACTOR FOR WALLS

$54000 \quad 550 \quad L=1,4$

$L P=L+5$

$L P D=L+9$

$-C S U 1=B(t, H) \neq(0.8 E \neq G P(1, t, A) \neq G P(1, L P, H))$

$1 \neq X, M S G(1, L, M)$

$-\operatorname{CSU2}=$

$1+.85 * F(L) *(3 I(L, M) * G P(3, L, M) * G P(3, L P, M)-3 ! L, *) * G P(2, L, M) * G P(2, L P$,

2(A) $) \neq \times \times S G(2, L$, , in $)$

CSU $=$ CSUI + CSUZ

IF $110.1-1.2+C S t=0.0$

$C S L=B(L, M) *(0.15 * G P(1, L P P, *) * G P(1, L P, M))$

$C S L=0.5 \neq C S L$

IF (ID.LT.3) CSL $=C .0$

$C S=C S U+C-S L$

CUI $=$

$2+.85 * B \cup(L, M) \neq(G P(4, L, 4) \neq G P(4, L P, 14)-G P(1, L,: 4) \neq G P(1, L P, M))$

$1 \neq X M S G(3, L, M)$

$C U 2=0.85 * F(L) *$

$3(B \cup I(L, M) *(G P(j, L, M) \neq G P(5, L P, Y)-G P(3, L, M) \quad * G P(3, L P, M))$

$4-B U(L, M) *(G P(4, t, M) \neq G P(4, t P, H)-G P(I, L, H) \neq G P(I, L P, H))\}$

$5 * X Y S G(4, L, M)$

$C U=C U 1+C U 2$

IF $(I D . G E .5) \quad C U=0.0$

$C L=$

$5+.15 * B L(L, M) *(G P(6, L P P, M) * G P(6, L P, M)-G P(1, L P P, M) * G P(1, L P, M))$

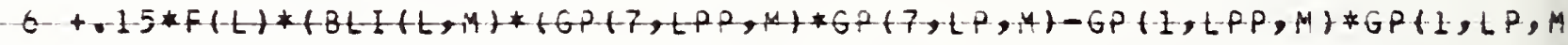

$7))-B L(L, M) \neq(G P(O, L P P, M) \neq G P(\sigma, L P, M)-G P(I, L P P, M) * G P(I, L P, M)))$

$C L=0.5 * C L$

IF (ID.LT.4.OR.ID.GT.E) $C L=0.0$

C PRINT $1050, C S U 1, C S U 2, C S L, C U 1, C U 2, C L, B U(5, M), B L(5, M), X M S G(2, L, M)$

1050 FORMAT (IPQE 10.2$)$

$R F(L, H)=C S+B U(5,-M) * C L+B L(5, M) \neq C L$

550 CONTINUE

551 CONTINUE

GO TO 900

$600 \quad 00 \quad 650 \quad M=1,2$

DO $650 \quad L=1,5$

$650-R F(L, M)=0.0$

900 PRINT 1

PRINT 2

PRINT 920

DO $915 \quad L=1,5$

PRINT 910, $X(L),(R F(L, M), M=1,2)$

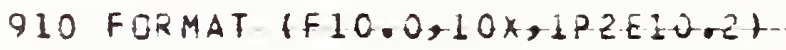

915 CONTINUE

920 FCRMAT $f$

$x$

RF-AS

$R F-F P(1$

RETURN

ENO 
$\$ G, 1 S H L D$

SUBROUTINE GHSHED (WH, HM, XL, H, HO, HI, HIU, HL, HT, HUR, XW, Y, GP, IW, $1 \times \sin 1$

DIMENSIEN XX(9), GP $\{7,10,2\}, X$ SWT $4,5,2), H M(4), Y(18,2), G$ M $(9,2), Y M(4)$

$1, X(4), T A U M R F(4), 6(9,2), W M(4)$

COMMUN XMAX,XTAE, STAE, ZTAE,YTAE,GTAO

$T A U(A, B)=2 . A T A N(A / B / 5 Q R T(A) 2+9 * 2+1.01+13.14159$

$c$
$c$
$c$
$c$
$c$
$c$
$c$
$c$
$c$

XMSIN(L,L, M IS THE MUTUAL SHIELOING FUR THE SOLIO WAL CONTRIBUTIUN TO CSU (IN RFSTCRI

XYN(2,L,M) IS THE MUYUAL SHIELOING FOE THE WINOOW CONTRIBUTION TO $6 S \mathrm{U}$

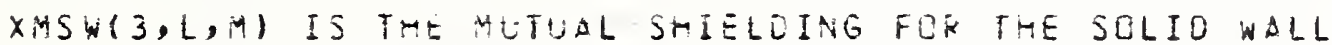
CONTRIBUTICN TO CU

XMSM(4,L,H) IS THE AUTUAL SHIELDING FUE THE WINOON CONTRIJUTION TOCU

XMS I $11,5,91)$ is THE MUTUAL SHIELOING FOR THE ROOF

$I L=C$

$Y Y(1)=0 \cdot 5 * W$

$Y(2)=0.5 * X L$

$Y M(3)=Y M(1)$

$Y, 4(4)=Y(4,(2)$

$00100 \quad L=1,4$

$\operatorname{IF}(M M(L)-H O) \quad 1 C, 10,30$

10 CO $15 \quad M=1,2$

DO $15 \mathrm{~J}=1,4$

$15 \times \operatorname{Sin}(J, L, M)=0.5$

GU TO 100

30 HTEST $=(H M(L)-H D)+Y M(L) /(N M(L)+Y M(L))$

$H U=H T-H L$

IF (HTEST-HU) $35,35,6 C$

35 CALL. SEETOK (IL, HFESF, HUR, HL, XL,W, Y)

CALL INTRPG $\left(X_{H}, Y, G M\right)$

$-C 0-50 \quad Y=1, Z-$

$X M S N(L, L, M)=(G P(1, L, W)-G M(L, M)) / G P(1, L, M) / 2$.

IF $(I M \cdot G T \cdot O)$

LXYSW $(2, L, M)=(G P(3, L, M)-G M(L, M) / G P(3, L, M) / 2$.

$X, 4 S *(3, L, M)=0.5$

$50 \times M S N(4, L, H)=0.5$

-... GO TO 100

$60 \mathrm{HU}=\mathrm{HI}-\mathrm{HL}$

IF (HTESI-HU) $65,65,80$

65 CALL SECTIR (IL,HTEST, AUF, HL, XL, N,Y)

CALL INTRPG $\left(X_{H}, Y\right.$, OXY $)$

$C$

REOUNDOANT WITH PREVICUS LGOP, BLT INCLUCED FOR POSSIBLE

C EUTURE CHANGES

DO $70 \quad M=1,2$

$X M S W(1, t, i)=(G P(1, t, n)-G M(t, n)) G P(1, t, n)+2$.

IF $(I N \cdot G T \cdot O)$

LXMSW(2,L, Y $)=(G P(3, L, M)-G H(L, 4)) / G P(3, L, H) / 2$.

PRINT 1050, GP(3,L,M), GM $(L, M), X$ X SW $(2, L, M)$

1050 FOR.AAT (1P4E10.2)

$X M S W(3, L, M)=0.5$

$70 \times M S W(4, L, M)=0.5$

GO TO 100

$80 H U=H I+H I U-H L$

IF (HTEST-HL) $85,85,95$

85 CALL SECTOR (IL, HTESF, HUR, HL, XL, H,Y)

CALL INTRPG $(X W, Y, G M)$

DO $90 \quad M=1,2$

$\operatorname{XMSW}(1, L, M)=0.0$

$x$ MS in $(2, L, M)=0.0$ 
$X H S+(3, L, M)=(G P(4, L, M)-G H(L, M)) /(G P(4, L, M)-G P(L, L, M)) / 2$. IF $(I, G T \cdot C)$

IXMSW $(4, L, M)=(G P(5, L, *)-G M(L, H)) /(G P(5, L, M)-G P(3, L, M)) / 2$.

90 CONTINUE

GO TO 100

95 $D C-98-7=1,2$

$X, Y S W(1, L, M)=0.0$

$X M S W(2, L, M)=0.0$

$X M S W(3, L, M)=0.0$

$98 \times A \operatorname{Sin}(-4, L, M)=0.0$

100 CONTINUE

Q.ELHALAUR

DO $300 \quad L=1,4$

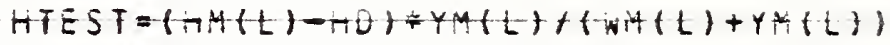

IF (HTEST-DELH) 22J, ČCC, Z4C

220. $X(L)=F M(L)$

GD TO 300

$240-X+L)=0 E L H *(W M(L)+Y H+L) /(H M(L)-H O)$

300 CONTINUE

$E P S=X(1) / X+2)$

$E T A=D E L H / X(2)$

TAUMRF(IH=TALIEPS,EFA)

$E P S=x(2) / \times(3)$

ETA $=0 E t H(-X(-3)$

TAUMRF $(2)=T A U(E P S, E T A)$

$E P S=X(3)+X(4)$

$E T A=D E L h / X(4)$

TAUMRF (3) = TAU (EPS, ETA

$E P S=X(4) / X(1)$

$E T A=D E L H / X(I)$

TAUMRF $(4)=T A U(E P S, E T A)$

$00 \quad 400 \quad L=1,4$

$Y(5,1)=T A U M R F(L)$

CALL INTRPG $\left(X_{\text {H }}, Y, G\right)$

DO 4 CO $M=1,2$

$400 G M(t, M)=6(5,4)$

$00 \quad 500 \quad M=1,2$

$500 \operatorname{XMSW}(1,5, M)=0.25 \neq 0.85 \neq(G .4(1, M)+G .4(2, M)+G M(3, M)+G .4(4, M)) / G P(1, j, M)$ RETURN

ENO 
INRN 
* SECTOR

SUBROUTINE SECTOR (IL, HU,HUR, RL, XL, N, Y)

OIMENSION Y(18,2), OM(4), SPHI(4)

C EXPRESSIGN FOR SOLID AVGLE SUBTENCEO EY A RECTANGLE

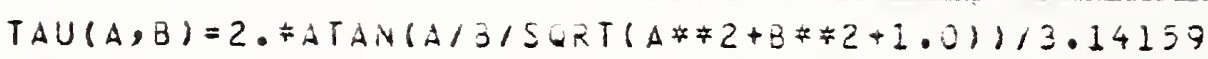
$\mathrm{H}=\mathrm{HU}$

CALL GEOH (H,XL, , OM, SPHI)

$c$ SET UO Y ARRAY FRJM VALUES OF OAEGA ANO SIN PHI

DO $20 \quad J=1,4$

$J P=j+5$

$Y(J, 1)=0,4(J)$

$20 \quad Y(J P, 2)=5 P H I(J)$

$c$ EQUATE FIFTH Y VALUE TO SELIG ANGLE-FRAEFION-SUBFENUEO BY ROOF $E P S=k+X L$

$T Z P=2$. $\#$ HUR

$E T A=T Z P / X L$

$Y(5,1)=$ TAU (EPS, ETA)

$c$

TEST TO SEE WHETHER TO CALGULATE Y ARRAY FOR PORTION OF WALL

6 - BELON UETECTOR-PLAHE TIL=I) GR EXIT (IL=U)

IF IIL.EO.CL GO TO $2 \mathrm{CC}$

$H=H L$

CALL GEQH- (H,XL, , EH, SPHI)

OO $40 \mathrm{~J}=\mathrm{i}, 4$

$J 1=J+9$

$J Z=J+14$

$Y(J 1,1)=0.4(J)$

$40 \quad Y(J 2,2)=S P H I(J)$

C

Calculate solis angle fraction subtended By floOr (NOT USED)

$T Z P=2 . \# H L$

$E T A=T Z P / X L$

$Y(14,1)=T A U(E P S, E T A)$

200 RETURN

END 
SUEREUTINE GEQH-THE, XL, H,OH, SPHE)
OIHENSION
CiA $(4), S P H I(4)$

c

EXPRESSIUN FUK SOLID ANGLE SUBTENDED EY A RECTANGLE

$\operatorname{TAU}(A, B)=2$. ATAN(A/B/SCRT(A*2+6*2+1.0) /3.14129

C

calculate parameters eta ano eps(llon) for solid angle fraction sue SUBTENDEO BY EACH-WALL

$00-40-J=1,4 \ldots$

$T Z P=W$

IF $(J . E Q \cdot 2 \cdot O R \cdot J \cdot E Q .4)-T Z P=X L$

$X L P=X L$

IF $(J \cdot E S .2 .0 R \cdot J \cdot E G .4) \times L P=W$

$E T A=T Z P / X L P$

C calculate azimuthal half-angle phi subtended by each iall

$P H I=A T A N(X L / H)$

IF $(J \cdot E Q \cdot 2 \cdot O R \cdot J \cdot E Q \cdot 4) \quad P H E=A F A P(+1) X E)$

$W P=2 \cdot H I$

$E P S=H P / \times L P$

$c$
$c$
$c$

FEPLACE EACH WALL EY SECTION OF CYLIOER WITH VERTICAL AXIS THRU OETECTOR POINT ANL CALCULATE SOLIO ANGLE FRACTION DMEGA SUETENO -ED BY EQUIVALENT CIRCULAR CEILIAG

EM(J)-1.-1.57C8*TAUREFS,ETAH/PHI

$40 S P H I(J)=S I N(P H I)$

200 RETURN

END 
* INPUTT

SUBROUTINE INPUTT (IPR, OMTAB,SPTAB)

OIMENSION XTAB(11), BTAB(11,4), ZTAB (6), OMTAB(11), SPTAB(1), GTAB(6,

$111,6), Y T A B(11,2)$

DIMENSION XLABEL ( $\$ 8)$

1. -OMRTAB $(17) \rightarrow 2 T A B(17,2)$

DIMENSION CMSTAB 117$), X M S T A B(17, \hat{2})$

COMMON XMAX, XTAB, OTAE,ZTAB, YTAB, OTAB

COMMON OMRTAB, RTAB, OMSTAB, XMSTAE

CATA XLABEL/4HG(X, , 4HEH)R, 4HN, , 4HG(X, , 4HGH)R, 4HG, , 4HG(X,,

$14 H O M) W, 4 H N \quad, 4 H G(X,, 4 H O M) W, 4 H G \quad, 4 H G 2(X, 4 H, S I N, 4 H) W N, 4 H G Z(X, 4 H$

$2 S I N, 4 H I N G-1$

C -... READ -EN TAGUTATES EARREER THICKNESSES

READ 1, $(X T A B(I), I=1, \theta)$

$0030 \quad I=1,6$

$30 \times T A B(I)=146 \cdot 6 * X-F A B(I)$

$c$

-REAO-IN-FABULATEQ ZARRIER-FAGFERS

REAQ - 4, HETAZ(I, $+1, I=1,3),-1=1,4)$

4 FORMAT (6E10.3)

$B F A B(1,2)=1.0 E-10$

$E T A B(1,4)=1.0 E-10$

1 FERMAT $(8 E 10.3)$

2 FORMAT (IHO)

3. FERMAT (1H-)

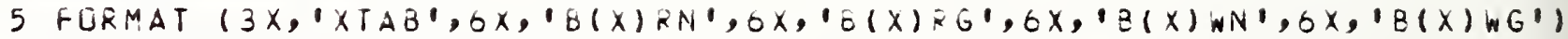

7-FGRMAT (FIG,j,1P4E12,j3)

IF $(I P R \cdot E Q .0)$ GO TO 60

PRINT 2

PRINT 5

PRINT 2

OC $50 \quad I=1,0$

50 CONTINUE

C

C

60 READ 110, ITAE

READ 110, (OMTAÓ(I), I = I,11)

FEAD 110, SPTAB

OMTAB $(1)=1$.OE-10

$S P T A B(I)=1.0 E-10$

110 FORMAT (12FE.4)

C

read in tabulated gecmetry factcks

OC $150 \quad k=1,4$

130 READ $110,(16 T A B(1, J, K), I=1,61, J=1,11)$

$14000145 \mathrm{I}=1, t$

IF $(K, L E .2) G F A B(I,-1, K)=1.0 E-10$

IF $(K . G T .2) \quad G T A B(I, 11, K)=1.0 E-10$

IF $(K, G T, 2, A N O, K, L E \cdot 4)-G T A B(I, 11, K)=1.0 E-10$

145 CONTINUE

150 CONTINUE

DO $154 \quad K=5,3$

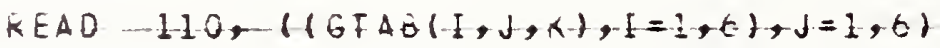

OC $154 \quad I=1,6$

OO $15.3, J=7,11$

$153 G T A B(I, J, K)=1.0 E-10$

154 GTAB $(I, 1, K)=1.0 E-10$ 
IF $(I P R . E Q .0)$ GO TO 260

PRINT- 2

PFINT 105

ISO FORMAT $(23 \times, 1 \times(P S F)=1,6 F I 0 . E)$

1 CL FCRMAT $(50 \times, 344)$

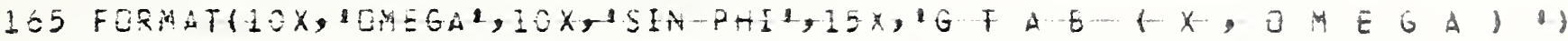
1)

$00-250 k=1,6$

PRINT 2

$K 1=3 \neq K-2$

$K 2=K L+2$

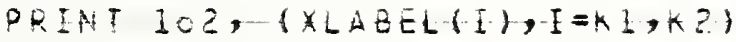

PRINT 3

PRINT IOU, ZTAB

PRITT 3

DE $250 \quad j=1,11$

PRINT 170 , CMTAB(J), SPTAZ(J), (GTAÜ I, J,K), I =1, b)

170 FOKMAT (2F13.4, 6F13.4)

250 CONTINUE

6

READ IN OUCT REFLECTION FACTORS

20O REAO 110, (OMRTAE(J),J=1,17)

QHRTAB $(1\}=1.0 E-10$

READ 110, (RTAB(J,I),J $=1,17), I=1,2)$

RTAB $(1,2)=1.0 E-10$

IF $(I P R .5 Q .0)$ GO TO 400

PRIVT 265

265 FORMAT (5X, 'JMEGA', OX, 'RHJ', $4 X$, ' RHC-SUB-E''

$D C \equiv 50 \quad J=1,17$

PFINT 270 , OMRTAE(J), (RTAB (J,i), I =1,2)

270 FORMAT $(F 15.4,2 F 10.4)$

350 COATINUE

C

READ in MUTUAL SHIELOING factoRs

400 REAO 110, (OMJTAB(J),J=1,17)

QMSTAB (1) $=1 . O E-10$

$00420 \quad I=1,2$

420 READ 110, (XMSTAB(J,-1), $=1,17)$

$X M S T A B(1,1)=1.0 E-10$

$X$ YSTAB $(1,2)=1.0 E-16$

IF (IPR.EQ.O) 60 TO 500

PRINT 430

430 FORMAT (5X, 'CMEGA', 9X, 'MS', 8X, '4R')

$00450 \quad J=1,17$

PRINT 270, OMSTAB $(J),(X M S T A B(J,[), I=1,2)$

450 CENTINUE

500 CONTINUE

RETURN

END 
*INTRPR

SUBROUTINE INTRPR (OMRTAB,RTAB,TALR, RHE)

OIMENSION UMRTAB (17), RTAJ 117,2$)$, TAUR (5), RHU (5, 2)

DO $400 \quad I=1,5$

$J=1$

$250-j=j+1$

IF (TAUR(I).LT.OKRTAB(J)) GO TO 300

$300 \mathrm{j} 2=\mathrm{J}$

$J 1=j-1$

DO $350 \quad K=1,2$

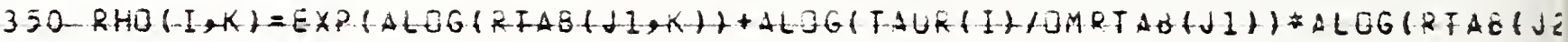

$12, x) / R T A B(J 1, X)$ )/ALOG(OMRTAO(J2)/CMETAB(J1)))

400 CENTINUE

RETURN

END 
*INTRPE

SUOROUTIVE-INTRPE-

DIMENSION XTAB(11), STAS(11, 4), $8(5,2), x(5)$

C

RELAXATICN LENGTHS FOR EXTRAPOLATION

$C$

RELATE K ITYPE JF RAOIATIEN) ANO L TENOEX OF WALL GR OVEKHEAO $c$

TO PARAMETER J WHICH INOEXES BARRIER FACTOR TABLES

$100 \quad 00 \quad 250 \quad k=1,2$

$00250 \quad L=1,5$

IF $(K . E Q \cdot 1 \cdot A N D \cdot L, E Q .5, j=1$

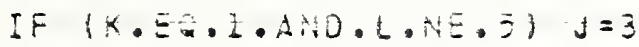

If $(K . E Q .2 . \lambda N J \cdot L \cdot E, .5) \quad J=2$

$200 \quad I=1$

IF $(K \cdot E G \cdot 2 \cdot A N Q \cdot L \cdot$ ivE.5) $J=4$

$210 \quad I=I+1$

If $(I . E Q .6)$ GO TO 220

IF $(X(L) . L T \cdot X T A B(I))$ GO TO $2 \hat{2} O$

60 TO 210

C

LINEAR INTER?OLATION OA X AND LOG JF BAFRIER FACTOR

$220 B(L, K)=E X P(A L O G(3 T A B(I-1, J))+A L O G(B T A B(I, J) / B T A B(I-1, J)) *$

$1(X(L)-X T A B(I-1)) /(X T A B(I)-X T A B(I-1))$

250 CONTINUE

300 RETURN

END 
*INTRPG

SUBRCUTINE INTRPG $(X, Y, G)$

OIMENSION ZTAB( 0$), Y T A B(11,2), G T A B(O, 11,6), Y(18,2), G 1(11,6), X(9)$,

$1 G(9,2), X T A B(11), B T A B(11,4)$

COMMON XYMAX,XTAB, ÓTAB, ZTAB, YTAU, GTAE

C

RELATE M (TYPE JF RAOIATION) AND L (INOEX CF WALL OR CVERHEAD)

TO PARAMETER K WHICH INEEXES GEEHETRY FACTOR TABLES

$00-450-M=1,2$

$00 \quad 450 \quad L=1,9$

IF $(M . E O \cdot-1 \cdot A N D \cdot L \cdot E G .51-k=1$

IF $(M \cdot E Q .2 \cdot A N D \cdot L \cdot E Q . E) k=2$

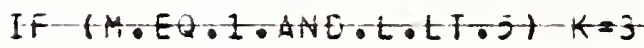

IF (Y.EQ.2.AND.L.LT. S) $K=4$

IF $(M \cdot E Q \cdot 1$. AA+Q. $t \cdot G F \cdot 5)-K=5$

IF $(M \cdot E Q \cdot 2 \cdot A N O \cdot L \cdot G T \cdot 5) K=0$

C

INDEX I FOR TWO NEAREST BARRIER THICKNESSES

$I=1$

$110 \quad I=I+1$

IF $(I . E Q .6)$ GO TO 200

IF $(x+t-1 \cdot L T \cdot 2 T A B+1+1-60-F O-200$

$200-I X=I$

GC TO 110

$I N=I-1$

C

CETERMINE IF VARIABLE IS CMEGA (K.LE.4) OR SIN PHI (K.GT.4)

IF $(x-4) 320,320,33 \mathrm{~J}$

$320 \quad K I=1$

GO TO 350

$330 \mathrm{KI}=2$

C

- INDEX + FQR THO-NEAREST GHEGA OF SIN PHI VALUES

$350-\mathrm{J}=1$

$360 \mathrm{~J}=\mathrm{J}+1$

IF $(Y(L, K I), L T \cdot Y T A B(J, K I))$ GO TO 300

$300-72=7$

GC TO 360

$\mathrm{J} I=\mathrm{J}-\mathrm{I}$

C

TWO-WAY INTERPOLATION ON GEOMETRY FACTURS

$390 \quad 00 \quad 400 \quad J=J 1, J 2$

C

LINEAR INTERPOLATICN ON BARPIEX THICKNESS $X$ AND LOG OF GECMETRY FACTORS

$G 1(J, K)=E \times P(A L Q G(G T A B(I N, J, K))+A L G G(G F A E+I X, J, K)$ FGTAGEIN,J,K)) $1 *(X(L)-Z T A B(I N)) /(Z T A B(I X)-Z T A B(I N)))$

400 CONIIAUE

C

LINEAR INFERPOLATIOA OA LQG Y ANG-LGG OF GEOMETRY FACFCRS

IF $(K \cdot E O \cdot 3 \cdot G R \cdot K \cdot E Q \cdot 4)$ GE - TO- 425

$G(L, M)=E X P(A L O G(G I(J), K))+A L C G(G)(J Z, K) / G I(J 1, K)) \neq A L Q G(Y(L, K I) /$

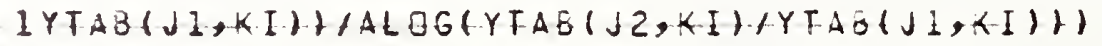

GO TO 450

6. FOR $k=3$ ANO $k=4$, INTERPJLATE ON LOG(1-OMEGA) 
$425 \quad Y I=1 .-Y(L, K I)$

IF (YI.LT.1.0E-10) YI $=1.0 E-10$

$Y 1=1 .-Y T A B(U 1, K I)$

IF $1 Y 1 \cdot t F \cdot 1 \cdot 0 E-10+Y \cdot 1=1.0 E-10$

$Y Z=1,-Y T A S(J \geq, K I)$

-IF (YZ.LF.1.OE-1OT YZ=1.OE-IO

$G(L, M)=E X P(A L O G(G I(J I, K))+A L O G(G I(J 2, K) / G I(J 1, K))+A L O G(Y I / Y I) / A L C G$

$1(Y 2 / Y 1))$

450 CONTINUE

RETURN

END 
* INNER

SLBROUTINE INNER (IP, XE, XI, XUE, XUI, XXLE, XXLI, XW, XU, XXL)

DIMENSICN $X E(5), X I(5), X U E(5), X U I(5), X X L E(5), X X L I(5), X N(9), X U(9)$,

$1 \times \times(9)$

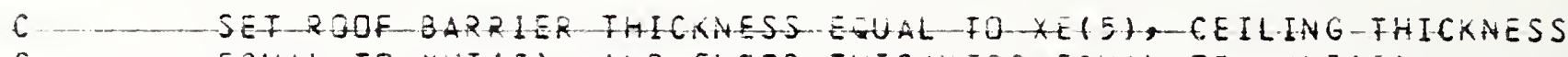

C EQUAL TO XUI(5), ANO FLOCR THICKNESS EQUAL TO XXLIIS)

$X W(5)=X E(5)$

$X(5)=X U I(-5)$

$X X L(\Sigma)=X X L I(\Sigma)$

$c$

FOLD GEILING INTI LPPER STORY NALLS AND

$\mathcal{C}$

FEDER-INTE LUKER GTERY NALLS FER NEUTXOHS AHO N-GAMAS

IF (IP.GF.O) GO- FO 50

OO $20 \quad L=1,4$

$X W(t)=X E(t)$

$X \cup(L)=X \cup E(L)+X U I(5)$

$x \times(t-1)=x * t-E(t)+x \cdot x(-I+5)$

$X \cup I(L)=X \cup I(L)+X \cup I(E)$

$20 \times x L E(L)=x \times L I(L)+X X L I(E)$

GO TO 200

50-IF (-IP.GFIT-GO TO 100

OD $6 C \quad L=1,4$

$X$ iw $(L)=X E(L)+X I(L)$

$X U(L)=X U E(L)+X U I(L)+X U I(5)$

$X X L(L)=x X L E(L)+X X L I(L)+X X L I(5)$

$x \cup I(L)=x \cup I(L)+X \cup I(5)$

$60 \times X L I(L)=X \times L I(L)+\times X L I(-b)$

GO TO 200

$100 \times W(1)=X E(-1)+X I+1)$

$x_{n}(3)=x_{n}(1)$

$X_{N}(2)=X E(2)$

$x_{W}(4)=x_{N}(2)$

$X U(1)=X U E(1)+X U I(1)+X U I(5)$

$X \cup(3)=X \cup(1)$

$x U(2)=X U E(2)+x U I(5)$

$x \cup(4)=x U(2)$

$X \cup I(1)=x \cup I(1)+X U I(5)$

$x \cup I(3)=x \cup I(1)$

$x U I(2)=x U I(2)+x U I(5)$

$X U I(4)=X U I(2)$

$X X L(1)=X X L E(1)+X X L I(I)+X X L I(5)$

$X X L(3)=X X L(1)$

$X X L(2)=X X L E(2)+X X L I(5)$

$X X L(4)=X X L(2)$

$x \times L I(I)=x x L I(1)+x x L I I 5)$

$x \times L I(3)=x \times L I(1)$

$x \times L I(2)=X X L I(2)+X X L I(5)$

$X X L I(4)=X X L I(2)$

200 RETURN

END 


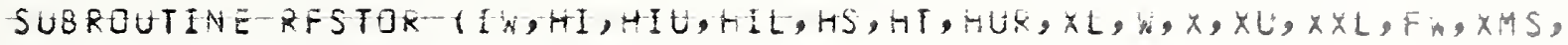

1 ID, IPR, IP, HR, HD, XI, XUI, XXLI, RF)

-OIMENSICN XTAO(1Z), OTAB $(12,4), Y(18,2), Y T A Z(11,2\}, G(9,2), X(9)$

OIMENSICN ZTAB(E),

$G T A B(6,11,6), B(5,2)$

DIYENSIDA EP(7,-18, Z), XW(G), CSR (4), CLR $(4), C(R(4)$

DIMENSIGN RF $(5,2), X M S(5,2), F(4), X U(9), X X L(5), B U(5,2)$, OL $(5,2)$

1 , OKRTAB (17), RTAB $(17,2)$, TAUR (5), RHE(5, Z)

DIMENSION XI(j), XUI (5), XXLI (5), XX(9), BI(5,2), BUI(5,2), ELI (5, 2)

CEMMEN XMAX,XTAZ,BFAB,ZFAE, YFAB,GFAE

COMMON OMRTAB, RTAE, OMSTAB, XMSTAB

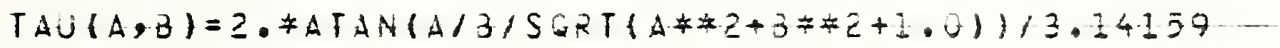

1 FORMAT (IHI)

2 FORMAT (1HO)

3 FCRMAT (IH)

4 FORMAT $\left(5 x, 1 x^{1}, 7 x, 2 B(x) N^{1}, 8 x, 15(x) G^{\prime}\right)$

8 FCRMAT (F10.3,1P2E12.4)

9 FORMAT (F10.0,3F10.4)

DO $50 \quad M=1,2$

$0050 \mathrm{j}=1,18$

DO $50 \quad K=1,7$

$50 G P(K, J, M)=0.0$

CALL INTRPE (XTAE,X,ETAE,B)

CALL INTRPE (XTAB,XU, BTA3, BU)

CALL INTRPB (XTAB,XXL, ETAB,BL)

CALL INTKPB (XTAB,XI, BTAB,BI)

CALL-INTRPE $+X T A Z, X U I$, BTAZ, ELII

C PRINT $999, \times U I, 3 U I$

C 999 FORMAT-(IOFIO.5)

CALL INTRPS (XTAE, XXLI, BTAE,BLI)

60. 1075

$600070 \quad k=1,2$

$0 \bar{\theta}-70 \quad t=1,5$

$B I(L, K)=1.0$

$B U I(L, K)=1.0$

$70 \quad B L I(L, K)=1.0$

75 CONTINUE

PRINT 2

PRINT-2

PRINT 4

PRINI-2

DO $80 \mathrm{~L}=1,5$

80 PRINT $8, \quad K(L),-(B(1, K), K=1,2)$

PRINT 2

DC $81-1=1,5$

81 PRINT $8, X U(L),(B \cup(L, K), K=1,2)$

PRINT 2

DO $82 L=1, E$

82 PRINT 8, - X K $(L L-1,(3 L(-1, K), K=1,2)$

PRINT 2

$0083 L=1,5$

83 PRINT $3,-X I(L),(3 I(L, K), K=1,-2)$

PRINT 2

DO $84 L=1,5$

84 PRINT 8, XUI $(L),(B U I(L, K), K=1,2)$

PRINT-2

DO $85 \mathrm{~L}=1,5$

85 PRINT 8, XXLI(L), $(B L I f L, K), K=I, 2)$ 
$00-300-1=1,4$

IF $\left(I_{*} \cdot E 0.0\right) \quad F(L)=0.0$

IF I IN.GF.O) $F(t)=F$.

IF (IW.GT.I.ANO.L.EQ.2) $F(L)=0.0$

3 CO CON TINUE

IF-(IH.GT.1.AND., L.EQ. 4$) \quad F(t)=0.0$

$X(E)=x(5)$

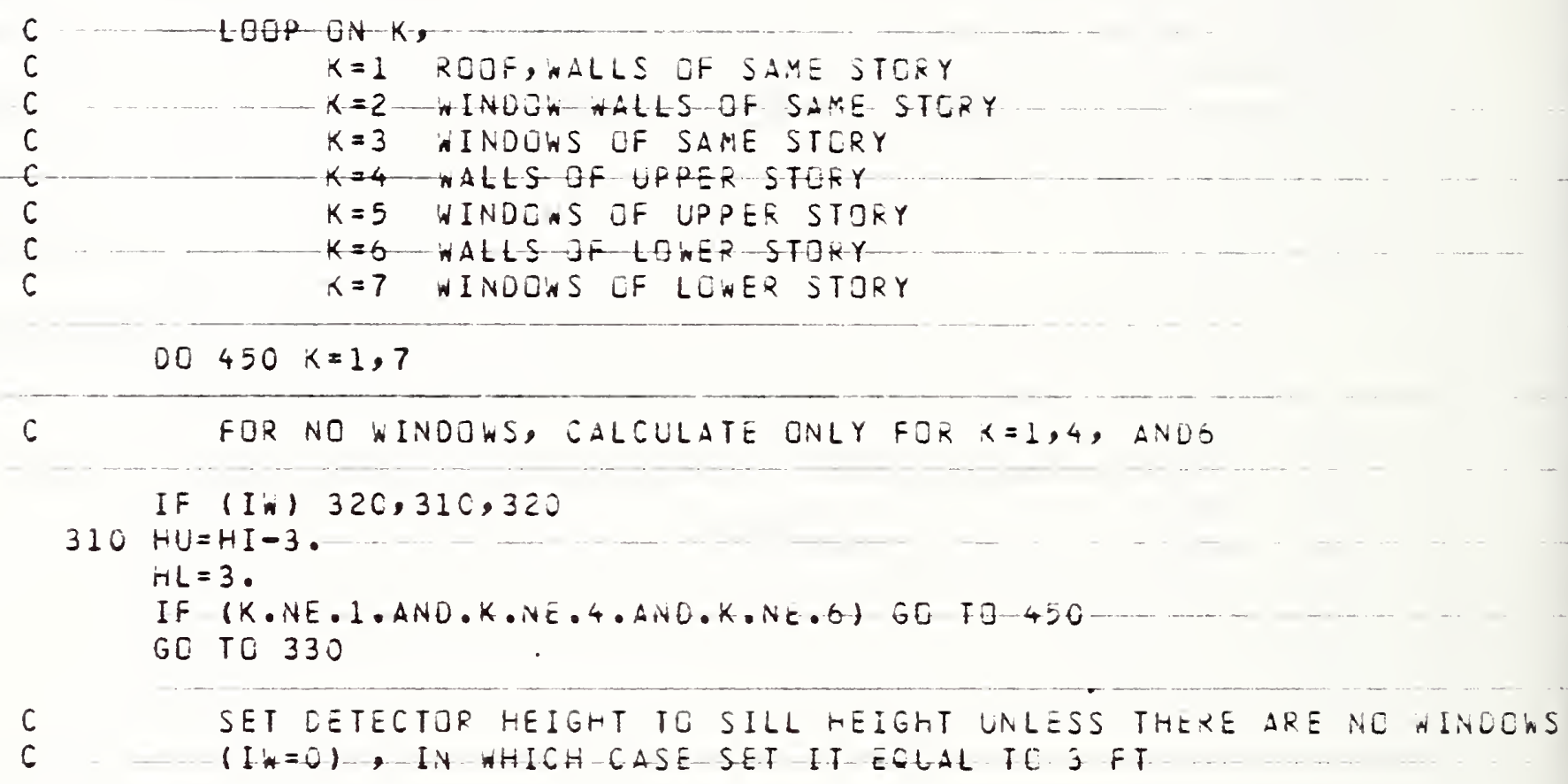

320. $H U=H F-H S$

$H L=H S$

IF $(K \cdot E O \cdot I)-H U=H I-H S$

330 IF $(K \cdot E Q \cdot 4 \cdot 0 R \cdot K \cdot E Q .5) \quad H U=H I+H I U-H S$

IF $(K . E Q .6 . C R \cdot K . E O .7) \quad H L=H L+H I L-$

IF $(K . E O .1) \quad H U K=H R-H O$

$I L=0$

$c$

CALCULATE GEOMETRY FACTCR FOR WALLS GELOA DETECTOR PLANE ON FIRS FIRST PASS $(K=1)$ THEL' 'DO 450 ' LOUP

IF $(K \cdot E Q \cdot 1 \cdot U R \cdot K \cdot E Q \cdot O \cdot U R \cdot K \cdot E Q \cdot 7)$ IL $=1$

OC $340 \quad L=1,4$.

$L P=L+5$

$-X H(L)=X(L)$

$X X(L)=X I(L)$

$X X(L P)=X I f L)$

$X(L P)=X(L)$

$340 \times W(t P)=x(t)$

IF $(K-4) 345,341,343$

$34100342 \quad L=1,4$

$L P=L+5$

$x \in(L)=X U(L)$

$X X(L)=X \cup I(L)$

$x \times(L-P-)=X U L(L)$

$342 \times W(L P)=X U(L)$

GO $T O-345$

343 IF (K.NE.6) GO TO 34 ל 
C IF (L.EQ.1.ANO.H.EQ.1)

C IPRINF $988, M, t, C U$

IF $(I D . G E .5) \quad C U=0.0$

$E L=$

$5+.42 * B L(L, M) \neq(G P(O, L P P, M) * G P(G, L P, M)-G P(1, L F P, M) * G P(1, L P, M))$

$0+.42 * F(L) \neq(B L I(L, H) \neq f G P(7, L P P, M) \neq G P(7, L P, I 4)-6 P(1, L P P, A) \neq G P(1, L P, M$

$7))-B L(L, M) *(G P(6, L P P, M) * G P(O, L P, M)-G P(L, L P P, M) * G P(1, L P, M))$

IF (IQ.LT.4.QR.IO.GT.5) CL $=0 . C$

C TEMPORARY CHANGE 7-9-86

IF $(H \cdot E Q \cdot-1 \cdot A N Q \cdot I D \cdot t T \cdot 2) \cdot E S R(t)=E S *(F H O(L, 1)+R H O(L, Z))$

IF $(M . E Q .1$. AND.ID.GE.2) CSR $(L)=C S *(R H O(L, 1)+R H O(L, 2) \neq(1,-F W)$

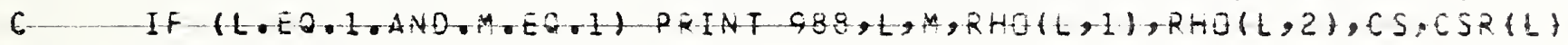

IF $(M \cdot E Q .1) \quad C S=C S+C S R(L)$

C PRINT G9G8,-CSU,CSL,CSF (L), RHC(L,I), RHO(L, Z)

C7998 FORMAT (' CSU,CSL,CSK,RHCL, RHOZ, =1, ZPEE12.4)

IF $(M . E Q .2)-C S=C S+0.3 * C S R(L)$

C AOD REFLECTION TO CONTRB FROM OTHER STORIES

C TEMPORARY CHANGE 7-G-80

IF (M.EQ.1.ANO.IO.LT.2) CUR $(L)=C U *(R H Q(5,1)+R H O(5,2))$

IF (M.EQ.I.ANU.ID.GE.2) CUR $L)=C U *(F H D(5,1) \neq(1 .-F W)+R H O(5,2))$

C TEMPORARY CHANGE T-S-E6

C IF $(M . E Q .1) C L R(L)=C L *(R H O+5,1)+R H Q(E, \bar{C}))$

IF $(M, E Q .1) \quad C L R(L)=C L *(R H O(5,1) \neq(1 .-F *)+R H Q(5,2))$

IF $(M . E Q \cdot-1)-E U=C U+E U K(t)$

IF $(H . E Q .1) \quad C L=C L+C L R(L)$

IF $(M, E Q .2) \quad C U=C U+t .3 \neq C U R(t)$

IF $(M . E O .2) \quad C L=C L+0.3 * C L R(L)$

C ATTENUATIEN IN-CEILING IS NE INELUDEO IN WALL BARRIER

$R F(L, M)=C S+C U+C L$

$R F(L, M)=2 F(L, M) * M S(L, M)$

C PRINT $9999, C S, C U, C L, X Y S(L, M)$

C9999 FORMAT (' CS,CU,CL, XMS =1,1P4ELZ.41

550 CONTINUE

551 CONTINUE

900 PRINT 1

PRINT Z

PRINT 920

$00 \quad 915 \mathrm{~L}=1,5$

PRINT $910, X(L),(R F(L, M), M=1,2)$

910 FORAAT (F10.0,10K,-1R2E10.2)

915 CONTINUE

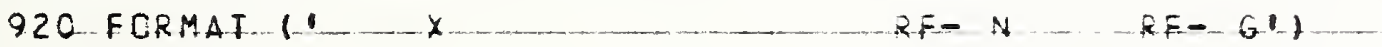

1000 RETURN

ENO. 
PROGRAM TEST (INPUT, OUTPUT, TAPES= INPUT, TAPEO=OUTPUT)

DIMENSION XTAB(11), BTAE $(11,4), \quad$ YTAB $(11,2)$,

DIMENSIDN ZTAB $(6)$, GMTAE(11, SPTAB $(11), G T A B(0,11,6)$

DIMENSION RF $(5,2), X M S(5,2), X U(9), X X L(9)$

OIMENSION UNSTAB(17), XMSTAB(17,2)

DIMENSICA XLM(4), WM (4), HM( 4$), X E(5), X I(5), X U E(5), X U I(5), X X L E(5)$,

$1 \times X L I(5), T I F L E(20)$

1 , ONRTAB (17), RTAB (17,2)

COMMON XMAX,XTAB,ETAB,ZTAB, YTAB, GTAB

COMMCN OMRTAB,RTAB, OMSTAB, XMSTAZ

1 FQRHAT (EE:O.3)

2 FORMAT (IHC)

3 FGRMAF- 1 IH

4 FORMAT $\left(5 x, 1 x^{1}, 7 x, 13(x)\right.$ AS', $2 x, 1 E(x)$ FP' $)$

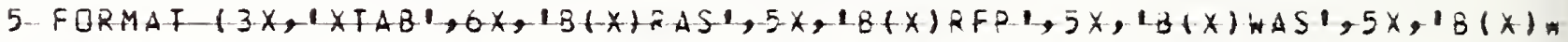
IFPI)

6 FORMAT (IHI)

8 FORMAT (FIO.3,1P2E12.4)

9 FCRMAT $\{F 10.0,3 F 10.3\}$

11 FCRMAT (20A4)

REAO (5, 11)-TITLE

WRITE $(6,6)$

WREFE $(0, Z)$

WRITE $(5,11)$ TITLE

FEAD $(5,10)$ - IW, IB, IPR, EMS, IP, HI, HS, HT,HE, HR, FW, HIU,HIL, XL,W

ARITE $(6,1 C)$ I $, I D, I P R, I M S, I P, H I, H S, H T, H D, H R, F W, H I U, H I L, X L, W$

10 FORMAT $(215,5 F 10.215 F 10.2)$

HUR $=H R$

40 KEAO $-42, \quad X L M$

PRINT 45, XLY

READ 45, WM

PRINT 45, iM

REAO 45, H.4

PRINT 45, H.Y

45 FCRMAT (4F10.3)

CALL INPUTT (IPR, OMTAB,SPTAB)

DO $310 \quad J=1,1-1$

$Y \operatorname{TAB}(\mathrm{J}, I)=C M T A B(\mathrm{~J})$

$310 Y T A B(J, 2)=S P T A B(J)$

READ $(5,1)(X E(L), L=1,5)$

WRITE $(0,1) \quad(X E(L), L=1,-5)$

READ $(5,1) \quad(X I(L), L=1,5)$

WRITE $(6,1)(X I(L), L=1,5)$

READ $(5,1) \quad(X \cup E(L), L=1,5)$

WITE $(6,1)$ (XUE $(L), L=1,5)$

READ $(5,1) \quad(X \cup I(L), L=1,5)$

WITE $(6,2)$ (XUI(L), L. $1,-5)$

READ $(5,1)(\times \times L E(L), L=1,5)$

WRITE (6,I) ( $X \times L E(L-), L=1,2)$

FEAD $(5,1) \quad(x \times L I(L), L=1,5)$

WRITE $(6,-1)(X \times 1-1-(t), t=1,5)$

CALL INNER (IP, XE, XI, XUE, XUI, XXLE, XXLI, X, XU,XXL)

$X M A X=681$.

IF (IMS) $60,60,80$

$6000-70 \quad I=1,2$

$0065 \mathrm{~J}=1,4$

$65 \times, 4 S(J, I)=0.5$

$70 \times M S(5, I)=0.58$

GD TO 600

80 CALL

G CO CONTINUE

CALL

NMSHLD (XLM, WM, HM, XL, W,HC,HR, XMS)

1-ID, IFR, IP, HR, HD, XI, XUI, $X X \mid L I, F F I$ 
1000 STOP

END 
SUBROUTINE NMSHLD (XLM, HM,HM, XL, N,HO,HR, XMS)

OIYENSION XTAB(11), BTAB(1I,4), ZTAB (t), GTAB (5, 11,6), YTAB (11, Z)

DIMENSION XLM(4), WM (4), HM(4), TAUM $(5), X(4), Y(4)$

OIMENSIUN TAUMRF $(5)$, XMS $(5,2)$, XMSP $(5,2)$, OMSTAB $(17)$, XMSTAB $(17,2)$

OIMENSION OMRTAB(17),RTAB(17,2)

COMMON XMAX,XTAB, ETAB, ZTAB, YTAB, GTAE

COYMON OARTAZ,RTAZ,OMSTAE, XMSTAZ

$\operatorname{TAU}(A, B)=2$. $\operatorname{ATAN}(A / B / \operatorname{SORT}(A * 2+B * 2+1.0)) / 3.14159$

C PRINT 4I, XLM

C 41 FORMAT (1OEIO.4)

40 DO $50 \mathrm{~J}=1,4$

DELH $=H M(J)-H D$

IF (CELH) $42,42,44$

42 FAUM $(J)=1 \cdot 0$

GO TO 50

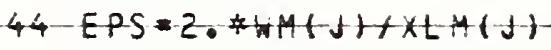

$E T A=2$ * $(H M(J)-H O) / X L M(J)$

TAUM $(J)=T A U(E P S, E T A)$

50 CONTINUE

HHAX $=H M(1-)$

IF $(H M(2), G T \cdot H M A X) \quad H M A X=H M(2)$

IF $(H M(3)$. CT.HMAX) HAX $A=H M(-3)$

IF $(H M(4), G T \cdot H M A X) \quad H M A X=H M(4)$

$Y(I)=0.5 *$

$Y(2)=0.5 * X L$

$Y(3)=Y(1)$

$Y(4)=Y(2)$

DELH $=H M A: X-H R$

DC $70 \mathrm{~J}=1,4$

IF $(H M(J)-H R)-52,52,5,4$

$52 \times(\mathrm{J})=1000$.

$60-10-70$

$54 X(J)=D E L H *(H M(J)+Y(J)) /(H, Y(J)-H R)$

70 CONTINUE - ...

IF (DELH) $400,400,10 \mathrm{C}$

$100 E P S=X(1) / \times(2)$

$E T A=D E L H / X(2)$

TAUMRF (I) $=$ TAU (EPS, ETA)

$E P S=X(2) / \times(3)$

$E T A=D E L H / X(3)$

TAUMRF $(2)=T A U(E P S, E T A)$

$E P S=X(3) / X(4)$

$E T A=D E L H / X(4)$

TAUMRF (3)=TAU(EPS.ETA)

$E P S=X(4) / X(1)$

$E T \perp=D E L H / X(1)$

TAUMRF (4) = TAU(EPS, ETA)

$400 \operatorname{TAUM}(5)=1.0$

TAUMRF $(\Sigma)=1.0$

CALL INTRPK (OMSTAE, XMSTAE, TAUM, XMSP)

C PRINT 41 , TAUM, XMSP

DO $500 \quad I=1,2$

$00480 \quad j=1,4$

$480 \times M S(J, I)=0.5 * \times M S P(J, Z)$

500 CQNTINUE

IF (DELH) $520,520,530$

$52000525 \quad 1=1,2$

$525-x_{14} 5(5,-1)=6.50$

GO TO 200

530-CALL-INTRPR (OMSTAB,XMST-AE, FAUMRF, XMSP)

DO $550 \quad I=1,2$

$550 x, 4 S(5,1)=0.25 *(X M S P(1,11+X * S P(2,1)+X M S P(i, 1)+X M S P(4,-1)+0.58$ 
APPENDIX D 
BENCHMARK STRUCTURE NC 51 EASEMENT, 8-12-0́

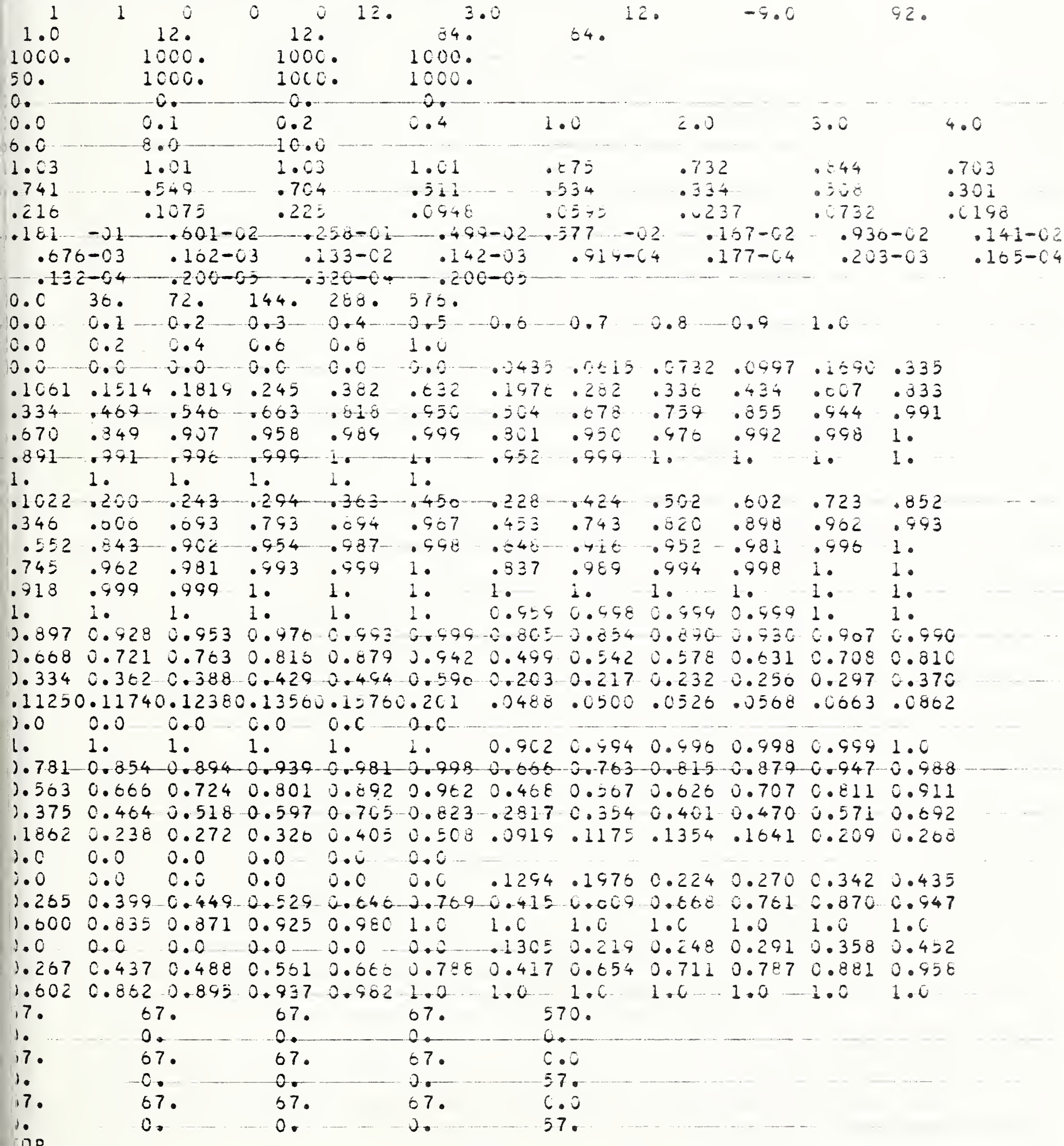

OR 
BENCHMARK STRUCTURE NC $三 1$ BASEMENT) 8-23-60

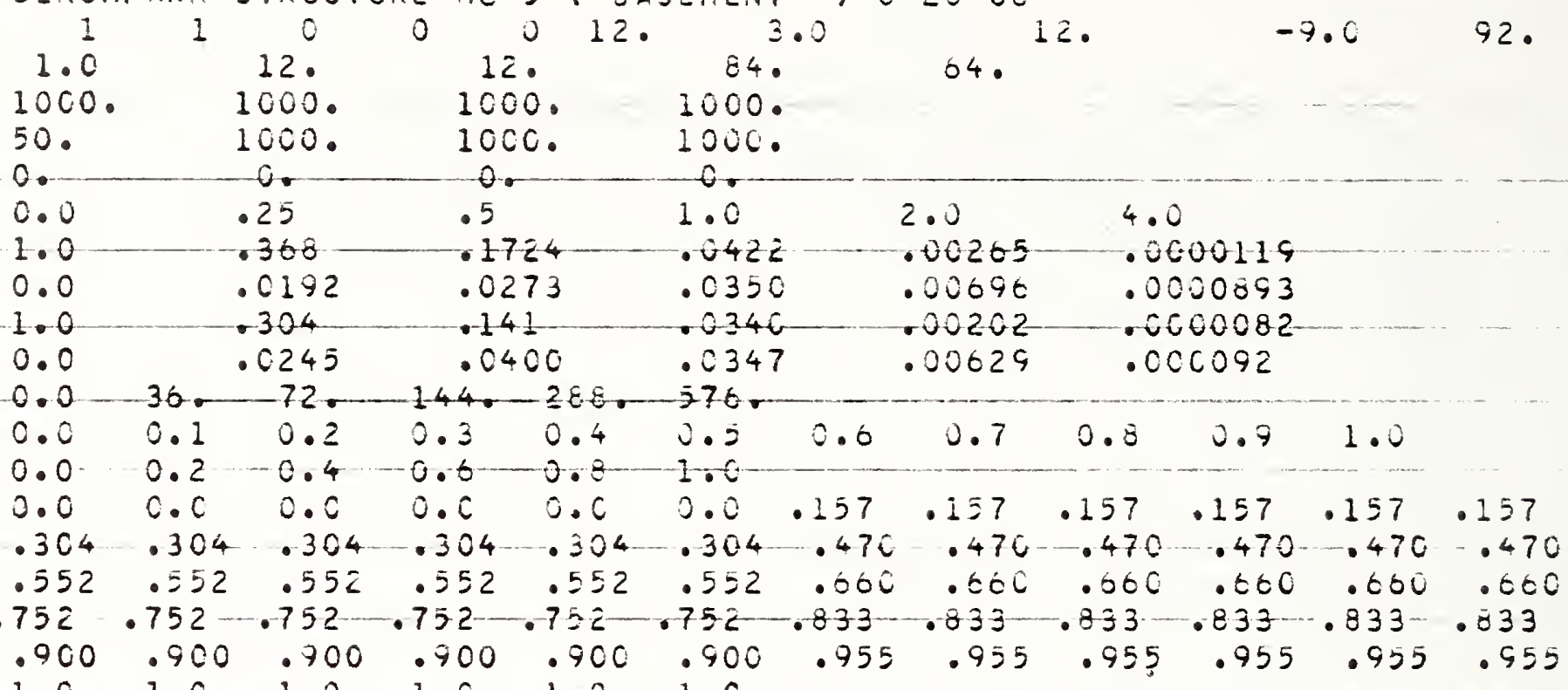
$1.0-1.0 \quad 1.0-1.0-1.0-1.0$

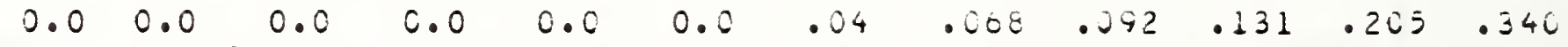

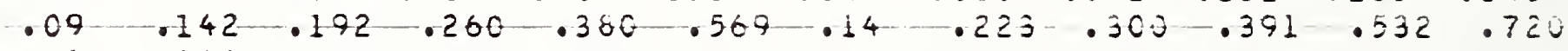

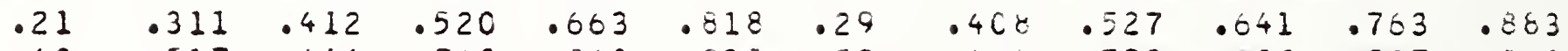
$.40-.517-.044-.743-.843-.93-.52-.540-.753-.030-.907 .963$

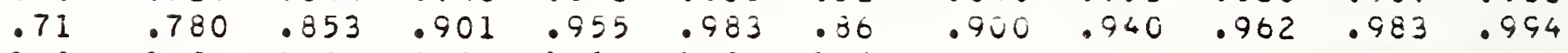
1.0 1.0 .85 .678 .46 .238 0.0 1.0 .730 .52

.34

.160

0.0

0.0

.262

.59

0.0

.16

.40

.00

.60

.55

.77

.150

.00

.60

0.0 .840

$\begin{array}{ccccc}0.0 & .0012 & .0033 & .0061 & .009 \\ .530 & .650 & .780 & .900 & 1.00\end{array}$

07

0.

67

0.

$-6.7$.

$1.0-1.0$

1.0

$1.0-1.0-1.0$

1.01 .0

.858

.858

1.0

$1 . C \quad 1.0 \quad .930$

.956

.936

.936

.936 .936

.678

$.67 \varepsilon$

.858

$.858 . .858$

.773

.773

.773

.773

.773

.773

.464

.238

.464

$. .464-$

.678 .678

.573

.573

.573

.573

.573

.573

0.0

0.0

.238

.238 .238

.353

.353

.353

.353

$-.353$

.353

$1.0 \quad 1.0$

$.7 € 2$

.799

$1.0 \quad 1.0$

.122

.122

.122

.122

.122

.559

.597

.848

.902

1. $\mathrm{C}$

.050 .974

$.898 \quad .935$

.962

.983

.366

.395

.650

.730 .829

.020

.652

.049

.750

$-.823$

.908

.179

.198

.446

. 516

.594

.030

.462

.494

.547

.628

.721

$0.0-0.0$

$-0.0$

$0.0 \quad 0.09$

.080

.058

.297

- 334

.393

.455

$\begin{array}{lllll}0.0 & 0.0 & 0.0 & 0.0 & 0.0\end{array}$

.262 .262

.262 . 262

.262

.128

.128

.128

.128

.133

.156

.590 .590

.590

$.590 \quad .590$

.410

.410

.410

.410

.128

.128

0.0

0.0

0.0

0.00 .0

1. $\mathrm{C}$

1. 0

1.0

1.0

.410

.410

$.198 \quad .25$

.320

.427 .595

.070

.093

.12

.152

1.0

1.0

.492

.594

.717

. Eटt

.270

.322

.401

.502

.21

.320

$.01 \quad .02$

.03

.04

.07

1.0

1.0

1.0

1. 0

.631

.790

.70 .80

.50

$\begin{array}{lrr}.55 & .58 & .65 \\ .64 & .04 & .35\end{array}$

1. CO

. 15

.20

.30

1.0

1.0

. $80 \quad 1.251 .45$

1.00

$1.55 \quad 1.30 \quad 1.10 \quad 0.92$

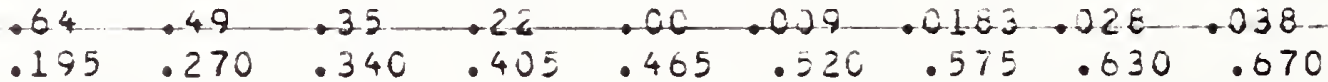

$\begin{array}{llll}.01 & .02 & .03 & .04 \\ .70 & .80 & .90 & 1.00\end{array}$

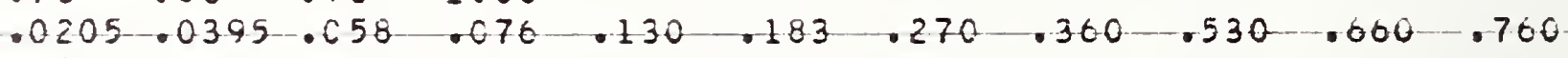

$.900 \quad .950 \quad .980 \quad 1.00$

$.650 \quad .780 \quad .900 \quad 1.00$

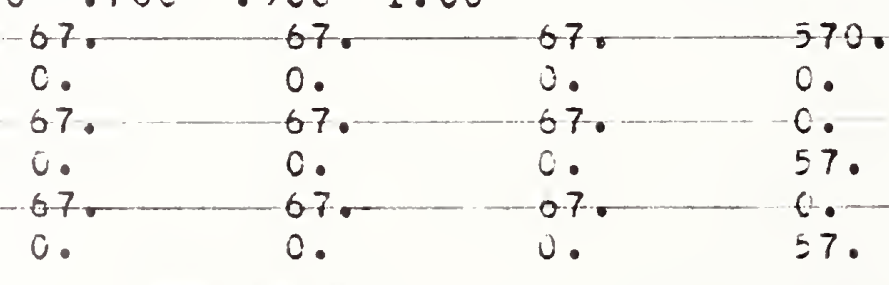


APPENDIX E 


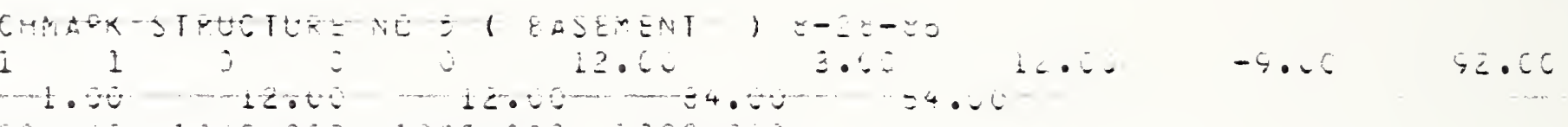

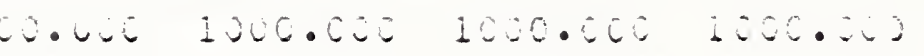
E. . icc - 65 .60 $\cdots \hat{c}$

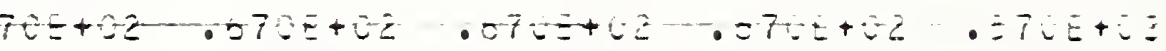
$\mathrm{CCE}+\mathrm{SO} \cdot \operatorname{COCE} \mathrm{COCO}$

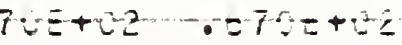
$\mathrm{COC}+\mathrm{CC}$ $7 C E+02$ $C 0 E+2)$ . 060 . 00 $.57 \hat{L}+\hat{C} \bar{c}$ - $ن G E+c i$

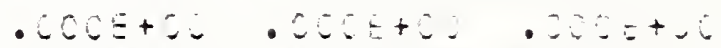

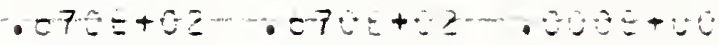
- CUE+CC . COE+ . .

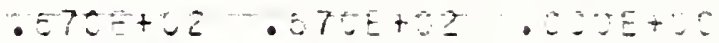

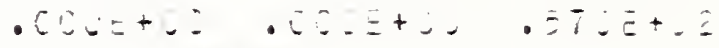

$x-2-x(x)$ -

$67.060 \quad 1.26515-01 \quad 2.07 c=\overline{1}=62$ 67.000 1.t091E-01 2. t7.c00 1.0091E-ji j.t7caE-j2 $=7 \cdot 020-1 \cdot 0 C^{2}+E-21-3 \cdot 07=8 E-02$ 70.020 I.01015-65 1.1344E-

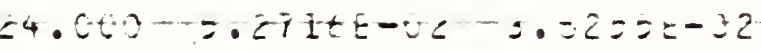

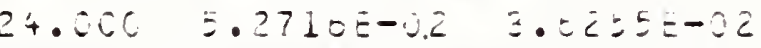

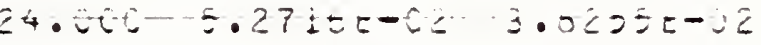

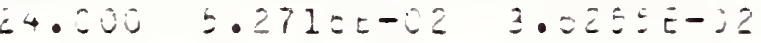

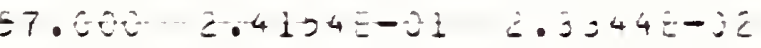

$24.6065 .27100-.23 .6255 E-32$

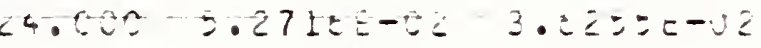

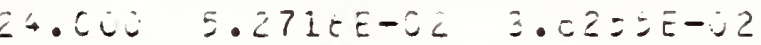

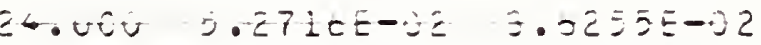
$57.600 \quad 2.4124 t-i 1 \quad 2.3344=-i 2$

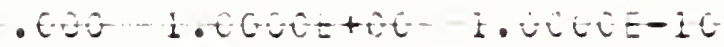
- COO 1.COOOE+3: 2.ECCLE-1C

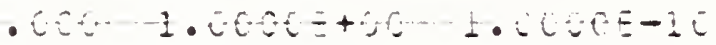
- lec 1.jecletaj hujude-10 -wjo 1.20

$=7 \cdot c_{0} \quad 1.7843 E-1 \quad 2.24=4 E-0 z$

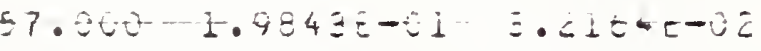

$57.6001 .98435-21 \quad \therefore \cdot 21=4 E-22$

$-7 \cdot 600109843 E-1 \quad 3.2154 t-i 2$

7. Civ $2 .+154 i-1 \geq 032445-j 2$

57.t000 1.4843E-C1 2. $4164 E-02$

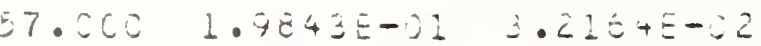

-7.10 -

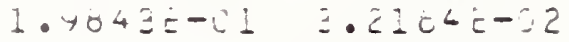

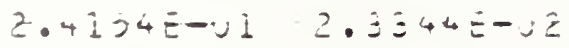


$\leq 7$.

$=7$.

$=7$.

67.

$=70$.

$$
\begin{aligned}
& r-r \quad x+c
\end{aligned}
$$

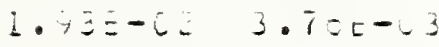

$$
\begin{aligned}
& \text { 1. } 2=-\because 2 \quad ? \cdot 37 \leq-03
\end{aligned}
$$

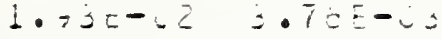

$$
\begin{aligned}
& \text { 1.2EE-CZ2.375- 2 }
\end{aligned}
$$

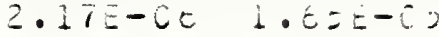



BIBLIOGRAPHIC DATA

SHEET (See instructions)

$$
\begin{aligned}
& \text { 1. PUBLICATION OR } \\
& \text { REPORT NO. } \\
& \text { NBSIR } 87-3507
\end{aligned}
$$

2. Performing Organ. Feport No.f 3. Publication Date

FEBRUARY 1987

4. TITLE AND SUBTITLE

APPROXIMATE PROCEDURES FOR CALCULATING PROTECTION

FROM INITIAL NUCLEAR RADIATION FROM WEAPONS

5. $\operatorname{AUTHOR}(\mathrm{S})$

6. PERFORMING ORGANIZATION (If joint or other than NBS, see instructions)

7. Contracu Grant No.

NATIONAL BUREAU OF STANDARDS

DEPARTMENT OF COMMERCE

WASHINGTON, D.C. 20234

8. Type of Report \& Period Covered

9. SPONSORING ORGANIZATION MATE AND COMPLETE ADDRESS ( Street, CIIY. SIOTE, ZIP)

10. SUPPLEMENTARY NOTES

Document describes a computer program; SF-185. FIPS Software Summary, is attached.

11. ABSTRACT (A 200-word or less factual summary of most significant information. If document includes a significant bibliography or literature survey. mention it here)

In this report we discuss procedures for routine evaluation of the protection of complex structures against the initial radiations from nuclear detonations. We describe procedures for evaluating and combining dose reduction factors for four radiation components: early fission product gamma rays, air secondary gamma rays generated by neutron interactions in the air, neutrons, and wall capture gamma rays generated by neutrons through interactions with nuclei in structural materials. We describe computer codes developed to evaluate reduction factors for each of these components. The radiation field in the vicinity of the structure was generated for a $30^{\circ}$ elevation angle for the detonation, as well as a "ring source" averaging over the points of the compass. Comparisons are made with Monte Carlo calculations for a series of five benchmark structures.

12. KEY WORDS (Six to twelve entries; alphabetical order; capitalize only proper names; and separate key words by semicolons)

initial nuclear radiation; neutron transport; photon transport; protection

factor; reduction factor; shielding

13. AVAILABILITY

- Unlimited

For Official Distribution. Do Not Release to NTIS

Order From Superintendent of Documents, U.S. Government Printing Office, Washington, D.C. 20402.

14. NO. OF

PRINTED PAGES

Order From National Technical Information Service (NTIS), Springfield, VA. 2216I

130

15. Price 

